Aus der Klinik für Strahlentherapie und Radioonkologie

(Prof. Dr. med.C.F. Hess)

der Medizinischen Fakultät der Universität Göttingen

\title{
Analyse der Expression von Chemokinen und Chemokinrezeptoren in Kopf-Hals-Tumorzellen
}

\author{
INAUGURAL-DISSERTATION \\ zur Erlangung des Doktorgrades \\ der Medizinischen Fakultät der \\ Georg-August-Universität zu Göttingen
}

vorgelegt von

David Benjamin Rolke

aus

Berlin

Göttingen 2017 
Dekan:

Referent:

Ko-Referent:

Drittreferent/in:
Prof. Dr. rer. nat. H. K. Kroemer

PD Dr. med. H. A. Wolff

Prof. Dr. Martin Oppermann

PD Dr. Marian Grade

Tag der mündlichen Prüfung: $\quad$ 15.02.2018 


\section{Inhaltsverzeichnis}

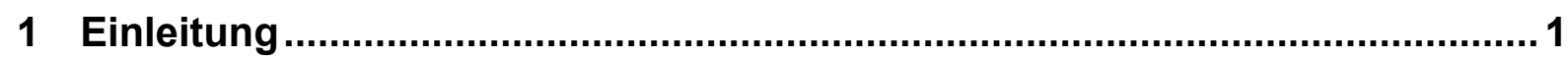

1.1 Epidemiologie und Risikofaktoren des Plattenepithelkarzinoms im HNOBereich

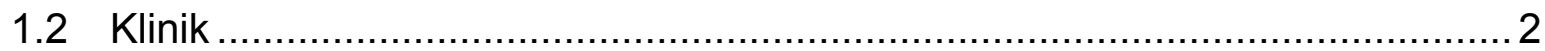

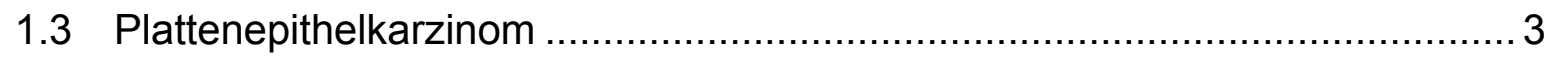

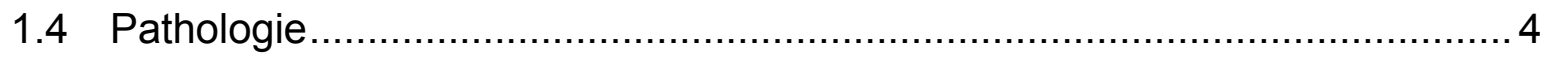

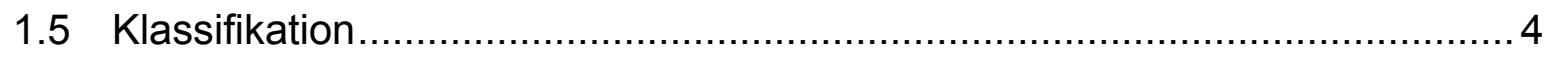

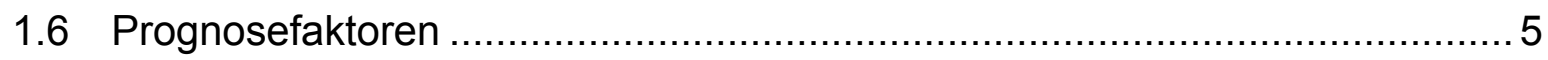

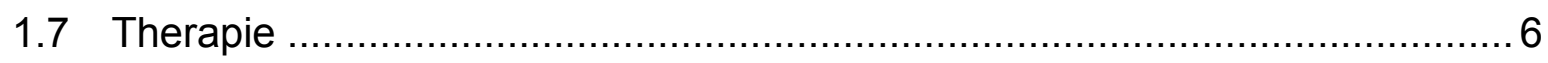

1.7.1 Chirurgische Therapie ................................................................ 7

1.7.2 Strahlentherapie und Chemotherapie ...............................................

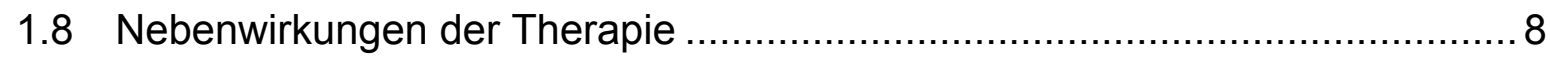

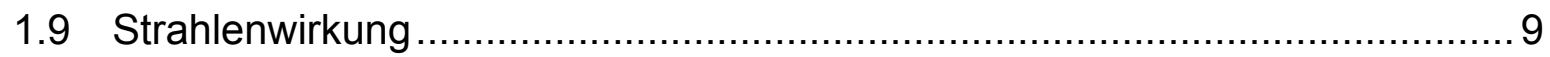

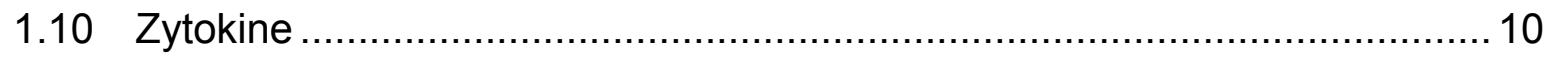

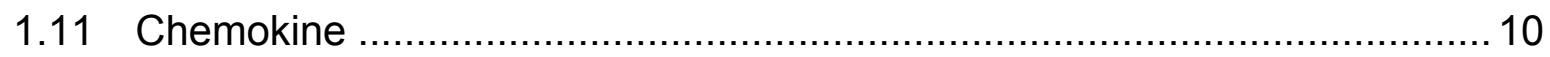

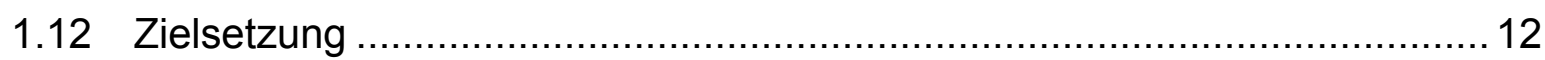

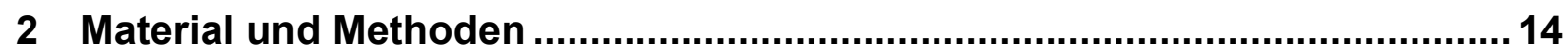

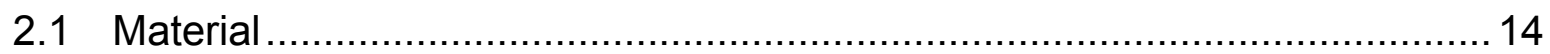

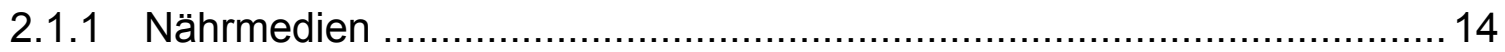

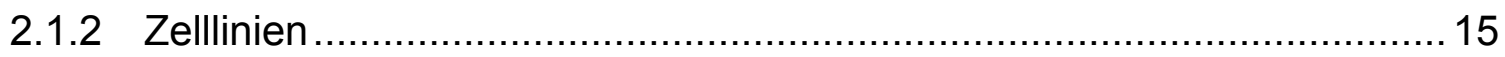

2.1.3 Chemokine und Chemokinrezeptoren ………................................. 17

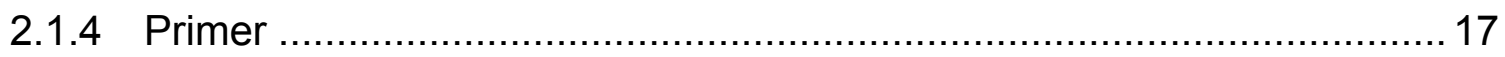

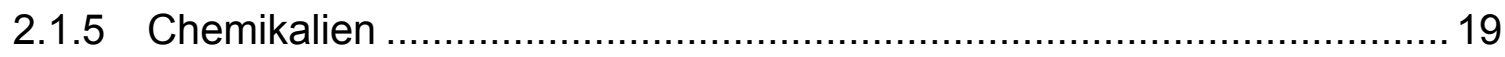

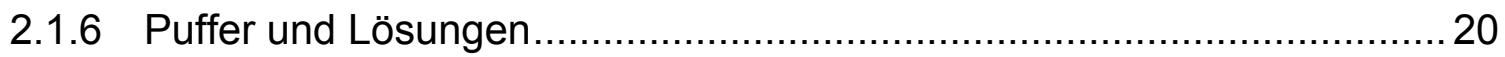

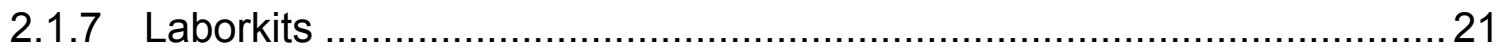

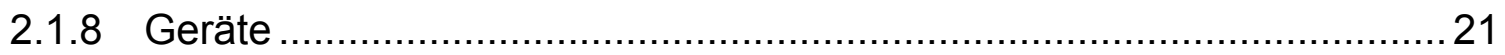

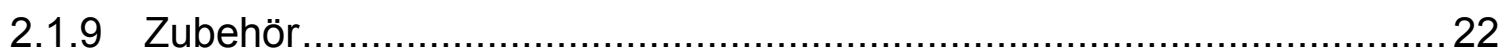




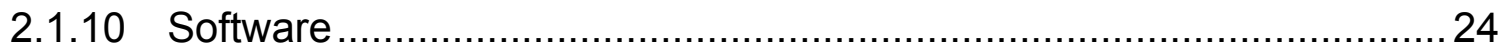

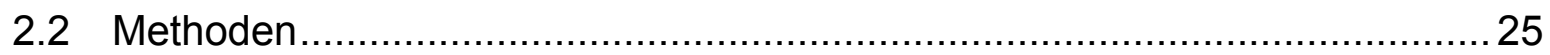

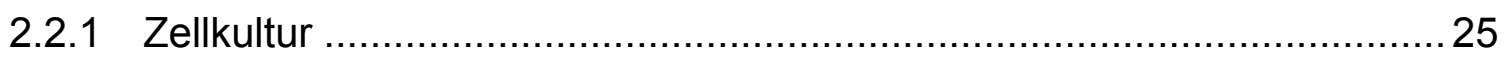

2.2.2 Mediumwechsel ..................................................................... 27

2.2 .3 Zählen der Zellen ................................................................... 28

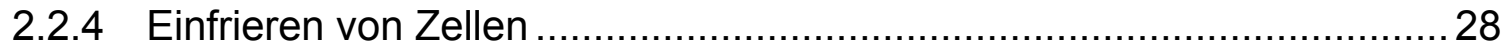

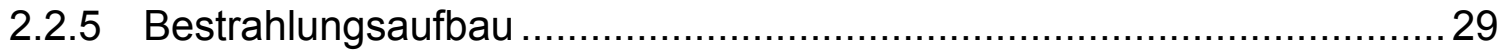

2.2 .6 Colony Forming Assay ........................................................... 30

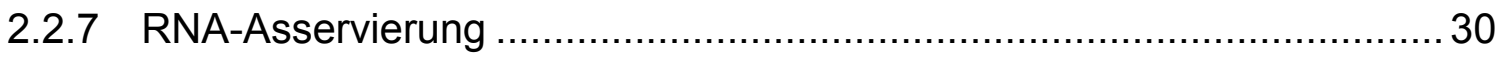

2.2.8 Isolation und Quantifizierung von RNA ......................................... 31

2.2.9 Synthese von komplementärer DNA (cDNA) ................................ 32

2.2.10 Quantitative Real-Time-PCR (qRT-PCR) .................................... 33

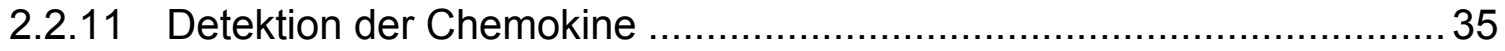

2.2.12 Enzyme-Linked Immunosorbent Assay (ELISA) ............................. 36

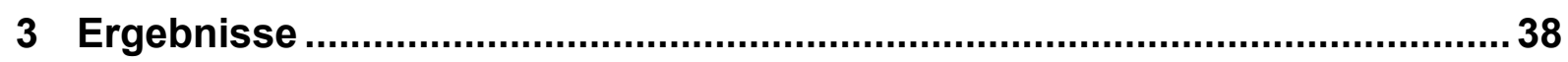

3.1 Überblick über die Chemokinexpression ............................................ 38

3.1.1 Genexpression des Chemokinliganden CCL2 .................................. 40

3.1.2 Genexpression des Chemokinliganden CCL3 .................................. 41

3.1.3 Genexpression des Chemokinliganden CCL5 ................................. 42

3.1.4 Genexpression des Chemokinliganden CCL20.............................. 43

3.1.5 Genexpression des Chemokinrezeptors CCR1 .............................. 44

3.1.6 Genexpression des Chemokinrezeptors CCR3 ................................. 45

3.1.7 Genexpression des Chemokinrezeptors CCR6 ............................... 46

3.1.8 Genexpression des Chemokinrezeptors CCR7 ............................... 47

3.1.9 Genexpression des Chemokinliganden CXCL1 ............................... 48

3.1.10 Genexpression des Chemokinliganden CXCL2 ................................ 49

3.1.11 Genexpression des Chemokinliganden CXCL3 ................................50

3.1.12 Genexpression des Chemokinliganden CXCL9 ................................ 51

3.1.13 Genexpression des Chemokinliganden CXCL10 .............................. 52

3.1.14 Genexpression des Chemokinliganden CXCL11 ............................... 53

3.1.15 Genexpression des Chemokinliganden CXCL12 _.............................. 54

3.1.16 Genexpression des Chemokinrezeptors CXCR1 .............................. 55

3.1.17 Genexpression des Chemokinrezeptors CXCR4 ............................... 56 
3.2 Kinetik der strahleninduzierten Expressionsänderungen 57

3.2.1 Zeitlicher Verlauf der Genexpression des Chemokins CCL20 nach

Bestrahlung

3.2.1.1 Strahleninduzierte relative Genexpressionsänderungen des

Chemokinliganden CCL20 in der Zelllinie DF19

3.2.1.2 Strahleninduzierte relative Genexpressionsänderungen des

Chemokinliganden CCL20 in der Zelllinie HaCat

3.2.1.3 Strahleninduzierte relative Genexpressionsänderungen des

Chemokinliganden CCL20 in der Zelllinie BHY

3.2.1.4 Strahleninduzierte relative Genexpressionsänderungen des

Chemokinliganden CCL20 in der Zelllinie BW225

3.2.1.5 Strahleninduzierte relative Genexpressionsänderungen des

Chemokinliganden CCL20 in der Zelllinie FaDuDD

3.2.1.6 Strahleninduzierte relative Genexpressionsänderungen des

Chemokinliganden CCL20 in der Zelllinie GR145 I

3.2.1.7 Strahleninduzierte relative Genexpressionsänderungen des

Chemokinliganden CCL20 in der Zelllinie GR145 II.

3.2.1.8 Strahleninduzierte relative Genexpressionsänderungen des

Chemokinliganden CCL20 in der Zelllinie ZMK1

3.2.2 Zeitlicher Verlauf der Genexpression der Chemokine CXCL1, CXCL2 und CXCL3 nach Bestrahlung

3.2.2.1 Strahleninduzierte relative Genexpressionsänderung der Chemokinliganden CXCL1, CXCL2 und CXCL3 in der Zelllinie DF19

3.2.2.2 Strahleninduzierte relative Genexpressionsänderung der

Chemokinliganden CXCL1, CXCL2 und CXCL3 in der Zelllinie HaCat

3.2.2.3 Strahleninduzierte relative Genexpressionsänderung der Chemokinliganden CXCL1, CXCL2 und CXCL3 in der Zelllinie BHY

3.2.2.4 Strahleninduzierte relative Genexpressionsänderung der

Chemokinliganden CXCL1, CXCL2 und CXCL3 in der Zelllinie BW225

3.2.2.5 Strahleninduzierte relative Genexpressionsänderung der

Chemokinliganden CXCL1, CXCL2 und CXCL3 in der Zelllinie FaDuDD ......70

3.2.2.6 Strahleninduzierte relative Genexpressionsänderung der

Chemokinliganden CXCL1, CXCL2 und CXCL3 in der Zelllinie GR145 I.......71 
3.2.2.7 Strahleninduzierte relative Genexpressionsänderungen der

Chemokinliganden CXCL1, CXCL2 und CXCL3 in der Zelllinie GR145 II......73

3.2.2.8 Strahleninduzierte relative Genexpressionsänderungen der

Chemokinliganden CXCL2 und CXCL3 in der Zelllinie ZMK1

3.2.3 Zeitlicher Verlauf der Genexpression des Chemokinrezeptors CCR6

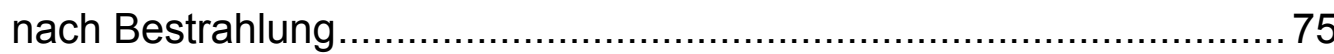

3.2.3.1 Strahleninduzierte relative Genexpressionsänderungen des Chemokinrezeptor CCR6 in der Zelllinie BHY 75

3.2.3.2 Strahleninduzierte relative Genexpressionsänderungen des Chemokinrezeptor CCR6 in der Zelllinie GR145 II. 76

3.2.4 Zeitlicher Verlauf der Genexpression des Chemokinrezeptors CCR7 nach Bestrahlung .76

3.2.4.1 Strahleninduzierte relative Genexpressionsänderungen des Chemokinrezeptor CCR7 in der Zellinie DF19 77

3.2.4.2 Strahleninduzierte relative Genexpressionsänderungen des Chemokinrezeptors CCR7 in der Zelllinie HaCat

3.2.4.3 Strahleninduzierte relative Genexpressionsänderungen des

Chemokinrezeptor CCR7 in der Zelllinie BHY .78

3.2.4.4 Strahleninduzierte relative Genexpressionsänderungen des

Chemokinrezeptors CCR7 in der Zelllinie ZMK1 79

3.2.5 Zeitlicher Verlauf der Genexpression des Chemokinrezeptors CXCR1 nach Bestrahlung

3.2.5.1 Strahleninduzierte relative Genexpressionsänderungen des

Chemokinrezeptor CXCR1 in der Zelllinie HaCat

3.2.6 Zeitlicher Verlauf der Genexpression des Chemokinrezeptors CXCR4 nach Bestrahlung

3.2.6.1 Strahleninduzierte relative Genexpressionsänderungen des Chemokinrezeptor CXCR4 in der Zelllinie FaDuDD.

3.2.6.2 Strahleninduzierte relative Genexpressionsänderungen des

Chemokinrezeptor CXCR4 in der Zelllinie ZMK1

3.2.7 Zeitlicher Verlauf der Genexpression des Chemokinliganden CXCL12 nach Bestrahlung

3.2.7.1 Strahleninduzierte relative Genexpressionsänderungen des

Chemokinliganden CXCL12 in der Zelllinie DF19 
3.2.7.2 Strahleninduzierte relative Genexpressionsänderungen des Chemokinliganden CXCL12 in der Zelllinie GR145 I

3.2.8 Zeitlicher Verlauf der Genexpression des Rezeptor-Liganden-Paar CXCR4/CXCL12 nach Bestrahlung

3.2.8.1 Strahleninduzierte relative Genexpressionsänderungen des

Rezeptor-Liganden-Paares CXCR4/CXCL12 in der Zelllinie BW225

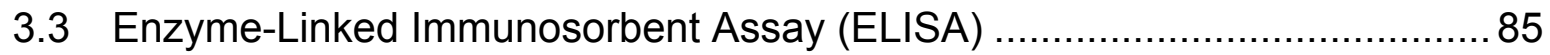

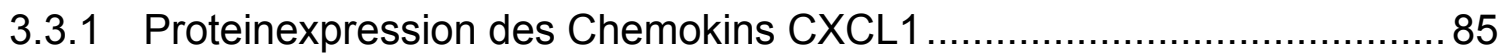

3.3.2 Proteinexpression des Chemokins CXCL12 …................................ 86

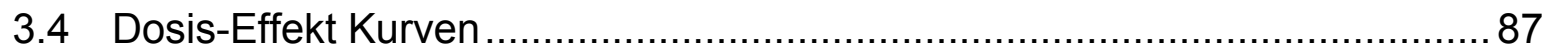

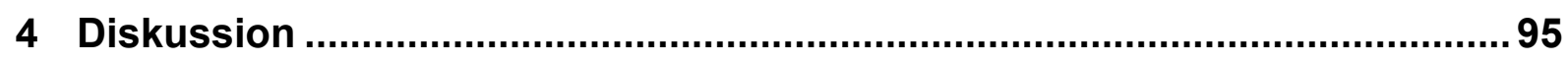

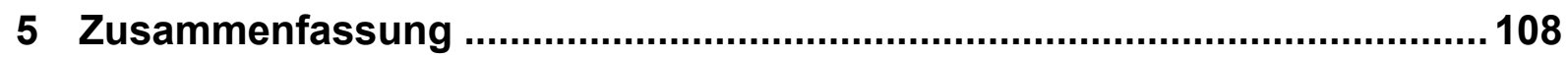

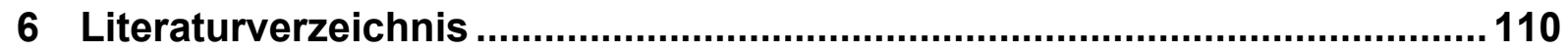




\section{Abkürzungsverzeichnis}

\begin{tabular}{ll} 
CDNA & Komplementäre Desoxyribonukleinsäure \\
CEA & Karzinoembryonales Antigen \\
$\mathrm{CO}_{2}$ & Kohlenstoffdioxid \\
CTC & common coxiticy criteria \\
CUP & cancer of unknown primarius \\
DKFZ & Deutsches Krebsforschungszentrum \\
DMSO & Dimethylsulfoxid \\
DNA & Desoxyribonukleinsäure \\
DSMZ & Deutsche Sammlung von Mikroorganismen und Zellkulturen \\
EDTA & Ethylendiamintetraacetat \\
EGFR & epidermal growth factor receptor \\
FKS & Fötales Kälberserum \\
g & Gramm \\
G-CSF & Granulozyten-Kolonie-stimulierende Faktor \\
GITC & Guanidinisothiocyanat \\
Gy & Gray \\
HCL & Salzsäure \\
HGF & hematopoetic growth factor \\
HPRT & Hypoxanthine-guanine phosphoribosyltransferase \\
HPV & Humanes-Papilloma-Virus \\
HSRRB & health science research resources bank \\
IFN & Interferon \\
Kv & Kilovolt \\
I & Minuten \\
Min & Million \\
mI & hiter \\
\hline
\end{tabular}


$\mathrm{mm} \quad$ Millimeter

ND not detected

ng Nanogramm

PBS phosphatgepufferte Salzlösung

PCR Polymerase-Kettenreaktion

pg Picogramm

RNA Ribonukleinsäure

RT-Dresden Strahlentherapie der Medizinischen Fakultät Universität Dresden

RT-Göttingen Strahlentherapie der Medizinischen Fakultät Universität Göttingen

$\mathrm{S}$

Sekunden

SCCHN

squamous cell carcinoma of the head and neck

SDS

Natriumdodecylsulfat

SybrGreen

cyanin-haltiger Farbstoff

TBP

TATA-binding protein

TE

Tris-EDTA-Puffer

TGF

transformierender Wachstumsfaktor

TNF- $\alpha$

Tumor-Nekrose-Faktor

TNM

Stadieneinteilung von malignen Tumoren

TPA

Tissue Polypeptide Antigen

TUBB

Tubulin, beta-Polypeptide

UICC

Union Internationale contre le cancer

USB

Cyanin-Farbstoff

UV

ultraviolett

z.B.

zum Beispiel

$\mu l$

Microliter

Anmerkung:

Die Abkürzungen der Puffer RPE, RLT und RW1 aus dem Extraktionskit „RNeasy“ der Firma Qiagen stammen vom Hersteller. Die genaue Zusammensetzung ist nicht bekannt. 


\section{$1 \quad$ Einleitung}

\section{$1.1 \quad$ Epidemiologie und Risikofaktoren des Plattenepithelkarzinoms im HNO-Bereich}

Kopf-Hals-Karzinome stellen die fünfthäufigste Tumorentität mit über 500.000 Neuerkrankungen weltweit dar (Parkin et al. 2005). Bei den Kopf-Hals-Karzinomen werden maligne Tumoren der Mundhöhle, des Oropharynx, Hypopharynx, Nasopharynx und des Larynx mit eingeschlossen. Im Jahr 2000 starben weltweit etwa 320.000 Patienten aufgrund von Kopf-Hals-Karzinomen (Shibuya et al. 2002). In den USA gibt es jährlich über 50.000 Neuerkrankungen, weiterhin sind über 10.000 Todesfälle pro Jahr zu erwarten. Tumore des Hals-Kopf-Bereichs sind bei Männern in den USA die achthäufigste Tumorentität, bei weiblichen Patienten in den USA sind die Karzinome des Hals-Kopf-Bereichs noch nicht unter den zehn häufigsten Tumorerkrankungen zu finden (Siegel et al. 2011). Die Inzidenz von KopfHals-Karzinomerkrankungen ist in den letzten Jahrzenten gefallen, liegt jedoch mit 15,7 pro 100.000 Männer und 6,2 pro 100.000 Frauen immer noch recht hoch (Jemal et al. 2010). Die Inzidenzraten des Kopf-Hals-Karzinoms sind weltweit unterschiedlich, da in hochentwickelten Ländern die Häufigkeit von Kopf-HalsKarzinomen in Relation gering ist, in anderen Teilen der Welt aber die am häufigsten beobachteten Tumoren repräsentiert. Die 5-Jahres-Überlebensrate hat sich in den USA in den letzten Jahren verbessert, wobei weltweit weniger als $50 \%$ der Patienten überleben (Siegel et al. 2011). In Deutschland erkranken jährlich etwa 2.800 Frauen und 7.600 Männer an Kopf-Hals-Karzinomen. Die Erkrankungs- und Sterberaten sind seit einigen Jahren bei Männern rückläufig, bei Frauen etwa konstant. Die 5-JahresÜberlebensraten liegen bei ca. 55\% für Frauen und $47 \%$ für Männer (Krebs in Deutschland, 2013). Die Mundhöhle ist bei Kopf-Hals-Karzinomen am häufigsten betroffen (Simon und Plinkert 2008). Tabakkonsum gilt als Hauptrisikofaktor für KopfHals-Karzinome. Raucher haben gegenüber Nichtrauchern ein deutlich erhöhtes Risiko an einem Kopf-Hals-Karzinom, z.B. dem Larynxkarzinom, zu erkranken (Altieri et al. 2002; Sturgis et al 2004). Des Weiteren ist der Alkoholabusus ein wichtiger Risikofaktor für die Entwicklung eins Kopf-Hals-Karzinoms. Es gibt dabei 
einen Zusammenhang zwischen der Menge an Tabak- und Alkoholkonsum und des Risikos, ein Karzinom im Kopf-Hals-Bereich zu entwickeln (Talamini et al. 2002). Zwar steht der langjährige Tabakkonsum im Vordergrund bei der Entwicklung eines Kopf-Hals-Karzinoms, das Erkrankungsrisiko steigt jedoch bei zusätzlichem Alkoholabusus, da Alkohol- und Tabakkonsum einen synergetischen Effekt auf das Entartungsrisiko bei Kopf-Hals-Karzinomen haben (Hashibe et al. 2009). Es sind daher ca. $80 \%$ der Tumorerkrankungen auf Tabak und/oder Alkoholabusus zurückzuführen (Blot et al. 1988; Sankaranarayanan et al. 1998). Auch bei Passivrauchern ist von einem erhöhten Risiko für Kopf-Hals-Karzinome auszugehen (Tan et al. 1997). Zudem können chronische Reizungen, chemische Substanzen, Zahnprothesen oder chronische Entzündungen das Erkrankungsrisiko erhöhen (Lockhart et al. 1998; Tezal et al. 2009). Auch Virusinfektionen stehen im Zusammenhang mit der Entwicklung eines malignen Tumors im Kopf-Hals-Bereich. Hier steht vor allem die Infektion mit dem humanen Papillomavirus im Vordergrund (Ang et al. 2011). Die Entwicklung von malignen Hals-Kopf-Tumoren ist mit der durch eine chronische Virusinfektion hervorgerufene Funktionsstörung von TumorSuppressor-Genen verknüpft. Die Funktionsstörung fördert unreguliertes Zellwachstum, was zu maligner Entartung führen kann. Außer dem Papillomavirus korreliert auch das humane Herpesvirus-6 mit oralen Plattenepithelkarzinomen (Flaitz und Hicks 1998; Cattani et al. 1998).

\section{$1.2 \quad$ Klinik}

Die Diagnose eines malignen Tumors im Kopf-Hals-Bereich wird meistens erst in einem fortgeschrittenen Stadium der Erkrankung gestellt, denn spezifische Frühsymptome treten selten auf. Die Symptome der Patienten reichen von länger andauernder Heiserkeit, Dysphagie, Foetor ex ore, Zungenbrennen, Dyspnoe und Hämoptoe bis hin zu allgemeinen Symptomen einer malignen Erkrankung wie Abgeschlagenheit, Gewichtsverlust, Nachtschweiß oder Fieber. Eine ausgeprägte Schmerzsymptomatik tritt meistens erst in späten Stadien der Erkrankung auf. Dagegen können neu aufgetretene Haut- oder Schleimhauteffloreszenzen oder Gefühls- oder Funktionsausfälle (z. B. Fazialisparesen) recht früh erkannt werden. Eine makroskopisch sichtbare Schwellung im Kopf-Hals-Bereich führt meistens als Leitsymptom einer Tumorerkrankung zur Diagnose (Boenninghaus und Lenarz 
2005). Die klinische Symptomatik hängt dabei von der Lokalisation des Karzinoms ab, wobei Heiserkeit als Kardinalsymptom des Larynxkarzinoms hervorzuheben ist und dadurch vergleichsweise früh diagnostiziert wird. Karzinome anderer Lokalisation werden meistens in späteren Tumorstadien diagnostiziert und haben damit eine schlechtere Prognose, denn eine klinische Symptomatik kann lange Zeit auch völlig fehlen (Strutz und Mann 2009). Bei dem Verdacht auf eine Tumorerkrankung erfolgt nach HNO-ärztlicher Untersuchung die histopathologische Sicherung der Diagnose. Des Weiteren wird die Ausdehnung des Tumors sowie ein Befall der Lymphknoten oder ein Auftreten von Fernmetastasen mittels HNOärztlicher Diagnostik sowie Sonographie, Röntgen und Computer- und Magnetresonanztomographie ermittelt. Zur Beurteilung einer Knochenbeteiligung steht außerdem die Skelettszintigraphie zur Verfügung (Boenninghaus und Lenarz 2005).

\subsection{Plattenepithelkarzinom}

Die malignen Tumoren im Kopf-Hals-Bereich werden entsprechend ihrer anatomischen Lage eingeteilt. Die Einteilung der Karzinome umfasst Tumoren der Lippen und Mundhöhle, der großen und kleinen Speicheldrüsen, des Ohres, der Nase, der Nasennebenhöhlen, des Larynx, des Naso-, Oro-, Hypo- sowie Epipharynx. Am häufigsten kommen Karzinome in der Mundhöhle vor (Brockstein und Masters 2003). Maligne Tumoren der Halsweichteile umfassen meist Lymphknotenmetastasen oder Lymphome (Strutz und Mann 2009). Bei über $90 \%$ der Tumoren im Kopf-Hals-Bereich handelt es sich um Plattenepithelkarzinome. Adenokarzinome oder adenozystische Karzinome, Lymphome oder lymphoepitheliale Karzinome sind nur selten vertreten. Das Plattenepithelkarzinom im KopfHals-Bereich wird definiert als maligner Tumor mit plattenepithelialer Differenzierung. Man unterscheidet beim Plattenepithel einschichtiges von mehrschichtigem sowie mehrreihigem Plattenepithel. Des Weiteren kommt das Plattenepithel unverhornt oder verhornt vor (Böcker et al. 2012). Plattenepithel kommt in vielen Organen im oberen aerodigestiven Trakt vor. Mehrschichtig unverhorntes Plattenepithel kommt in der Mundhöhle, im Pharynx, Larynx und im oberen Teil des Ösophagus vor. Hier hat das Plattenepithel vor allem eine Barrierefunktion sowohl gegenüber Noxen, als auch Bakterien und Viren (Boenninghaus und Lenarz 2005). 


\subsection{Pathologie}

Die Entstehung von malignen Tumoren im Kopf-Hals-Bereich ist ein multifaktorieller Prozess, bei dem die Hauptrisikofaktoren wie Tabak- und Alkoholabusus neben HPV-Infektionen und genetischen Faktoren eine Rolle spielen (Crowe et al. 2002). Bei chronischer Exposition gegenüber den erwähnten Noxen reagiert das Plattenepithel mit Hyperplasie und Hyperkeratose. Dies steigert die Entartungswahrscheinlichkeit mit dem vermehrten Auftreten von Epitheldysplasien (Böcker und Heitz 2008). Ein Fortschreiten der Dysplasien kann zu einem Carcinoma in situ führen. Eine Epitheldysplasie imponiert makroskopisch als Leukoplakie, die definiert ist als weißliche, nicht abwischbare Schleimhautveränderung (Boenninghaus und Lenarz 2005). Diese Epitheldysplasie kann bereits ein Carcinoma in situ darstellen (Brockstein und Masters 2003). Das Carcinoma in situ beschränkt sich auf die Epithelschichten oberhalb der Basalmembran. Sobald die Basalmembran durchbrochen ist, spricht man von einem invasiven Karzinom. Ab dem Zeitpunkt des Durchbruchs durch die Basalmembran können bereits Metastasen entstehen, die beim therapeutischen Vorgehen und somit auch zur Prognose der Tumorerkrankung beitragen (Silverman et al. 1984; Stelow et al. 2007).

\section{$1.5 \quad$ Klassifikation}

Die Klassifikation maligner Kopf-Hals-Tumoren erfolgt nach der TNM-Klassifikation der Union Internationale contre le cancer (UICC). Diese wurde zur standardisierten Erfassung maligner Tumore entwickelt und in den letzten Jahrzenten weitergehend modifiziert und weiterentwickelt. Die aktuelle 7. Auflage der TNM-Klassifikation von Kopf-Hals-Tumoren stammt aus dem Jahr 2010 (Wittekind und Meyer 2010). Die TNM Klassifikation dient dazu, die klinische und pathologische Ausbreitung einer Tumorerkrankung zu systematisieren. Dies erlaubt eine Einschätzung zur Schwere der Erkrankung und dadurch auch über Prognose und Therapie. Die Klassifikation beruht auf den Befunden, die noch vor Therapiebeginn erhoben werden. Hierzu wird unter anderem die bildgebende Diagnostik wie Sonographie, Computer- und Magnetresonanztomographie genutzt. Des Weiteren sind klinische und endoskopische Untersuchungen von Bedeutung. Die pathologische Klassifikation 
beruht auf einem histopathologischen Befund. Bei der Klassifikation von Karzinomen steht das T für den Primärtumor sowie die Ausdehnung und Infiltration des Tumors. Hier werden die Stadien T1 bis T4 im Sinne einer zunehmende Größe sowie Zunahme der Ausdehnung des Primärtumors unterschieden. Das Stadium T0 bedeutet, dass der Primärtumor entweder unbekannt oder nicht mehr nachweisbar ist. Der Lymphknotenbefall wird ebenso von N0 (kein Lymphknotenbefall) bis hin zu ausgedehnten Lymphknotenmetastasen im Stadium N3 unterschieden. Die Metastasierung in andere Organe wird durch M1 angeben. Das Fehlen von Fernmetasen durch M0 (Wittekind und Meyer 2010; Wannenmacher et al. 2006). Das Grading der Karzinome bezeichnet die Einteilung nach der Differenzierung der Tumorzellen. Dieses geschieht histologisch und beinhaltet verschiedene Zellmerkmale. Abhängig davon reicht die Einteilung der Tumorzellen von G1 (gut differenziert) bis G4 (undifferenziert). Der Differenzierungsgrad der malignen Tumoren korreliert oft mit der Metastasierungstendenz und ist somit ein entscheidender prognostischer Faktor (Wiernik et al. 1991). Die TNM Klassifikation wird noch vervollständigt, indem die Feststellung der Klassifikation vor den TNM Komplex gestellt wird. Hier steht ein c für die klinische und ein $\mathrm{p}$ für die pathologische Feststellung (Wittekind et al. 2001). Eine komplette operative Entfernung des Tumors wird als R0-Resektion und eine Entfernung mit makroskopisch sichtbaren Tumorresten als R1-Resektion bezeichnet.

\subsection{Prognosefaktoren}

Das Ansprechen von Kopf-Hals-Karzinomen auf Therapiemaßnahmen ist stark abhängig von der Tumorlokalisation und der Tumorausdehnung. Wie bereits beschrieben, sind Tabak und Alkoholkonsum die Hauptrisikofaktoren bei der Entstehung von Kopf-Hals-Karzinomen (Wittekind et al. 2001). Darüber hinaus zeigt sich, dass die Tumorausbreitung bei rauchenden Patienten fortgeschrittener und die Prognose dadurch für die Patienten deutlich schlechter ist. Des Weiteren beeinflusst der Konsum von Alkohol und Tabak die Therapie negativ (Leon et al. 2009; Kumar et al. 2007). Wichtige prognostische Parameter sind die klinisch-chemischen und hämatologischen Laborparameter wie die Bestimmung des Blutbilds, der Gerinnungsparameter sowie der Leber- und der Nierenwerte (Hiddemann und Bartram 2009). Dazu kommen die molekularen Faktoren wie die Expression der 
Wachstumsfaktoren von Hematopoetic Growth Factor (HGF) und GranulocyteColony Stimulating Factor (G-CSF), die als negative Prognosefaktoren für das Patientenüberleben identifiziert werden konnten (Montag et al. 2009). Weiterhin werden bei Patienten mit einem Plattenepithelkarzinom im Kopf-Hals-Bereich die Tumormarker Squamous Cell Carcinoma Antigen (SCC) und das karzinoembryonale Antigen (CEA) im Verlauf bestimmt. Die Bestimmung dieser Tumormarker kann Hinweise auf eine Rezidivierung oder das Auftreten von Metastasen geben (Lordick et al. 2008; Diamandis et al. 2002). Der Tumormarker Tissue Polypeptide Antigen (TPA) korreliert hingegen mit dem Therapieansprechen und ist somit möglicherweise geeignet, um die Therapie bei Kopf-Hals-Karzinomen zu überwachen (Rosati et al. 2000). Die Infektion mit dem humanen Papillomavirus gilt ebenso als Risiko für die Entstehung eines Kopf-Hals-Karzinoms, allerdings haben Patienten eine deutlich bessere Prognose gegenüber Patienten mit klassischen Risikofaktoren wie Tabakund Alkoholkonsum. Es zeigt sich bei den Patienten mit einem HPV-assoziierten Kopf-Hals-Karzinom eine höhere 5-Jahres-Überlebensrate. Dies wird auf ein besseres Ansprechen der HPV-assoziierten Kopf-Hals-Karzinome auf Strahlen- und Chemotherapie zurückgeführt (Ang et al. 2012).

\subsection{Therapie}

Prinzipiell können Karzinome primär operiert oder auch primär radiochemotherapiert werden. Das Therapiekonzept richtet sich nach der Ausbreitung, der Lokalisation und der Operabilität des Tumors. Der Allgemeinzustand des Patienten spielt aber auch eine nicht unerhebliche Rolle bei der Konzeptfestlegung. Des Weiteren wird zwischen kurativen und palliativen Behandlungskonzepten unterschieden (Kauffmann et al. 2006; Hiddemann und Bartram 2009). Das Behandlungskonzept bei malignen Tumoren im Kopf-Hals-Bereich strebt die vollständige Tumorentfernung und den damit verbundenen krankheitsprognostischen Einfluss an. Allerdings ist zudem auch eine rekonstruktive Komponente zu beachten. Es geht nicht nur darum das Tumorgewebe komplett zu entfernen, sondern vielmehr die funktionelle Struktur zu erhalten oder wiederherzustellen (Brockstein und Masters 2003). Tumore in den Stadion UICC I und II werden vor allem einer chirurgischen Therapie zugeführt. Bei den lokal fortgeschrittenen Stadien UICC III und IVA/B kommt die kombinierte Radiochemotherapie adjuvant nach einer operativen Therapie zum Einsatz. Denn 
trotz primär erfolgreicher operativer Verfahren rezidivieren fortgeschrittene Tumoren häufig. Daher stellt die Radiochemotherapie neben der chirurgischen Therapie eine Ergänzung oder eine mögliche Behandlungsalternative dar. Eine Radiochemotherapie ist daher vor allem bei rezidivgefährdeten Patienten sinnvoll. Eine solche adjuvante Radiochemotherapie sollte daher bei lokal fortgeschrittenen Tumoren erfolgen. Ein enges interdisziplinäres Zusammenarbeiten ist somit erforderlich, um ein bestmögliches Behandlungsergebnis für den Patienten zu gewährleisten (Hiddemann und Bartram 2009). Das Gesamtüberleben der Patienten hängt dabei immer noch stark vom initial erhobenen TNM-Stadium ab (Pignon et al. 2009; Furness et al. 2011).

\subsubsection{Chirurgische Therapie}

Die Behandlung von Plattenepithelkarzinomen der verschiedenen anatomischen Regionen im Kopf-Hals-Bereich wird anhand der Empfehlungen der Leitlinien der Deutschen Krebsgesellschaft (Deutsche Krebsgesellschaft 2012) durchgeführt. Im europäischen Raum werden vor allem Kopf-Hals-Karzinome im UICC Stadium I und II primär operiert. Das Plattenepithelkarzinom wird meistens mit einem Sicherheitsabstand von $5 \mathrm{~mm}$ reseziert, dabei können auch umliegende Gewebe nicht immer geschont werden. So kann es im Kopf-Hals-Bereich zu Verletzungen von Nerven, Gefäßen und anderem Gewebe kommen. Ziel der kurativen chirurgischen Therapie ist immer eine R0-Resektion. Sollte eine Tumorpersistenz (R1) nach der Operation bestehen, kann versucht werden, durch eine Nachresektion ein R0Stadium zu erreichen. Die Resektion eines malignen Tumors wird häufig von einer Neck Dissection begleitet, also der Ausräumung von Lymphknotengruppen im umliegenden Gewebe oder des lymphatischen Abflussgebiets. Ist eine Lymphknotenbeteiligung nicht nachzuweisen, kann aufgrund der Kenntnis des typischen Metastasierungswegs eine selektive Neck Dissection indiziert sein.

\subsubsection{Strahlentherapie und Chemotherapie}

Die Radiotherapie wird bei der Behandlung von malignen Tumorerkrankungen auf unterschiedliche Weise eingesetzt. Eine primäre Radiochemotherapie kann aufgrund einer ausgeprägten Tumorausdehnung, einer deutlichen Infiltration des umliegenden Gewebes oder aufgrund des Allgemeinzustandes des Patienten Therapie der Wahl 
sein. Bei kurativen Konzepten kann nach der primären operativen Behandlung eines Karzinoms eine adjuvante Bestrahlung nötig sein. Sowohl die primäre als auch adjuvante Radiotherapie sollte als konkomitante Radiochemotherapie durchgeführt werden, da die begleitende Radiochemotherapie die lokoregionäre Tumorfreiheit und das Gesamtüberleben verbessert (Bourhis et al. 2005; Pignon et al. 2009; Wannenmacher et al. 2006). Die Radiotherapie sieht bei Kopf-Hals-Karzinomen im fortgeschrittenen UICC-Stadium III und IV eine Mindestdosis von 57,6 Gy für das Tumorbett vor. Die fraktionierte Einzelbestrahlung sollte 1,8 Gy betragen (Quon et al. 2011). Das zu bestrahlende Volumen sollte den Primärtumor sowie diagnostisch abgesicherte befallene Lymphknoten beinhalten. Das Lymphabflussgebiet sollte ebenfalls prophylaktisch mit einer Dosis von bis zu $60 \mathrm{~Gy}$ bestrahlt werden. Die

Bestrahlung der verschiedenen Lymphknotenlevel hängt weiterhin von der Tumorlokalisation, der Ausdehnung des Primärtumors und der davon ausgehenden Rezidivgefahr ab (Chao et al. 2002; Eisbruch et al. 2002). Die eingesetzten Chemotherapeutika sind vor allem platinhaltige Chemotherapeutika, 5-FU (Fluoruracil)- oder mitomycinhaltige Chemotherapeutika. Heutzutage werden überwiegend cisplatinhaltige Chemotherapeutika eingesetzt (Hiddemann und Bartram 2009; Pignon et al. 2009). Die Therapie mit Epidermal Growth Factor Receptor-Antagonisten wie Cetuximab kann begleitend bei der primären Radiotherapie oder in einem palliativem Konzept eingesetzt werden (Bonner et al. 2006). Die Strahlentherapie kann also in kurativer Intention als primäre Strahlentherapie oder adjuvant zu einer chirurgischer Therapie eingesetzt werden. Weiterhin kann die Strahlentherapie in einem palliativen Therapiekonzept zur Reduktion der Tumorlast eingesetzt werden und somit zur Verbesserung der Lebensqualität des Patienten beitragen.

\section{$1.8 \quad$ Nebenwirkungen der Therapie}

Radiotherapien im Kopf-Hals-Bereich gehen mit einer hohen Strahlenbelastung und damit mit einer möglichen Toxizität einher. Die Strahlenfolgen stehen in direktem Zusammenhang mit der Höhe der Einzeldosen und der Gesamtbehandlungszeit. Dabei ist zu beachten, dass jedes Gewebe eine unterschiedliche Radiosensitivität aufweist und sich jeder Patient hinsichtlich seiner Strahlenempfindlichkeit unterscheidet. Damit sich das Normalgewebe durch Reparaturmechanismen 
regenerieren kann und Schäden verringert werden, sollte eine Pause von mindestens 6 Stunden zwischen zwei Bestrahlungen gewährleistet sein. Man unterscheidet bei den Nebenwirkungen zwischen akut und spät einsetzenden Strahlenfolgen. Die akut einsetzende Toxizität wird bis zu 3 Monate nach Therapiebeginn beobachtet, während die spät oder chronisch einsetzenden Strahlenfolgen erst nach 3 Monaten beobachtet werden. Im Normalgewebe entsteht durch die Strahlung eine Entzündungsreaktion. Die akuten Strahlenfolgen treten vor allem bei schnell proliferierenden Geweben wie der Haut, Schleimhaut und dem Knochenmark auf. Hier sind vor allem die Mukositis und Dysphagie sowie die Radiodermatitis zu nennen. Die Akutreaktionen werden nach Common Toxity Criteria (CTC-Kriterien) in unterschiedliche Schweregrade eingeteilt und sind meistens reversibel (National Cancer Institute 2010). Chronische Strahlenschäden hingegen treten mit einer Verzögerung nach der Bestrahlung auf und sind zum Teil nicht reversibel. Chronische Strahlenfolgen werden durch länger anhaltende Strahlenbelastung auf langsam proliferierendes Gewebe erklärt. Die Strahlung verursacht hier eine Minderversorgung des Gewebes und bedingt damit Gewebsnekrosen. Langsam proliferierende Gewebe haben eine abweichende Strahlentoleranz, die bei der Therapieplanung mit einberechnet werden muss. $\mathrm{Zu}$ den chronischen Nebenwirkungen zählen unter anderem: Xerostomie nach Bestrahlung der Speicheldrüsen, Haut- und Gewebenekrosen sowie Lymphödeme. Die später auftretenden Nebenwirkungen werden nach den „late effects on normal tissues"-Kriterien ebenso in unterschiedliche Schweregrade eingeteilt (Sindermann et al. 2006).

\subsection{Strahlenwirkung}

Die Strahlenwirkung entsteht vor allem durch direkte oder indirekte DNASchädigung. Die direkte Strahlenwirkung entsteht durch direkte lonisierung der DNA. Die indirekte Strahlenwirkung entsteht vor allem durch freie Radikale, die in der Hydrathülle der DNA entstehen. Durch die Strahlung werden Wasserstoffbrücken geschädigt, die Basen der DNA werden verändert, geschädigt oder gehen verloren. Weiterhin können auch Einzelstrang- oder Doppelstrangbrüche entstehen, wobei die Dichte der ionisierenden Strahlung und die Strahlendosis von Bedeutung sind. Bei 
hoher Strahlendosis können DNA-Vernetzungen auftreten und die DNA-Synthese blockieren. Diese Vernetzungen können mehrfach und kombiniert auftreten, die dann nicht mehr reparabel sind. Die meisten DNA-Schäden werden zwar enzymatisch repariert, dennoch werden DNA-Schäden als wichtigster Wirkmechanismus einer Strahlentherapie angesehen (Hiddemann und Bartram 2009; Wannenmacher et al. 2006).

\subsection{Zytokine}

Zytokine bilden eine Gruppe von Proteinen, die beim Wachstum und der Differenzierung von verschiedenen Zellen eine wichtige Rolle übernehmen. Zytokine regulieren die Zellproliferation oder sind beispielweise für die Aktivierung verschiedener Faktoren zuständig, die modulierend auf das Immunsystem wirken. Zu den Zytokinen zählen unter anderem Interleukine, Wachstumsfaktoren sowie die chemotaktischen Zytokine. Zytokine können proinflammatorische Vorgänge bedingen, aber auch eine Entzündung hemmen. Bei den proinflammatorischen Zytokinen stehen die Zytokine wie z.B. der Tumor- Necrose- Faktor (TNF)- a oder Interferon- (IFN)- Y im Vordergrund (Belardelli et al. 1995; Mosmann et al. 2005). Bei den Entzündungshemmenden oder auch antiinflammatorischen Zytokinen ist der Transformierender Wachstumsfaktor( TGF)- $\beta$ hervorzuheben (Wahl et al. 1990).

\subsection{Chemokine}

Chemokine bilden eine Gruppe von Molekülen mit einem Molekulargewicht von ungefähr 8-14 kDa, die durch chemotaktische Zytokine mit anderen Zellen interagieren (Zlotnik et al. 2000). Es sind mehr als 50 verschiedene Chemokine bekannt, die in vier Klassen eingeteilt sind (Hesselgesser und Horuk 1999). Die Namensgebung der Chemokinklassen leitet sich entsprechend von der Struktur am aminoterminalen Ende der Chemokine ab. Die Nomenklatur der Chemokine erfolgt anhand der Cysteinreste und deren Abstand zueinander (Luster et al. 1998). So werden die C-Familie, die C-C-Familie, die C-X-C-Familie sowie die CX3C-Familie voneinander unterschieden, wobei das $X$ für eine Aminosäure zwischen den Cysteinresten steht (Charo et al. 2006). Die CC-Chemokine sind stark chemotaktisch 
für Monozyten, eosinophile und basophile Granulozyten, nicht aber für neutrophile Granulozyten. Zusätzlich können CC-Chemokine auf T-Zellen wirken. Die Chemokinrezeptoren sind G-Protein gekoppelte, 7-transmembran-Rezeptoren, die sich durch ihre Bindung von CC- oder CXC-Chemokinen unterscheiden. Die Rezeptoren werden auf der Oberfläche vieler verschiedener Zellen, darunter auch Tumorzellen, exprimiert (Murphy et al. 1994). Es sind etwa zwanzig verschiedene Chemokinrezeptoren bekannt, wovon zehn CC-Rezeptoren (CCR1-10), sieben CXCRezeptoren (CXCR1-6 und CXCR3B) und ein CX3C-Rezeptor voneinander zu unterscheiden sind. Einige Chemokine können an mehr als einen Rezeptor binden, wodurch sie vielfältige Funktionen haben. Die Expression von Chemokinen wird von Zytokinen, Wachstumsfaktoren sowie pathogenen Stimuli induziert, wobei Chemokine unter anderem die Immunantwort des Körpers regulieren. Dies geschieht zum Beispiel durch Chemotaxis von Leukozyten zum Zielgewebe (Baggiolini und Loetscher 2000). Chemokine spielen in der Rekrutierung von Entzündungszellen sowie bei der Ausbildung residenter Lymphozyten und der Zirkulation in lymphatischen Organen eine wichtige Rolle. Des Weiteren steuern die lokal sezernierten Chemokine die Leukoyztenreifung im Knochenmark. Chemokine werden auch von verschiedenen Tumorzellen im Rahmen der Onkogenese sezerniert, wobei hier die Funktion zur Zellproliferation und Metastasierung im Vordergrund zu stehen scheint (Arya et al. 2003; Muller et al. 2006; Payne et al. 2002; Strieter et al. 1995). Chemokine der CC-Klasse, wie der Chemokinligand CCL2, zeigen einen Einfluss auf die Tumorausbreitung in lymphatische Organe sowie eine damit verbundene schlechtere Prognose für Patienten mit einer malignen Tumorerkrankung (Ferreira et al. 2008). Auch das CXCL12-Chemokin und der spezifische Rezeptor CXCR4 werden von vielen neoplastischen Zellen exprimiert (Balkwill et al. 2004). Das CXCL12/CXCR4-System hat einen direkten Einfluss auf die Ausbreitung von Tumorzellen in lokoregionäre Lymphknoten, die Angiogenese von Tumoren sowie Tumorinvasion, Zellproliferation und auf die Immunantwort (Kryczek et al. 2007). Plattenepithelkarzinome im Kopf-Hals-Bereich scheinen zu einem großen Teil den Rezeptor CCR7 zu exprimieren, der auch in Lymphknoten vorhanden ist und dessen Expression mit einer schlechten Prognose einhergeht (Tsuzuki et al. 2006; Muller et al. 2006). Die Liganden des CCR7 sind die Chemokine CCL19 und CCL21. Der Signalweg dieser Chemokine und des Rezeptors sind für die Steuerung von naiven T-Zellen und dendritischen Zellen in sekundär lymphatischen 
Organen wie Lymphknoten zuständig (Loetscher et al. 2000). Der CCL21-CCR7Signalweg beeinflusst die Ausbreitung von Tumorzellen in Lymphknoten (Raman et al. 2007). Der C-C Chemokinrezeptor 6 wird im Gegensatz zum CCR7 in Kopf-HalsMetastasen vermindert exprimiert (Wang et al. 2005). CX3CL-Chemokine werden nicht sezerniert, sondern sind im Gegensatz zu den anderen Chemokinen nur membranständig anzutreffen (Zlotnik et al. 2006). Das Chemokin CCL3 bindet an die CC-Rezeptoren 1 und 5 und hat einen widersprüchlichen Einfluss auf Tumorausdehnung und Progression (Silva et al. 2007). CCL5, das ebenfalls an den CCRezeptor 5 bindet, erhöht die Migration von oralen Tumorzellen (Chuang et al. 2009). Der Chemokinligand CCL20 scheint das Wachstum von oralen Plattenepithelkarzinomen zu begünstigen und an der Immunabwehr bei bakteriellen Infektionen beteiligt zu sein (Abiko et al. 2003). Der CXC-Rezeptor 3, mit den beiden Liganden CXCL9 und CXL 10, steht in Verbindung mit chemotaktischen Prozessen bei Kopf-Hals-Plattenepithelkarzinomen (Chakraborty et al. 2008). Das CXCL5Chemokin ist an der Karzinogenese und Metastasierung bei Kopf-HalsPlattenepithelkarzinomen beteiligt, wobei die Inhibition des Chemokins ein Therapieansatz sein könnte (Miyazaki et al. 2006). Eine erhöhte Konzentration der Chemokine CXCL8, CXCL10 und CCL14 konnte außerdem mit dem ELISAVerfahren in Speichelproben von Patienten einer Kopf-Hals-Karzinomerkrankungen nachgewiesen werden (Michiels et al. 2009).

Trotz der oben zitierten Untersuchungen ist die Rolle von Chemokinen bei malignen Tumorprozessen noch nicht vollständig verstanden. Bisherige Ergebnisse haben gezeigt, dass das Wachstum als auch die Ausbreitung der Kopf-Hals-Karzinome von Chemokinen und deren Rezeptoren beeinflusst wird. Weiterhin sind Chemokine an inflammatorischen Prozessen beteiligt, die auch unter Radiotherapie zu beobachten sind und dort eine prognostische Rolle spielen könnten (Wolff et al. 2011).

\subsection{Zielsetzung}

Die Radiotherapie ist eine etablierte Therapieoption bei Kopf-Hals-Karzinomen, wobei sich die malignen Tumoren hinsichtlich ihrer Strahlensensibilität unterscheiden. So kann es unter Radiotherapie zu einer kompletten Remission der Erkrankung, zur partiellen Remission oder aber zur Rezidivierung kommen. Ebenso 
ist die Strahlenempfindlichkeit von Normalgewebe und Risikoorganen der Patienten unter Radiotherapie sehr unterschiedlich. Hier wurde beobachtet, dass einige Patienten starke Akutreaktionen zeigen, andere Patienten hingehen ohne starke strahleninduzierte Nebenwirkungen radiotherapiert werden können. Die von KopfHals-Karzinomzellen exprimierten Chemokine und deren Rezeptoren könnten in der Therapie von Kopf-Hals-Karzinomen von Bedeutung sein, da die Therapieresistenz oder Metastasierung durch die Expression von Chemokinen und deren Rezeptoren beeinflusst werden kann (Muller et al. 2006; Zlotnik 2006). Des Weiteren kann die Entzündungsreaktion, die bei einigen Patienten unter Radiotherapie auftritt, mit Chemokinen verknüpft sein und ist noch nicht vollständig verstanden (Wang et al. 2009). Der Zusammenhang von vermehrten akuten Nebenwirkungen und dem Therapieansprechen unter Radiotherapie ist zudem ein interessanter Aspekt, der mit der Expression von Chemokinen korrelieren könnte. In der Literatur über Hals-KopfTumore wurde die Expression von Chemokinen und deren Rezeptoren im Verlauf der Radiotherapie noch nicht eingehend beschrieben. In der vorliegenden Arbeit wird daher die Genexpression von 11 Chemokinen und deren Rezeptoren in 15 KopfHals-Karzinomzellinien und zwei Normalgewebszellinien umfangreich untersucht. Zudem wird die Genexpressionsänderung der untersuchten Chemokine und Chemokinrezeptoren im zeitlichen Verlauf nach Bestrahlung der Kopf-HalsKarzinomzellen analysiert. Die Strahlenwirkung auf die untersuchten Zelllinien und das Überleben der Zellen wird in der vorliegenden Arbeit durch Koloniebildungstests untersucht. Die genauere Kenntnis der Chemokinexpression in Kopf-HalsKarzinomen könnte in der Therapie dazu genutzt werden, bestehende Therapieschemata möglicherweise zu verändern oder zu erweitern. Das Ziel dieser Arbeit ist es daher, die strahleninduzierte Genexpression von Chemokinen und deren Rezeptoren in Kopf-Hals-Karzinomzellinien zu analysieren, um daraufhin einen möglichen Einfluss der Chemokine auf eine Radiochemotherapie bei Kopf-HalsKarzinomen weiterführend untersuchen zu können. 


\section{Material und Methoden}

\section{$2.1 \quad$ Material}

\subsubsection{Nährmedien}

Alle verwendeten Medien wurden mit zweifach destilliertem Wasser angesetzt und steril filtriert.

MEM: Minimum Essential Medium (Katalog-Nr. T 031-05 Biochrom, Berlin, D) Ein Minimalmedium von Eagle, das für viele humane Zellen zur Kultivierung genutzt werden kann.

RPMI: Roswell Park Memorial Institute (ohne Phenolrot, Katalog-Nr. 1640, Biochrom, Berlin, D)

Das Medium wird mit Vitaminen und Aminosäuren angereichert. Zudem werden dem Medium Serum und Wachstumsfaktoren hinzugefügt, um ein breites Spektrum an humanen Zellen zu versorgen.

DMEM: Dulbecco`s Modified Eagle's Medium (ohne Phenolrot, mit 1000 mg/l Glukose, Katalog-Nr. D2902, Sigma-Aldrich, Steinheim, D)

Dieses Medium ist ein standardisiertes Nährmedium mit einem breiten Spektrum an Verwendbarkeit für humane und tierische Zellen. Das Medium ist eine Modifikation von Eagle's Minimum Essential Medium (MEM), enthält aber um ein vielfaches mehr Vitamine, Aminosäuren (essentielle und nicht essentielle) und Glukose als das Basalmedium.

HAM`s F12: (ohne Phenolrot, Katalog-Nr.C-72117, PromoCell, Heidelberg, D): HAM's F12 ist ein Medium mit erhöhtem Gehalt an Aminosäuren und Zinksulfat. Zudem ist das biogene Amin Putrescin und die Fettsäure Linolsäure dem Medium beigesetzt. Das Medium eignet sich, angereichert mit Serum, um diverse humane Zellen zu kultivieren. 


\subsubsection{Zelllinien}

Die verwendeten Zelllinien wurden von verschiedenen Patienten etabliert, kommerziell erworben oder freundlicherweise von den Kollegen der Universitätsklinik der Technischen Universität Dresden, Klinik für Strahlentherapie und Radioonkologie, zur Verfügung gestellt.

Tabelle 2.1.2 Name und Ursprung der Zelllinien

\begin{tabular}{|c|c|c|c|}
\hline Zelllinie: & Medium: & Bezogen von: & Gewebeart: \\
\hline $\mathrm{BHY}$ & DMEM & DSMZ & $\begin{array}{l}\text { Plattenepithel } \\
\text { Mundhöhle }\end{array}$ \\
\hline BW225 & DMEM + HAM's F12 & RT-Göttingen & $\begin{array}{l}\text { Plattenepithel } \\
\text { Oropharynx }\end{array}$ \\
\hline CAL27 & DMEM & DSMZ & Plattenepithel Zunge \\
\hline CAL33 & DMEM & DSMZ & Plattenepithel Zunge \\
\hline DF19 & DMEM & RT-Göttingen & Dermale Fibroblasten \\
\hline FaDuDD & DMEM & RT-Dresden & $\begin{array}{l}\text { Plattenepithel } \\
\text { Pharynx }\end{array}$ \\
\hline GR145 I & DMEM + HAM's F12 & RT-Göttingen & $\begin{array}{l}\text { Plattenepithel } \\
\text { Oropharynx }\end{array}$ \\
\hline
\end{tabular}




\begin{tabular}{|c|c|c|c|}
\hline GR145 II & DMEM + HAM's F12 & RT-Göttingen & $\begin{array}{l}\text { Plattenepithel } \\
\text { Oropharynx }\end{array}$ \\
\hline HaCat & DMEM & DKFZ & $\begin{array}{l}\text { Epidermale } \\
\text { Keratinozyten }\end{array}$ \\
\hline HK 147 & DMEM + HAM's F12 & RT-Göttingen & $\begin{array}{l}\text { Plattenepithel } \\
\text { Oropharynx }\end{array}$ \\
\hline HO1u1 & DMEM + HAM's F12 & HSRRB & $\begin{array}{l}\text { Plattenepithel } \\
\text { Mundschleimhaut }\end{array}$ \\
\hline $\mathrm{HSC} 4$ & MEM & HSRRB & Plattenepithel Zunge \\
\hline KOSC2 & RPMI & HSRRB & $\begin{array}{l}\text { Plattenepithel } \\
\text { Mundschleimhaut }\end{array}$ \\
\hline SAS & DMEM + HAM's F12 & HSRRB & Plattenepithel Zunge \\
\hline SKN3 & RPMI & HSRRB & $\begin{array}{l}\text { Plattenepithel } \\
\text { Mundhöhle }\end{array}$ \\
\hline XF354 & DMEM & DKFZ & $\begin{array}{l}\text { Plattenepithel } \\
\text { Metastase } \\
\text { Mundhöhle }\end{array}$ \\
\hline ZMK1 & DMEM + HAM's F12 & RT-Göttingen & $\begin{array}{l}\text { Plattenepithel } \\
\text { Oropharynx }\end{array}$ \\
\hline
\end{tabular}




\subsubsection{Chemokine und Chemokinrezeptoren}

Die in Tabelle 2.1.3 aufgeführten Chemokine wurden in der vorliegenden Arbeit untersucht. Die verschieden Chemokine haben in der Literatur zum Teil keine einheitliche Nomenklatur. Die Chemokine binden zum Teil an mehrere Rezeptoren, die in der Tabelle mit aufgeführt sind.

Tabelle 2.1.3 Chemokine und Chemokinrezeptoren

\begin{tabular}{|l|l|l|l|}
\hline Chemokine: & Namen: & Name: & Rezeptoren: \\
\hline CCL2 & MCP-1, SCYA-2 & Monocyte chemoattractant protein 1 & CCR2 \\
\hline CCL3 & MIP-1a, SCYA3 & $\begin{array}{l}\text { Macrophage inflammatory protein 1 } \\
\text { Alpha }\end{array}$ & CCR1, 5 \\
\hline CCL5 & RANTES & $\begin{array}{l}\text { Regulated upon activation of normal } \\
\text { T cell }\end{array}$ & CCR1, 3, \\
\hline CCL20 & MIP3-a, LARC & $\begin{array}{l}\text { Macrophage inflammatory protein 3 } \\
\text { Beta }\end{array}$ & CCR6 \\
\hline CXCL1 & GROa, SCYB1 & Growth-related oncogene Alpha & CXCR1, 2 \\
\hline CXCL2 & GROß, SCYB2 & Growth-related oncogene Beta & CXCR1, 2 \\
\hline CXCL3 & GROY, SCYB3 & Growth-related oncogene Gamma & CXCR1, 2 \\
\hline CXCL9 & MIG, SCYB9 & $\begin{array}{l}\text { Monokine induced by interferon } \\
\text { gamma }\end{array}$ & CXCR3 \\
\hline CXCL10 & IP-10, SCYB10 & Interferon-inducible protein-10 & CXCR3 \\
\hline CXCL11 & I-TAC, SCYB9B & $\begin{array}{l}\text { Interferon-inducible T-cell alpha } \\
\text { chemoattractant }\end{array}$ & CXCR3 \\
\hline CXCL12 & SDF-1, SCYB12 & Stromal cell-derived factor 1 & CXCR4 \\
\hline
\end{tabular}

\subsubsection{Primer}

Die Primerpaare der untersuchten Gene wurden von der Firma MWG, Ebersberg, Deutschland hergestellt. Einige Primer lieferten keine zufriedenstellenden 
Ergebnisse, daher wurde in wenigen Fällen auf etablierte Primarpaare der Firma Qiagen zurückgegriffen.

Tabelle 2.1.4 Verwendete Primer

\begin{tabular}{|c|c|c|c|}
\hline Gen: & Forward Primer (5'-3'): & Reverse Primer (3'-5'): & Quelle: \\
\hline CCL2 & CAGCCAGATGCAATCAATGCC & TGGAATCCTGAACCCACTTCT & PrimerBank \\
\hline CCL3 & AGTTCTCTGCATCACTTGCTG & CGGCTTCGCTTGGTTAGGAA & PrimerBank \\
\hline CCL5 & АТССТСАTTGСTACTGСССТС & GCCACTGGTGTAGAAATACTCC & PrimerBank \\
\hline CCL20 & TGCTGTACCAAGAGTTTGCTC & CGCACACAGACAACTTTTTCTTT & PrimerBank \\
\hline CXCL1 & СTTGCCTCAATCCTGCATC & CCTTCTGGTCAGTTGGATTTG & $\begin{array}{l}\text { Bachmeier } \\
\text { et al. } 2008\end{array}$ \\
\hline CXCL2 & CGAAGTCATAGCCACACTCAAG & CTTCTGGTCAGTTGGATTTGC & $\begin{array}{l}\text { Bachmeier } \\
\text { et al. } 2008\end{array}$ \\
\hline CXCL3 & GCAGGGAATTCACCTCAAGA & GGTGCTCCCCTTGTTCAGTA & $\begin{array}{l}\text { Kato et al. } \\
2009\end{array}$ \\
\hline CXCL9 & TGCAAGGAACCCCAGTAGTGA & GGTGGATAGTCCCTTGGTTGG & $\begin{array}{l}\text { Okamoto et } \\
\text { al. } 2008\end{array}$ \\
\hline CXCL10 & GAGCCTACAGCAGAGGAACC & GAGTCAGAAAGATAAGGCAGC & $\begin{array}{l}\text { Okamoto et } \\
\text { al. } 2008\end{array}$ \\
\hline CXCL11 & GCTGTGATATTGTGTGCTACAGT & GCTTCGATTTGGGATTTAGGCA & PrimerBank \\
\hline CXCL12 & GGTCGTGGTCGTGCTGGT & CGGGCTACAATCTGAAGGG & $\begin{array}{l}\text { Zhou et al. } \\
2008\end{array}$ \\
\hline CCR1 & CACGGACAAAGTCCCTTGGA & TGTGGTCGTGTCATAGTCCTCTGT & $\begin{array}{l}\text { Deutsch et } \\
\text { al. } 2008\end{array}$ \\
\hline CCR3 & ATACAGGAGGCTCCGAATTATGA & ATGCCCCCTGACATAGTGGAT & PrimerBank \\
\hline CCR6 & CTCCAGGCTATTTGTACCGATTG & CACTGCCCAGAATGGGAGAG & PrimerBank \\
\hline CCR7 & GGGCACAGCCTTCCTGTG & CCACCACCAGCACGCTTT & $\begin{array}{l}\text { Deutsch et } \\
\text { al. } 2008\end{array}$ \\
\hline CXCR1 & GCAGCTCCTACTGTTGGACACA & САTGTCCTCTTCAGTTTCAGCAA & $\begin{array}{l}\text { Deutsch et } \\
\text { al. } 2008\end{array}$ \\
\hline CXCR4 & TACACCGAGGAAATGGGCTCA & AGATGATGGAGTAGATGGTGGG & PrimerBank \\
\hline
\end{tabular}




\begin{tabular}{|l|l|l|l|}
\hline HPRT & TGACACTGGCAAAACAATGCA & GGTCCTTTTCACCAGCAAGCT & $\begin{array}{l}\text { Calcagno } \\
\text { et al. } 2006\end{array}$ \\
\hline TBP & GGTCCGTTGATGTTGGTATCTC & ACTGTTTGAGGATTCGCTGGTA & PrimerBank \\
\hline TUBB & TGGACTCTGTTCGCTCAGGT & TGCCTCCTTCCGTACCACAT & PrimerBank \\
\hline
\end{tabular}

\subsubsection{Chemikalien}

Alle Lösungen, Medien und Puffer wurden mit zweifach destilliertem Wasser angesetzt.

Tabelle 2.1.5 Chemikalien

\begin{tabular}{|c|c|c|}
\hline 2-Mercaptoethanol & Merck & $\begin{array}{l}\text { Darmstadt, } \\
\text { Deutschland }\end{array}$ \\
\hline Fötales Kälber Serum, Katalog-Nr. S0115 & Biochrom AG & Berlin, Deutschland \\
\hline Methanol & Merck & $\begin{array}{l}\text { Darmstadt, } \\
\text { Deutschland }\end{array}$ \\
\hline SDS & Sigma-Aldrich & $\begin{array}{l}\text { Taufkirchen, } \\
\text { Deutschland }\end{array}$ \\
\hline Trypsin/EDTA Solution & Biochrom AG & Berlin, Deutschland \\
\hline SYBR Green qPCR-Master Mix & USB & Cleveland, USA \\
\hline DMSO & Sigma-Aldrich & $\begin{array}{l}\text { Taufkirchen, } \\
\text { Deutschland }\end{array}$ \\
\hline EDTA & Sigma-Aldrich & $\begin{array}{l}\text { Taufkirchen, } \\
\text { Deutschland }\end{array}$ \\
\hline Ethanol $100 \%$ & Merck & $\begin{array}{l}\text { Darmstadt, } \\
\text { Deutschland }\end{array}$ \\
\hline Ethanol $99,9 \%$ vergällt & DeRaSo & $\begin{array}{l}\text { Dassel-Lauenberg, } \\
\text { Deutschland }\end{array}$ \\
\hline
\end{tabular}




\begin{tabular}{|l|l|l|}
\hline Glutamin & Merck & $\begin{array}{l}\text { Darmstadt, } \\
\text { Deutschland }\end{array}$ \\
\hline $\mathrm{HCL}$ & Merck & $\begin{array}{l}\text { Darmstadt, } \\
\text { Deutschland }\end{array}$ \\
\hline Kristallviolett & Sigma-Aldrich & $\begin{array}{l}\text { Taufkirchen, } \\
\text { Deutschland }\end{array}$ \\
\hline $\mathrm{NaCl} \mathrm{0,9 \%}$ & Braun & $\begin{array}{l}\text { Melsungen, } \\
\text { Deutschland }\end{array}$ \\
\hline
\end{tabular}

\subsubsection{Puffer und Lösungen}

Tabelle 2.1.6 Puffer und Lösungen

\begin{tabular}{|l|l|l|}
\hline Ethanolamin & Biochrom AG & Berlin, Deutschland \\
\hline Phosphate Buffered Saline & Biochrom AG & Berlin, Deutschland \\
\hline Phosphoethanolamin & Biochrom AG & Berlin, Deutschland \\
\hline SDS & Sigma-Aldrich & Taufkirchen, Deutschland \\
\hline Trypanblau Solution 0,4\% & Sigma Aldrich & Taufkirchen, Deutschland \\
\hline Recombinant RNase Inhibitor & USB & Cleveland, USA \\
\hline Super-Script II reverse & Invitrogen & Carlsbad, USA \\
\hline transcriptase & Affymetrix & Santa Clara, USA \\
\hline Nukleosidtriphosphate & Roche & Mannheim, Deutschland \\
\hline Hexanukleotid-Primer & Invitrogen & Carlsbad, USA \\
\hline TE-Puffer & Sigma Aldrich & Taufkirchen, Deutschland \\
\hline Dithiothreitol & Invitrogen & Carlsbad, USA \\
\hline
\end{tabular}




\subsubsection{Laborkits}

Tabelle 2.1.7 Laborkits

\begin{tabular}{|l|l|l|}
\hline ELISA CXCL1/ GROa Immunoassay & R\&D Systems & Abingdon, UK \\
\hline ELISA Human CXCL12/SDF-1 alpha & R\&D Systems & Abingdon, UK \\
\hline RNeasy Plus Mini Kit & Qiagen & Hilden, Deutschland \\
\hline
\end{tabular}

\subsubsection{Geräte}

Tabelle 2.1.8 Geräte

\begin{tabular}{|l|l|l|}
\hline Airflow Sterile Werkbank & Heraeus & Hanau, Deutschland \\
\hline Bio photometer & Eppendorf & Hamburg, Deutschland \\
\hline $\begin{array}{l}\text { Brutschrank } 37^{\circ} \mathrm{C} \text { und } 5 \% \\
\text { CO2 }\end{array}$ & Heraeus & Hanau, Deutschland \\
\hline $\begin{array}{l}\text { ELISA Reader Dynatech MR } \\
5000\end{array}$ & Dynatech & Ashford, United Kingdom \\
\hline $\begin{array}{l}\text { Gefrierschrank }-80^{\circ} \mathrm{C} \text { VIP } \\
\text { Series }\end{array}$ & Sanyo & Moriguchi, Japan \\
\hline Mastercycler gradient & Eppendorf & Hamburg, Deutschland \\
\hline Messzelle LabelGuard & Implen & München, Deutschland \\
\hline Mikroskop Standard 18 & Zeiss & Oberkochen, Deutschland \\
\hline Neubauer Zählkammer & Marienfeld & Lauda Königshofen \\
\hline PCR TaqMan 7900HT & Applied Biosystems & Darmstadt, Deutschland \\
\hline Pipett Boy comfort & Eppendorf & Hamburg, Deutschland \\
\hline Pipettierhilfe Pipetboy accu & Integra Biosciences & Chur, Schweiz \\
\hline Qiacube & Qiagen & Hilden, Deutschland \\
\hline Reinstwassersystem Arium & Sartorius & Göttingen, Deutschland \\
\hline
\end{tabular}




\begin{tabular}{|l|l|l|}
\hline $\begin{array}{l}\text { Röntgenröhre Gulmay } \\
\text { Medical RS225 }\end{array}$ & Gulmay medical Itd. & Surrey, England \\
\hline Sterilisator & Memmert & Schwalbach, Deutschland \\
\hline Stickstofftank & Messer Griesheim & Griesheim, Deutschland \\
\hline Thermomixer comfort 5436 & Eppendorf & Hamburg, Deutschland \\
\hline Trockenschrank & Memmert & Schwalbach, Deutschland \\
\hline Vortexer MS1 Minishaker & IKA & Taquara, Brasilien \\
\hline Waage: TE Precision & Sartorius AG & Göttingen, Deutschland \\
\hline Balance TE 612 & GFL & Burgwedel, Deutschland \\
\hline Zentrifuge Megafuge 1.0 R & Heraeus & Hanau, Deutschland \\
\hline Zentrifuge ministar & VWR International & Darmstadt, Deutschland \\
\hline
\end{tabular}

\subsubsection{Zubehör}

Tabelle 2.1.9 Zubehör

\begin{tabular}{|l|l|l|}
\hline 10-ml-Röhren & Sarstedt & Nümbrecht, Deutschland \\
\hline 50 -ml-Röhren & Sarstedt & Nümbrecht, Deutschland \\
\hline 8er Cups optically clear & Sarstedt & Nümbrecht, Deutschland \\
\hline 8er Deckel, optically clear & Sarstedt & Nümbrecht, Deutschland \\
\hline Combitips 1ml, 0,5ml, 0,1ml & Eppendorf & Hamburg, Deutschland \\
\hline CryoRöhrchen Nunc & Sigma Aldrich & Taufkirchen, Deutschland \\
\hline
\end{tabular}




\begin{tabular}{|c|c|c|}
\hline Deckgläser & $\begin{array}{l}\text { LO-Laboroptik } \\
\mathrm{GmbH}\end{array}$ & $\begin{array}{l}\text { Friedrichsdorf, } \\
\text { Deutschland }\end{array}$ \\
\hline Reaktionsgefäße 1,5 ml und 2,0 ml Safe-lock & Eppendorf & Hamburg, Deutschland \\
\hline Eppendorf Pipette 100-1000 $\mu \mathrm{l}$ mit Spitzen & Eppendorf & Hamburg, Deutschland \\
\hline Eppendorf Pipette 20-200 $\mu$ l mit Spitzen & Eppendorf & Hamburg, Deutschland \\
\hline Falcon Röhrchen 15ml & $\begin{array}{l}\text { Greiner Bio- } \\
\text { One }\end{array}$ & $\begin{array}{l}\text { Frickenhausen, } \\
\text { Deutschland }\end{array}$ \\
\hline Falcon Röhrchen 50ml & Sarstedt & Nümbrecht, Deutschland \\
\hline Filter tips $1000 u l$ & Qiagen & Hilden, Deutschland \\
\hline $\begin{array}{l}\text { Gewebekulturflaschen, } \\
25 \mathrm{~cm}^{2}, 40 \mathrm{ml} \text { mit Filterkappen }\end{array}$ & Nunc & Roskilde, Dänemark \\
\hline $\begin{array}{l}\text { Gewebekulturflaschen, } \\
75 \mathrm{~cm}^{2}, 250 \mathrm{ml} \text { mit Filterkappen }\end{array}$ & $\begin{array}{l}\text { Greiner Bio- } \\
\text { One }\end{array}$ & $\begin{array}{l}\text { Frickenhausen, } \\
\text { Deutschland }\end{array}$ \\
\hline Kodan® Tinktur forte farblos, & $\begin{array}{l}\text { Schülke \& } \\
\text { Mayr GmbH }\end{array}$ & Norderstedt, Deutschland \\
\hline Kryoröhrchen 2 ml & Schütt & Göttingen, Deutschland \\
\hline Objektträger & $\begin{array}{l}\text { Waldemar } \\
\text { Knittel GmbH }\end{array}$ & $\begin{array}{l}\text { Braunschweig, } \\
\text { Deutschland }\end{array}$ \\
\hline Optically clear adhesive seal sheets & $\begin{array}{l}\text { Thermo } \\
\text { scientific }\end{array}$ & Waltham, USA \\
\hline Parafilm pechiney plastic packaging & $\begin{array}{l}\text { Greiner Bio- } \\
\text { One }\end{array}$ & $\begin{array}{l}\text { Frickenhausen, } \\
\text { Deutschland }\end{array}$ \\
\hline Pasteur-Pipetten & Brand & Wertheim, Deutschland \\
\hline PCR 384 well plate TF-0384 & $\begin{array}{l}\text { Thermo } \\
\text { scientific }\end{array}$ & Waltham, USA \\
\hline
\end{tabular}




\begin{tabular}{|l|l|l|}
\hline PCR 384 well-plate & $\begin{array}{l}\text { Thermo } \\
\text { scientific }\end{array}$ & Waltham, USA \\
\hline Pipetten steril $2 \mathrm{ml}, 10 \mathrm{ml}, 25 \mathrm{ml}$ & Sarstedt & Nürmbrecht, Deutschland \\
\hline Pipettenspitze Sarstedt $200 \mu \mathrm{l}$ & Sarstedt & Nürmbrecht, Deutschland \\
\hline Rnase Zap & Sigma-Aldrich & Taufkirchen, Deutschland \\
\hline Rotor adapters & Qiagen & Hilden, Deutschland \\
\hline Sample Tube RB, 2ml & Qiagen & Hilden, Deutschland \\
\hline Shaker adapter 2ml Microzentrifuge Tubes & Qiagen & Hilden, Deutschland \\
\hline Sterilfilter Filtropur L 0.2 LS & Sarstedt & Nümbrecht, Deutschland \\
\hline Sterilfilter Minisart 2000 & Sartorius & Göttingen \\
\hline Zellkulturflaschen 50 und 250ml & $\begin{array}{l}\text { Greiner Bio- } \\
\text { One }\end{array}$ & $\begin{array}{l}\text { Frickenhausen, } \\
\text { Deutschland }\end{array}$ \\
\hline
\end{tabular}

\subsubsection{Software}

Tabelle 2.1.10 Software

\begin{tabular}{|l|l|l|}
\hline Bio-photometer PC online v1.00 & Eppendorf & Hamburg, Deutschland \\
\hline KaleidaGraph, Version 3.5 & Synergy Software & Reading, USA \\
\hline Word, Version 2011 & Microsoft & Redmond, USA \\
\hline Excel, Version 2011 & Microsoft & Redmond, USA \\
\hline SDS 2.1 & Applied Biosystems & Darmstadt, Deutschland \\
\hline
\end{tabular}




\subsection{Methoden}

Die verwendeten Zellen aller Zellinien entstammen verschiedenen Patienten oder sind kommerziell erhältlich. Die Zellen wurden in einem Brutschrank in einer $5 \%$ $\mathrm{CO}_{2}$-Atmosphäre bei $37^{\circ} \mathrm{C}$ inkubiert. Die verwendeten Zellen benötigen die Nährmedien, die in Tabelle 2.1.2 aufgeführt sind. Die Zellen wurden in diesen Nährmedien über die gesamte Zeit unter Beigabe von fötalem Kälberserum kultiviert. Jede Art von Zellkultivierung wurde unter einer sterilen Werkbank durchgeführt. Es wurde darauf geachtet, nur mit sterilen Materialien zu arbeiten. Bei eventueller Kontamination wurden sofort alle verwendeten Materialien gewechselt. Die verwendeten Medien wurden vor der Benutzung immer im Wasserbad auf die Arbeitstemperatur von $37^{\circ} \mathrm{C}$ erwärmt.

\subsubsection{Zellkultur}

Die verwendeten Zellen der unterschiedlichen Zelllinien waren für den Transport in 2-ml-Kryoröhrchen eingefroren und wurden vor dem Gebrauch im $37^{\circ} \mathrm{C}$ Wasserbad aufgetaut, wobei darauf zu achten war, eine Kontamination der Zellen mit unsterilem Wasser zu verhindern. Um dies zu gewährleisten, wurde der Deckel der Kryoröhrchen mit einem mit 70\% Alkohol getränktem Tuch umwickelt und die Röhrchen ins Wasserbad getaucht. Nachdem die Zellen in den Kryoröhrchen aufgetaut wurden, folgte die Überführung der Zellen mit $5 \mathrm{ml}$ des entsprechenden Mediums in eine $25 \mathrm{~cm}^{2}$ Zellkulturflasche. Dies geschah unter sterilen Bedingungen durch einfaches Pipettieren des Mediums und der Zellen in Zellkulturflaschen. Um ein schnelles Anwachsen der Zellen auf dem Flaschenboden zu ermöglichen, wurden die Zellkulturflaschen für zwei Stunden im Brutschrank bei $37^{\circ} \mathrm{C}$ und $5 \% \mathrm{CO}_{2}$ kultiviert. Das Anwachsen der Zellen wurde unter dem Mikroskop kontrolliert. Sobald Zweidrittel der Zellen am Zellkulturflaschenboden angewachsen waren, wurde der Überstand des Mediums verworfen und ein Mediumwechsel durchgeführt. Dies war nötig, da sich in dem Medium der eingefrorenen Zellen ein gewisser Anteil des zytotoxischen Dimethylsulfoxid (DMSO) befand. Die verschiedenen Zellinien wuchsen unterschiedlich schnell und wurden je nach Bedarf und Wachstumsfortschritt passagiert. Bei der Subkultivierung wurde die Zellzahl 
entweder erhöht oder reduziert. Um die Zellzahl für die erreichte Zelldichte zu ermitteln, wurde diese entweder gezählt oder in frühen Stadien einer Zellzahlerhöhung vorerst nach Erfahrungswert angenommen und den Zellkulturflaschen angeglichen. Das Passagieren der Zellen sollte bei einer Konfluenz der Zellkulturflaschen von $70-80 \%$ erfolgen, da ansonsten sowohl das Nährstoffangebot als auch der pH-Wert des Mediums zu stark sinken. Adhärent wachsende Kulturen wurden enzymatisch oder mechanisch vom Flaschenboden abgelöst. Um den Zellrasen vom Flaschenboden zu lösen, wurde das proteolytische Enzym Trypsin verwendet. Vor der Verwendung der Trypsinlösung (10\% Trypsin in PBS-Puffer) wurde diese ebenfalls auf $37^{\circ} \mathrm{C}$ im Wasserbad erwärmt. Das alte Medium in den Zellkulturflaschen wurde rückstandslos mit einer sterilen Pipette abgesaugt und verworfen. Ansonsten würde es durch das im Medium enthaltene fötale Kälberserum zu einer Inaktivierung des Trypsins kommen. Der Zellrasen in den Zellkulturflaschen wurde zunächst zweimal mit $5 \mathrm{ml}$ PBS Puffer gespült, welcher vorher ebenfalls im Wasserbad erwärmt wurde. Der PBS Puffer wurde hiernach restlos durch Pipettieren entfernt, anschließend wurden $2 \mathrm{ml}$ Trypsin in eine $25 \mathrm{~cm}^{2}$ Zellkulturflasche über den Zellrasen gegeben. Die Zellkulturflasche wurde geschwenkt, um den Zellrasen in der Zellkulturflasche komplett zu benetzen und die Zellen für $5-7 \mathrm{~min}$ bei $37^{\circ} \mathrm{C}$ im Brutschrank inkubiert. Die Ablösung der Zellen vom Kulturflaschenboden wurde mit dem Lichtmikroskop kontrolliert. Eventuell musste die Inkubationszeit um wenige Minuten verlängert werden. Nach der Inaktivierung des proteolytischen Trypsins mit einem serumhaltigem Medium, wurde die Zelllösung mit einer 2-ml-Pipette gemischt, um am Flaschenboden haftende Zellen zu lösen und zusammenhängende Zellen zu vereinzeln. Die Zellen wurden danach entweder in größere Zellkulturflaschen ausgeimpft und mit frischem Medium versorgt oder aber weiterführend behandelt, um sie beispielsweise zu bestrahlen oder einzufrieren. Das Einfrieren der Zellen war erforderlich, um die gleiche Passage der Zellen für spätere Zeitpunkte einer Behandlung vorzuhalten. Die Zelllinie HaCat benötigte eine etwas umfangreichere Behandlung, da sich die Zellen nur schlecht vom Kulturflaschenboden gelöst haben. Diese Zelllinie musste nach Verwerfung des Kulturmediums zunächst mit 2 ml EDTA/PBS Lösung einmalig gespült werden, um die Zellen anschließend mit einer EDTA/PBS Lösung für 2-3 Minuten bei $37^{\circ} \mathrm{C}$ im Brutschrank zu inkubieren. Nach der Inkubationszeit wurde die EDTA/PBS Lösung mit einer Pipette vollständig abgesaugt und anschließend mit $2 \mathrm{ml}$ Trypsin-EDTA für 
weitere 3 Minuten bei $37^{\circ} \mathrm{C}$ und $10 \% \mathrm{CO}_{2}$ im Brutschrank inkubiert. Die Ablösung der Zellen vom Kulturflaschenboden wurde erneut mit dem Lichtmikroskop kontrolliert. Falls erforderlich wurden die restlichen Zellen mit Hilfe eines Gummischabers mechanisch abgelöst. Die Inaktivierung des Trypsins erfolgte hier ebenfalls mit einem FKS-haltigem Medium und die Zellen wurden, wie oben beschrieben, weiterführend behandelt.

\subsubsection{Mediumwechsel}

Die verschiedenen Nährmedien dienen der Versorgung der Zellen mit lebenswichtigen Nährstoffen. Die Medien enthielten verschiedene Bestandteile, die essentiell für das Überleben, die Vitalität und das Wachstum der Zellen sind. Es musste in regelmäßigen Abständen ein Mediumwechsel durchgeführt werden, da die überlebenswichtigen Bestandteile entweder verbraucht wurden bzw. die Abbauprodukte der Zellen eine Verschiebung des $\mathrm{pH}-$ Werts in den sauren Bereich herbeiführten. Die Ansäuerung des Mediums durch die Abfallprodukte wird anhand eines gelblichen Farbumschlags des Mediums deutlich. Ein Mediumwechsel sollte daher regelmäßig und nach Bedarf der Zellen stattfinden. Es ist zu beachten, dass der Verbrauch der Nährstoffe im Medium abhängig von der Vitalität und dem Wachstum der Zellen ist. Ein reiner Mediumwechsel erfolgte ohne den am Zellkulturflaschenboden wachsenden Zellrasen enzymatisch oder mechanisch abzulösen. Hierbei wurde das Medium mit einer Pipette an der zellabgewandten Seite mit einer sterilen Pipette komplett abgesaugt und anschließend in einen Abwurfbehälter abgeworfen. Das Entnehmen des Mediums sollte an der gegenüberliegenden Seite der Flasche vom Zellkulturrasen stattfinden, um eine Beschädigung der Zellen auszuschließen. Nach der Entfernung des alten Mediums wurde die Zellkulturflasche zweimal mit jeweils $5 \mathrm{ml}$ PBS-Puffer gespült, um Rückstände auszuwaschen. Dazu wurde der auf $37^{\circ} \mathrm{C}$ erwärmte Puffer steril in die Zellkulturflasche pipettiert und danach langsam über den Zellrasen gegeben. Der PBS-Puffer wurde anschließend, wie oben beschrieben, komplett entnommen und abgeworfen. Nach dem Waschen der Zellen wurde das ebenfalls im Wasserbad auf $37^{\circ} \mathrm{C}$ vorerwärmte Medium den Zellen steril zugeführt. Um ein Aufschäumen des Mediums zu verhindern, wurde das frische Medium auf der Zellabgewandten Seite langsam hinzugeführt. Für das Wachstum bestimmter Zellen sind vom Zellverband 
sezernierte Bestandteile von Bedeutung. Wenn diese gewissen autokrinen Wachstumsfaktoren nötig waren, um ein optimales Wachstum zu gewährleisten, wurden bei einem Mediumwechsel 0,5 ml des alten Mediums zur Weiternutzung erhalten und der Schritt des Waschens der Zellen mit PBS Puffer entfällt.

\subsubsection{Zählen der Zellen}

Für die genaue Zellzahlbestimmung wurden die Zellen mit Hilfe einer Neubauer Zählkammer gezählt. Die Neubauer-Zählkammer wurde vorbereitet, indem ein Deckglas mit etwas Druck auf die beiden Trägerstege aufgesetzt wurde. Der korrekte Sitz des Deckglases wurde durch das Entstehen der sog. Newtonschen Ringe kontrolliert, die man am Rand der Deckgläser erkennen konnte. Durch das Aufbringen des Deckglases wurde ein Raum für die Zellsuspension geschaffen. Die zu zählenden Zellen wurden wieder enzymatisch vom Zellkulturflaschenboden abgelöst und anschließend in $1 \mathrm{ml}$ Nährmedium aufgenommen. Um eine gute Vermengung der Lösung zu erreichen, wurde die Suspension mit einer Pipette durchgemischt. Anschließend wurde die Teilmenge der Zellsuspension mit Hilfe einer Glaspipette entnommen und die Neubauer Zählkammer damit beschickt. Es wurden je zwei Quadrate der Zählkammer ausgezählt und daraus ein Mittelwert gebildet. Beim Zählen ist wichtig, dass auf Grenzlinien liegende Zellen nicht doppelt gezählt wurden und die Zellen gleichmäßig über die Quadrate verteilt waren. Andernfalls wurde die Zellsuspension nochmal mittels einer Pipette aufgemischt und neu aufgebracht. Die Zellzahl pro $\mathrm{ml}$ ergab sich aus dem ermittelten Wert, der mit dem Faktor 10.000 multipliziert wurde (Kehrwert des Produkts aus Quadratfläche und Kammerhöhe). Die Kenntnis der genauen Zellzahl einer Zellsuspension war für die weitere Behandlung, z. B. dem Einfrieren der Zellen oder auch bei den Koloniebildungstests, von Bedeutung.

\subsubsection{Einfrieren von Zellen}

Für spätere Aufarbeitung, wie Koloniebildungstests oder RNA Isolation, wurden Zellen zu je 2 Millionen pro Kryoröhrchen in Medium mit 10\% DMSO Lösung in flüssigem Stickstoff bei $-196^{\circ} \mathrm{C}$ eingefroren. Die Zelllinien wurden dafür wie gewohnt enzymatisch vom Flaschenboden gelöst. Dazu wurden die Zellen, wie bereits 
beschrieben, nach dem Verwerfen des alten Mediums zweimal mit $5 \mathrm{ml}$ PBS gespült, danach mit $2 \mathrm{ml}$ Trypsin überspült und für $5-7 \mathrm{~min}$ bei $37^{\circ} \mathrm{C}$ im Brutschrank inkubiert. Nach optischer Begutachtung unter dem Lichtmikroskop wurden die Zellen in $5 \mathrm{ml}$ Nährmedium aufgenommen und mit der Pipette gut durchmischt. Anschließend wurde die Zellsuspension bei 1500xg für 10 Minuten zentrifugiert. Das überstehende Medium wurde nach dem Zentrifugieren erneut verworfen und das entstandene Zellpelett für 2 min auf Eis gelagert. Die Zellen wurden in ein kaltes Medium gebracht und mit Hilfe einer Neubauer Zählkammer die Zellzahl pro ml bestimmt. Die Zellsuspension wurde mit dem benötigten Medium verdünnt bis sich 2 Millionen Zellen in einem Volumen von 1,65 $\mathrm{ml}$ befanden. Dem Einfriermedium wurde neben dem Kulturmedium mit fötalem Kälberserum auch ein Anteil von 10\% DMSO zugegeben. Das Medium wurde daher mit 0,15 ml DMSO versetzt und eine Suspension von $1,8 \mathrm{ml}$ pro Kryoröhrchen hergestellt. Die so hergestellte Zellsuspension wurde auf Eis in vorher beschriftete und gekühlte Kryoröhrchen mit der Pipette überführt und für 2 Stunden in einem ebenfalls vorgekühlten Papierumschlag auf $-20^{\circ} \mathrm{C}$ heruntergekühlt. Die Zellen wurden nach dieser Zeit in einen Gefrierschrank mit einer Temperatur von $-80^{\circ} \mathrm{C}$ überführt und nach $24 \mathrm{~h}$ im Stickstofftank bei $-196^{\circ} \mathrm{C}$ längerfristig eingefroren. Für anstehende Versuche werden die benötigten Kryoröhrchen wie weiter oben beschrieben wieder aufgetaut.

\subsubsection{Bestrahlungsaufbau}

Die Bestrahlung aller Zelllinien erfolgte bei einer Dosisrate von 2 Gy pro Minute mit einer Röntgenröhre der Firma Gulmay Medical. Die Röhrenspannung der Röntgenröhre betrug $200 \mathrm{kV}$, die Röhrenstromstärke $15 \mathrm{~mA}$, es wurde ein 0,5 mm Kupferfilter verwendet. Die jeweilige 0 Gy Kontrolle der Zelllinien wurde mit zum Bestrahlungsgerät transportiert, während der Bestrahlung der anderen Zellen jedoch außerhalb des Bestrahlungsgerätes gelagert. Die Zelllinien wurden direkt vor der Bestrahlung aus dem Inkubatorschrank entnommen und nach der Bestrahlung zu den erforderlichen Zeitpunkten aufgearbeitet. Die Dosimetrie wurde von den Physikern der Abteilung für Strahlentherapie und Radioonkologie der Universitätsmedizin Göttingen berechnet. 


\subsubsection{Colony Forming Assay}

Das Überleben der Zellen nach der Bestrahlung wurde mittels eines standardisierten Koloniebildungstests ermittelt. Definierte Zellzahlen zwischen 500 und 14.000 Zellen/25 $\mathrm{cm}^{2}$ Flasche wurden jeweils in 4 Zellkulturflaschen und $5 \mathrm{ml}$ der jeweiligen Nährlösung gegeben, um anschließend bei 1 Gy, 2 Gy, 3 Gy, 4 Gy oder 6 Gy bestrahlt zu werden. Nach Inkubation der Zellen für 7-10 Tage wurden die Zellen für das Zählen der Kolonien fixiert. Das alte Nährmedium wurde mit der Pipette komplett abgesaugt und verworfen. Anschließend wurden die Zellen zweimal mit $5 \mathrm{ml}$ PBS gespült und dann mit $4 \mathrm{ml}$ 70\% Alkohol für 15min bei Zimmertemperatur fixiert. Der Alkohol wurde danach verworfen und die Zellkulturflaschen im Trockenschrank für 24 h getrocknet. Nach dem Trocken wurden die Zellkolonien mit Kristallviolett gefärbt. Dafür wurde eine Färbelösung $(0,5 \mathrm{~g} / \mathrm{l}$ in 20\% Ethanol) für 200 Zellkulturflaschen mit $800 \mathrm{ml}$ Aqua dest., 0,5 ml Kristalviolett und $200 \mathrm{ml}$ absolut Alkohol hergestellt. Von der Färbelösung wurden je $5 \mathrm{ml}$ in die Kulturflaschen gegeben und darauf geachtet, möglichst nur den Flaschenboden zu benetzen, um den größtmöglichen Färbeeffekt zu erzielen. Die Zellen wurden mit der Färbelösung für 20 min bei Raumtemperatur gefärbt und danach wurde die gesamte Färbelösung durch einfaches Dekantieren verworfen. Die Kulturflaschen wurden danach mit ca. $10 \mathrm{ml}$ Aqua destillata gespült und wiederholt für $24 \mathrm{~h}$ im Trockenschrank bei $60^{\circ} \mathrm{C}$ getrocknet. Die fixierten und gefärbten Kulturflaschen wurden auf eine zu den Zellkulturflaschen passenden Schablone unter ein Mikroskop bei 16-25facher Vergrößerung gelegt und die Kolonien gezählt. Jeder Zellkulturflaschenboden wurde von oben rechts nach unten links gezählt. Definitionsgemäß wurden nur Zellkolonien von 50 Zellen und mehr in die Wertung genommen und gezählt. Zellansammlungen mit weniger als 50 Zellen wurden nicht berücksichtigt. Die Versuche wurden dreimal wiederholt, um die Überlebenskurve aus mehreren Messpunkten zu ermitteln.

\subsubsection{RNA-Asservierung}

Grundsätzlich wurde für die Zellanalytik aller Zellen die gleiche Methodik angewandt. Die Zellen der unterschiedlichen Zelllinien wurden alle in den jeweiligen Nährmedien zu je ca.1 Million in Zellkulturflaschen ausgesät und dann mit 2 Gy bestrahlt bzw. nur zur Kontrolle transportiert und anschließend nicht bestrahlt. Nach den jeweiligen 
Inkuabtionszeiten wurden die Zellen mit Trypsin gelöst und in $2 \mathrm{ml}$ Nährmedium aufgenommen. Die Zellsuspension wurde in ein 10-ml-Falcon-Röhrchen überführt, mit $5 \mathrm{ml}$ sterilem PBS-Puffer aufgefüllt und nach gutem Durchmischen mittels Pipette bei $1500 \mathrm{~g}$ für $10 \mathrm{~min}$ bei Raumtemperatur zentrifugiert. Nach vollständigem Abnehmen des Überstands wurde das Waschen des Zellpellets mit $10 \mathrm{ml}$ sterilem PBS-Puffer zweimal wiederholt. Nach dem letzten Waschschritt wurde nach Abnehmen des Überstands ohne Restflüssigkeit $350 \mu$ l RLT-Plus- Puffer (aus dem RNeasy Mini Plus Kit der Firma Qiagen, wie angegeben mit $\beta$-Mercaptoethanol ad $1 \%)$ zügig zugegeben und für 2 min bei Raumtemperatur ruhen gelassen. Nach der erforderlichen Wartezeit wurde die Zellsuspension kräftig mit einer Pipette durchgemischt und exakt $350 \mu \mathrm{l}$ in vorbeschriftete 2-ml-Eppendorf-Cups überführt. Anschließend wurden die Eppendorf-Cups für weitere 5 min bei Raumtemperatur ruhen gelassen und bis zur weiteren Verwendung bei $-80^{\circ} \mathrm{C}$ eingefroren. Der Überstand aus den Zellkulturflaschen wurde $\mathrm{zu}$ jeweils $1,8 \mathrm{ml}$ in 2-mlReaktionsgefäße überführt und anschließend bei $-80^{\circ} \mathrm{C}$ eingefroren.

\subsubsection{Isolation und Quantifizierung von RNA}

Zur Bestimmung der Expression der interessierenden Gene in den zu untersuchenden Zelllinien zu den einzelnen Zeitpunkten musste zunächst RNA isoliert werden. Da die RNA sehr empfindlich gegenüber abbauenden RNasen ist, mussten bei der Isolation von RNA besondere Vorsichtsmaßnahmen getroffen werden. Vor Arbeitsbeginn wurden daher der Arbeitsplatz sowie die benutzten Materialien wie Pipetten, Reagenzhalter, Spitzenbehälter und Handschuhe mit einer RNase-inaktivierenden Lösung gereinigt. Die bei $-80^{\circ} \mathrm{C}$ gelagerten Proben wurden zur Isolation langsam auf Eis aufgetaut. Die Isolierung erfolgte mittels des RNesay Plus mini Kit unter Benutzung des QiaCUBE-Roboters, wodurch auch genomische DNA entfernt wurde. Es wurde nach Herstelleranleitung verfahren. Am Ende des Isolierprotokolls erhält man gebrauchsfertige RNA, welche in RNase-freiem Wasser gelöst ist. Die Proben wurden dem Roboter entnommen und sofort auf Eis gelagert. Die Konzentration der isolierten RNA wurde anschließend spektrophotometrisch bei $260 \mathrm{~nm}$ mit einem Biophotometer bestimmt. Dabei wurde eine für den MikroliterBereich konzipierte Messzelle benutzt. Es wurden die Absorptionsmaxima bei $260 \mathrm{~nm}$ (Nukleinsäuren) und $280 \mathrm{~nm}$ (Proteine) gemessen. Der Quotient 
$260 \mathrm{~nm} / 280 \mathrm{~nm}$ erlaubt eine Aussage über die Verunreinigung der Proben mit Proteinen und sollte zwischen 1,8 und 2,2 liegen. Die quantifizierten Proben wurden während der gesamten Messung auf Eis gelagert und dann bei $-80^{\circ} \mathrm{C}$ eingefroren.

\subsubsection{Synthese von komplementärer DNA (cDNA)}

Um die Expression spezifischer Sequenzabschnitte mittels DNA-basierter quantitativer Real-Time-PCR messen zu können, musste zuvor RNA in DNA umgeschrieben werden. Diese DNA wird daher als komplementäre DNA (cDNA) bezeichnet. Dies erfolgte mit Hilfe einer Reversen Transkriptase. Es wurde hierzu $1 \mu \mathrm{g}$ der isolierten RNA eingesetzt, welche jeweils mit $2 \mathrm{ng}$ eines Hexa-NukleotidPrimergemisches jedweder Kombination (dN6) versetzt und mit RNase-freiem Wasser zu 18,5 $\mu \mathrm{l}$ ergänzt wurden. Diese so hergestellten Proben wurden nun zur Denaturierung der RNA für $10 \mathrm{~min}$ bei $72^{\circ} \mathrm{C}$ im Thermocycler inkubiert und anschließend sofort auf Eis geführt. Nach dem Abkühlung der Proben wurden 11,75 $\mu l$ eines hergestellten Mix (siehe 2.2.9) den Proben hinzugefügt. Die Proben wurden anschließend bei $42^{\circ} \mathrm{C}$ für $60 \mathrm{~min}$ im Thermocycler inkubiert und dann die Reverse Transkriptase anschließend bei $70^{\circ} \mathrm{C}$ für 15 min Hitze-inaktiviert. Nach der Inkubation wurden die Proben mit TE-Puffer auf eine Konzentration von $2 \mathrm{ng} / \mathrm{ml}$, bezogen auf die initial eingesetzte RNA-Menge, verdünnt und auf 96-Well-Platten ausgebracht.

Tabelle 2.2.9 Zusammensetzung des Mastermixes zur cDNA-Synthese

\begin{tabular}{|l|l|}
\hline Komponente: & Für 1 Probe $(\mu \mathrm{l}):$ \\
\hline $5 x R T-P u f f e r$ & 6,0 \\
\hline 0,1 M Dithiotriol & 2,5 \\
\hline Wasser, RNAse-frei & 1,5 \\
\hline 10 mM Nukleosidtriphosphate & 1,0 \\
\hline RNAse Inhibitor & 0,5 \\
\hline SuperScript-II-Reverse Transkriptase & 0,25 \\
\hline Summe & 11,75 \\
\hline
\end{tabular}




\subsubsection{Quantitative Real-Time-PCR (qRT-PCR)}

Das Funktionsprinzip der quantitativen Real-Time-PCR (qRT-PCR) beruht auf dem Prinzip einer Polymerase-Ketten-Reaktion. Bei der qRT-PCR wird die Quantifizierung der Produkte allerdings in der Zeit der Vervielfältigung gemessen. Diese Quantifizierung geschieht durch die Einlagerung eines Fluoreszenzfarbstoffes in den Elongationszyklen. Während der Amplifikationsphase der qRT-PCR ist die Signalstärke einer fluoreszierenden Verbindung proportional zur Menge der entstandenen Produkte. Innerhalb der Versuchsreihe wurde für die qRT-PCR ein Mastermix mit dem fluoreszierenden Farbstoff SYBR-Green verwendet. In diesem Bereich wird für alle zu vergleichenden Proben eine bestimmte Signalstärke der Fluoreszenz definiert und für jede Probe der Ct-Wert (Cycle threshold) als Zahl der PCR-Zyklen bestimmt, bei dem die vorgegebene Signalstärke erreicht wird. Der CtWert erlaubt auch eine quantitative Aussage über die in einer Probe ursprünglich vorhandene Kopienzahl der gemessenen Gene. Je höher dieser Ct-Wert ist, desto mehr Zyklen waren erforderlich, um die definierte Signalstärke zu erreichen, d.h. desto weniger RNA-Transkripte des betreffenden Gens waren ursprünglich in der Probe enthalten.

Spezifische Primerpaare für die untersuchten Gene wurden von der Firma MWG hergestellt. Einige wenige dieser Primarpaare lieferten keine zufriedenstellenden Ergebnisse, daher wurden in diesen wenigen Fällen etablierte Primarpaare der Firma Qiagen benutzt. Die Qualität der entstandenen Produkte wurde über eine Schmelzkurvenanalyse direkt im Anschluss an die qRT-PCR ermittelt. Dabei sollte ein Fluoreszenzsignal in Form eines singulären Peak zu sehen sein (als Beispiel siehe Abbildung 2.2.10). Dieser singuläre Peak gilt dann als Ausdruck eines spezifischen Amplifikationsproduktes. Die Effizienz der PCR wurde über eine Eichgerade aus einem seriell verdünnten Pool verschiedener Gewebearten nachgewiesen. Gefordert war hier eine Effizienz von mindestens 90\%. Grundsätzlich wurde die Expressionsmessung eines Gens für alle zu vergleichenden Proben auf einer 384-Well Platte durchgeführt. Alle zu untersuchenden Gene wurden auf die gleiche Weise gemessen. Dabei wurde zunächst ein Mix entsprechend der Anzahl der jeweils als Duplikate zu bestimmenden Proben hergestellt. Dazu wurden pro Probe zu $5 \mu \mathrm{l}$ des oben genannten qRT-PCR-Mastermixes je $200 \mathrm{nM}$ eines spezifischen Vorwärts- und Rückwärts-Primers gegeben und mit Wasser auf $7 \mu \mathrm{l}$ 
ergänzt, welche dann auf einer 384-Well-Platte vorgelegt wurden. Danach wurden $3 \mu \mathrm{l}$ der zu messenden cDNA-Proben hinzugefügt. Die 384-Well-Platte wurde nach diesem Schritt mit einer für Fluoreszenzlicht durchlässigen Folie überzogen. Die Folie wurde mit einem Kantstück sorgfältig abgeschlossen. Die Platte wurde nach dem Verschließen für $30 \mathrm{~s}$ zentrifugiert und dem Messgerät TaqMan ${ }^{\circledR}$ zugeführt.

Die qRT-PCR startete mit der Aktivierung des durch Antikörper geblockten Enzyms Polymerase. Dies geschah bei $95^{\circ} \mathrm{C}$ für $2 \mathrm{~min}$. Daran schlossen sich - je nach Expressionsstärke des analysierten Gens - 45-55 Zyklen an, die jeweils aus Denaturierung $\left(15 \mathrm{~s}, 95^{\circ} \mathrm{C}\right)$, Primeranlagerung $\left(20 \mathrm{~s}, 60^{\circ} \mathrm{C}\right)$ und Kettenverlängerung $\left(40 \mathrm{~s}, 72^{\circ} \mathrm{C}\right)$ bestanden. Während der Phase der Kettenverlängerung erfolgte außerdem die Messung des Fluoreszenzsignals. Nach Ende der qRT-PCR wurde eine Schmelzkurve ermittelt. Die Auswertung der Daten erfolgte anhand der Software SDS 2.1. In dieser Arbeit wurde mit der qRT-PCR die Expression der Gene von Chemokinen und deren Rezeptoren aus der CC- bzw. CXC-Klasse vor und nach Bestrahlung gemessen.

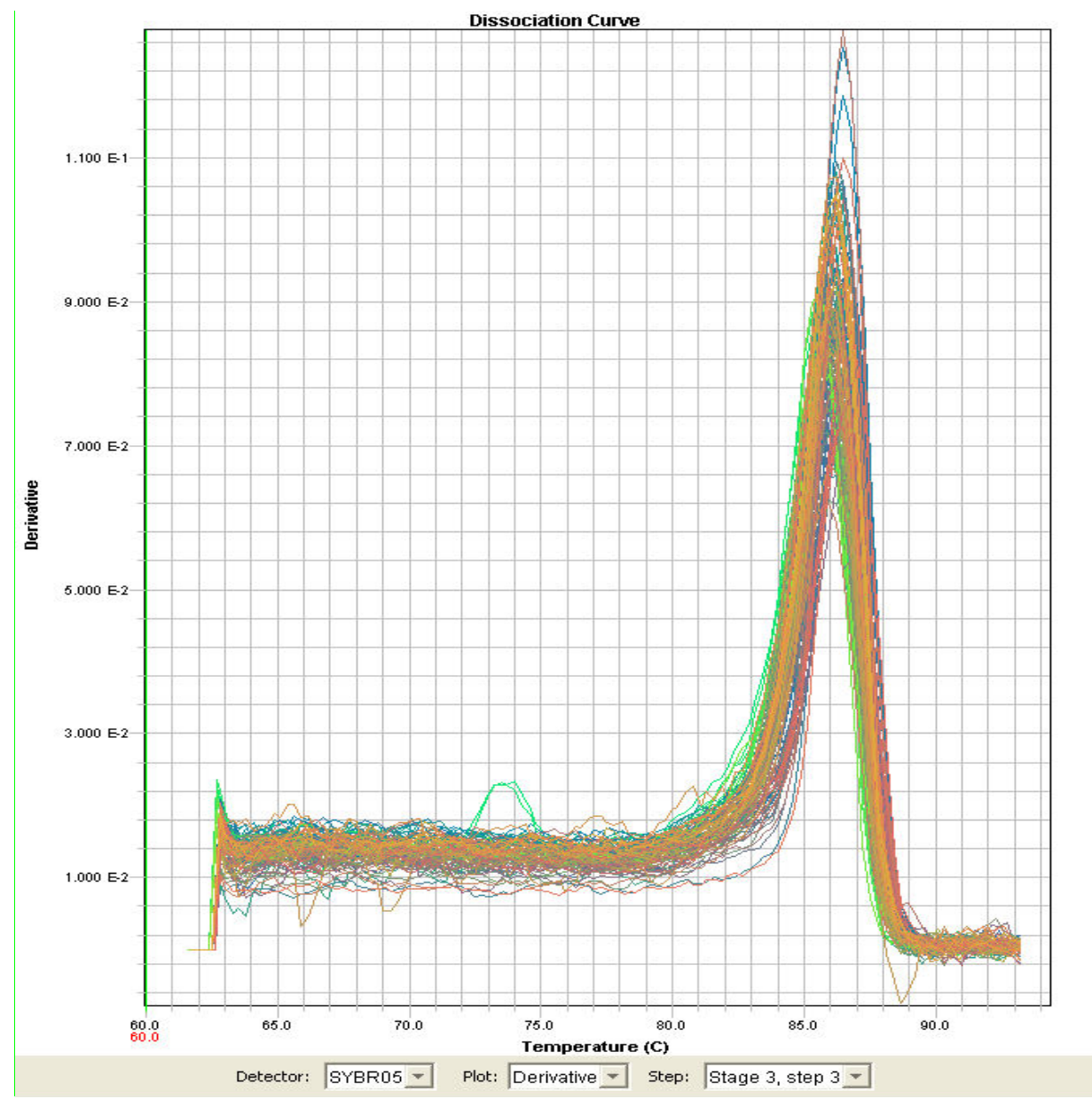

Abbildung 2.2.10 Dissoziationskurve des Chemokins CXCL12 


\subsubsection{Detektion der Chemokine}

Die Genexpression der in Tabelle 2.1.3 aufgeführten Chemokine und deren Rezeptoren wurde zunächst mit Hilfe eines Zellpools aus Lymphozyten, Leberzellkarzinom- und Kolorektalkarzinomzellen detektiert. Die Genexpression der untersuchten Chemokine bzw. deren Rezeptoren konnten in dem Pool der genannten Zellen signifikant nachgewiesen werden. Daher konnte mit den vorliegenden Expressionstranskripten der zu untersuchenden Chemokine und Chemokinrezeptoren gearbeitet werden. Die in den Tabellen 2.2.11.1 und 2.2.11.2 aufgeführten Werte zeigen die Expression aller Chemokine und ihrer Rezeptoren in dem aus Lymphozyten, Leberkarzinom- und Kolorektalkarzinomzellen bestehenden Zellpool. Die Tabelle 2.2.11.1 zeigt die Cycle-Threshold-Werte der einzelnen Chemokine in dem untersuchten Zellpool. Die untersuchten Chemokinrezeptoren sind in der Tabelle 2.2.11 aufgezeigt. Der Cycle-Threshold-Wert gibt eine bestimmte Mindestmenge an entstandenen Produkten zu den dafür erforderlichen PCR-Zyklen als Mindestmaß an. Dieser Wert erlaubt also eine quantitative Aussage über die in einer Probe ursprünglich vorhandene Kopienzahl der gemessenen Gene. Hervorzuheben ist, dass die ermittelten Cycle-Threshold-Werte deutlich unter dem Wert von 35 liegen und die Expression der Chemokine und Chemokinrezeptoren in dem Zellpool als signifikant detektierbar eingestuft werden konnte.

Tabelle 2.2.11.1 Transkriptexpression der Chemokine in dem Zellpool aus Lymphozyten, Leberzell- und Kolorectalzellen

\begin{tabular}{|l|c|}
\hline Chemokine & Cycle Threshold \\
\hline CCL2 & 20,327208 \\
\hline CCL3 & 26,082056 \\
\hline CCL5 & 26,422277 \\
\hline CCL20 & 18,064552 \\
\hline CXCL1 & 19,061092 \\
\hline CXCL2 & 19,887836 \\
\hline CXCL3 & 20,576551 \\
\hline
\end{tabular}




\begin{tabular}{|l|c|}
\hline CXCL9 & 29,66092 \\
\hline CXCL10 & 26,91338 \\
\hline CXCL11 & 25,991661 \\
\hline CXCL12 & 30,03405 \\
\hline
\end{tabular}

Tabelle 2.2.11.2 Transkriptexpression der Chemokinrezeptoren in dem Zellpool aus Lymphozyten, Leberzell- und Kolorektalzellen

\begin{tabular}{|l|l|}
\hline Rezeptoren & Cycle Threshold \\
\hline CCR1 & 30,796896 \\
\hline CCR3 & 28,583965 \\
\hline CCR6 & 22,773434 \\
\hline CCR7 & 30,34114 \\
\hline CXCR1 & 29,851158 \\
\hline CXCR4 & 24,841522 \\
\hline
\end{tabular}

\subsubsection{Enzyme-Linked Immunosorbent Assay (ELISA)}

Der ELISA bezeichnet ein Antigen-Antikörper-Verfahren, das die quantitative und qualitative Bestimmung mit Hilfe einer enzymatischen Farbreaktion ermöglicht. Das Grundprinzip des ELISA beruht auf dem Nachweis durch Bindung eines spezifischen Antigens an einen Antikörper. Die Farbreaktion wurde photometrisch erfasst und ausgewertet. Der Nachweis der untersuchten Chemokine wurde mit den Quantikine $®$ Immunoassays von R\&D Systems durchgeführt. Der Nachweis erfolgte durch die Zugabe des zu testenden Zellkulturüberstands auf eine Mikrotiterplatte. Die in dem Serum vorhandenen Antigene lagerten sich an die Antikörper der Miktotiterplatte an. An die Antigene lagerte sich wiederum das enzymmarkierte Antiserum an. Die zu messende Farbreaktion wurde durch ein erneut hinzugegebenes Substrat hervorgerufen, indem das gebundene Enzym umgesetzt wurde. Zwischen den beschriebenen Reaktionsschritten wurde die Mikrotiterplatte gründlich gewaschen, um unspezifische Reaktionen auszuschließen. Die Extinktion wurde photometrisch 
bei einer Wellenlänge von $450 \mathrm{~nm}$ und $540 \mathrm{~nm}$ in einem Microplate Reader gemessen. Die Intensität der Farbreaktion ist dabei proportional zu der Konzentration des nachzuweisenden Antigens. Die Expression der Chemokine auf Proteinebene in Kopf-Hals-Karzinomzellen wurde exemplarisch aus den Überständen ausgewählter Zelllinien nachgewiesen. Alle benötigten Reagenzien wurden, wie in dem Quantikine Immunoassay Kit beschrieben, hergestellt. Hier wird nur der CCL12 (MCP-5) Immunoassay stellvertretend für die untersuchten Chemokine beschrieben. Zunächst wurde zu der Kontrolle $1 \mathrm{ml}$ destilliertes Wasser hinzugefügt, dem $25 \mathrm{ml}$ Waschpufferkonzentrat wurden $600 \mathrm{ml}$ destilliertes Wasser zugegeben. Die Farbreagenzien A und B werden 15 Minuten vor Gebrauch zu gleichen Teilen vermischt. $100 \mu \mathrm{l}$ dieser Reagenz wurden später pro Well benötigt. Dem Standard wurden $5 \mathrm{ml}$ der Calibrator Diluent RD5-3 hinzugefügt, sodass eine Konzentration von 1000 pg/ml entstand. Im Folgenden wurden $200 \mu$ l Calibrator Diluent RD5-3 in die sechs vorbereiteten Cups vorgelegt. Durch Pipettieren des 1000 pg/ml Standards wurde eine Verdünnungsreihe mit 500 pg/ml, 250 pg/ml, 125 pg/ml, 62,5pg/ml, 31,2 $\mathrm{pg} / \mathrm{ml}$ und 15,6 pg/ml des Standards erstellt. Anschließend wurden $50 \mu \mathrm{l}$ des Assay Diluents und danach $50 \mu \mathrm{l}$ des zu untersuchenden Zellüberstands in jedes Well pipettiert. Die Reagenzien wurden durch leichtes Antippen der Platten gemischt. Die 96-Well-Platte wurde mit der mitgelieferten Folie verschlossen und bei Raumtemperatur für zwei Stunden inkubiert. Nach der Inkubationszeit wurde die Reagenz aus jedem Well aspiriert und jedes Well insgesamt fünfmal mit $400 \mu$ l Wash Buffer gewaschen. Dafür wurde der Wash Buffer in jedem Waschschritt abgenommen und zuletzt durch dekantieren vollständig entfernt. Im nächsten Schritt wurden $100 \mu \mathrm{l}$ des CCL 12 Conjugats zu jedem Well hinzugefügt und erneut für 2 Stunden bei Raumtemperatur inkubiert. Die beschriebenen Waschschritte wurden erneut wiederholt. Im Folgenden wurden $100 \mu$ der Substrat Solution in jedes Well gefüllt und für 30 Minuten erneut bei Raumtemperatur inkubiert. Nach der Inkubationszeit wurden $100 \mu$ Stop Solution hinzugefügt und durch leichtes antippen gemischt. Der Farbumschlag wurde nach 15 und 30 Minuten bei einer Wellenlänge von $450 \mathrm{~nm}$ und $540 \mathrm{~nm}$ photometrisch in einem Microplate Reader gemessen. Alle Werte wurden doppelt bestimmt. 


\section{Ergebnisse}

In dieser Arbeit wurde die Genexpression von 11 Chemokinen und 6 Chemokinrezeptoren der CC-Klasse bzw. CXC-Klasse in 15 Kopf-HalsKarzinomzelllinien analysiert. Zum Vergleich der Expression in Tumorzelllinien wurde die Expression ebenfalls in zwei Normalgewebszellinien getestet. Die Tumorzelllinien wurden aus Plattenepithelkarzinomen gewonnen. Eine Ausnahme stellt hier die Zelllinie XF354 dar, deren Zellen einer Lymphknotenmetastase eines oralen Plattenepithelkarzinoms gewonnen wurden.

\section{1 Überblick über die Chemokinexpression}

Im Anschluss an die ersten Ergebnisse der Expressionsanalyse aus dem Zellpool, bestehend aus Lymphozyten, Leberzellkarzinom- und Kolorektalzellkarzinomzellen (Tabelle 2.2.10 und 2.2.11), wurde die Chemokin- und Chemokinrezeptorexpression in ausgewählten Kopf-Hals-Karzinomzelllinien und Normalgewebszellinien nachgewiesen. In dieser ersten ausführlichen Analyse wurde folgende Expression von Chemokinen und Chemorezeptoren detektiert. Der Chemokinligand CCL2 wurde nur in den beiden Normalgewebszelllinien und einigen Tumorzelllinien exprimiert (Abb. 3.1.1), während der Chemokinligand CCL5, mit Ausnahme der Zelllinien HO1u1 und SAS, in allen untersuchten Zelllinien exprimiert wurde (Abb. 3.1.3). Die Expression des Chemokindliganden CCL20 konnte in allen untersuchten Zellinien nachgewiesen werden (Abb. 3.1.4). Die Chemokine CXCL1, CXCL2, CXCL3, CXCL10 und CXCL11 wurden in der großen Mehrheit oder in allen Zelllinien exprimiert, wohingegen die Expression von CXCL9 auf die Fibroblastenzelllinie DF19 und die Tumorzelllinien BW225, CAL27, CAL33 und XF354 beschränkt blieb (Abb. 3.1.9 - Abb. 3.1.12). Der Chemokinligand CXCL12 wurde in den Zelllinien DF19, GR145 I, GR145 II, HK 147 und den BW225 exprimiert (Abb. 3.1.15). Keine der analysierten Zelllinien exprimierte die Chemokine CCL4, CCL19 oder die Rezeptoren CCR2, CCR5, CCXR2 und CCXR3. Der Rezeptor CCR6 wurde in den 
Tumorzelllinien BHY, GR145 II, HK 147, KOSC2 und SKN 3 exprimiert (Abb. 3.1.7). Der Rezeptor CXCR1 wurde nur in den Zelllinien CAL33, HaCat, HSC4 und der Metastastenzelllinie XF354 exprimiert (Abb. 3.1.16). Die Expression des Chemokinrezeptors CXCR4 konnte hingegen in den Zelllinien BW225, FaDuDD, HO1u1 und ZMK1 nachgewiesen werden (Abb. 3.1.17). Der Rezeptor CCR7 wurde von den zwei Normalgewebszelllinien DF19 und HaCat sowie einigen Tumorzelllinien exprimiert (Abb. 3.1.8). Der Rezeptor CCR3 wurde nur von der Tumorzellinie KOSC2 exprimiert (Abb. 3.1.6). Die Genexpression des Chemokinrezeptors CCR1 (Abb. 3.1.5) sowie des Chemokinligands CCL3 konnte nur in der Zelllinie BHY nachgewiesen werden (Abb. 3.1.2). Die Bestrahlung mit 2 Gy verursachte in allen untersuchten Zelllinien eine veränderte Expression der Chemokine und Chemokinrezeptoren. Die relative Expression, bezogen auf die Housekeepinggene, war bei den untersuchten Rezeptoren insgesamt gering ausgeprägt und nach Bestrahlung mit 2 Gy vorherrschend herunter reguliert. Die folgenden Abbildungen 3.1.1 bis 3.1.17 stellen jeweils die Genexpressionen der untersuchten Chemokine und Chemokinrezeptoren dar. Auf der Ordinate sind jeweils die verschiedenen Zelllinien zum Zeitpunkt Oh ohne Bestrahlung und $6 \mathrm{~h}$ nach Bestrahlung mit 2 Gy aufgeführt. Die Abszisse stellt die relative Genexpression des Chemokinligandens bzw. Chemokinrezeptors bezogen auf die Housekeepinggene dar. Die Zellen der verschiedenen Zelllinien wurden $6 \mathrm{~h}$ nach der Bestrahlung mit 2 Gy oder Scheinbestrahlung isoliert, die RNA gewonnen und die Genexpression mittels RealTime-PCR gemessen. Die ermittelten Werte sind doppelt bestimmt worden. Die Genexpression der untersuchten Chemokine und deren Rezeptoren wurden in Relation zu der Expression der Housekeepinggene gesetzt und in den Diagrammen aufgetragen. So kann die Steigerung oder Minderung der Chemokin- und Chemokinrezeptorexpression sowohl in Relation zu den Housekeepinggenen als auch untereinander verglichen werden. Eine Expression von 1 bedeutet in diesem Zusammenhang eine unveränderte Expression in Bezug auf die Housekeepinggene. Eine zweifach gesteigerte oder verminderte Genexpression in den untersuchten Zelllinien wurde als signifikant angesehen. 


\subsubsection{Genexpression des Chemokinliganden CCL2}

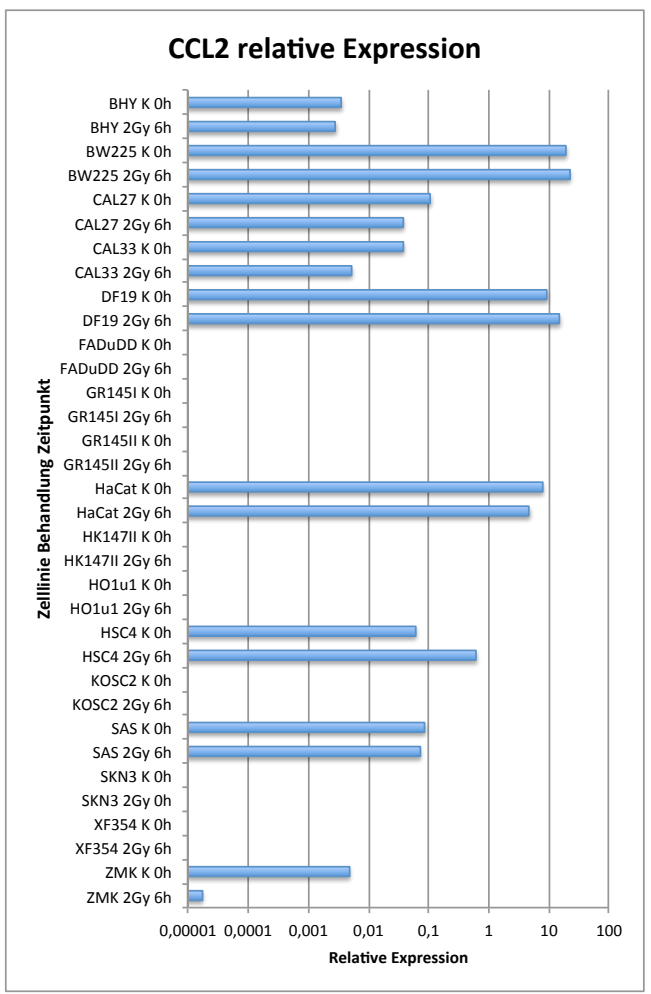

Abbildung 3.1.1: Relative Genexpression CCL2

Die Abbildung 3.1.1 zeigt die relative Genexpression des Chemokinliganden CCL2 der untersuchten Zelllinien. Die Expression des Chemokinliganden CCL2 ist auf bestimmte Zelllinien beschränkt. Die beiden Normalgewebszelllinien DF 19 und HaCat, sowie die Tumorzelllinie BW 225 exprimieren den Chemokinliganden CCL2 in Relation zu den Housekeepinggenen verstärkt. Die relative Chemokinexpression ist in den Zellen BHY, CAL27, CAL33, HSC4 und ZMK1 geringer. Nach Bestrahlung der Zellen mit 2 Gy ist die Expression bei den Zelllinien unterschiedlich verändert. Hervorzuheben ist hier die signifikante Expressionssteigerung nach der Bestrahlung der Zellen der Zelllinie HSC 4 und die signifikante Expressionsminderung bei den Tumorzelllinien CAL33 und ZMK. 


\subsubsection{Genexpression des Chemokinliganden CCL3}

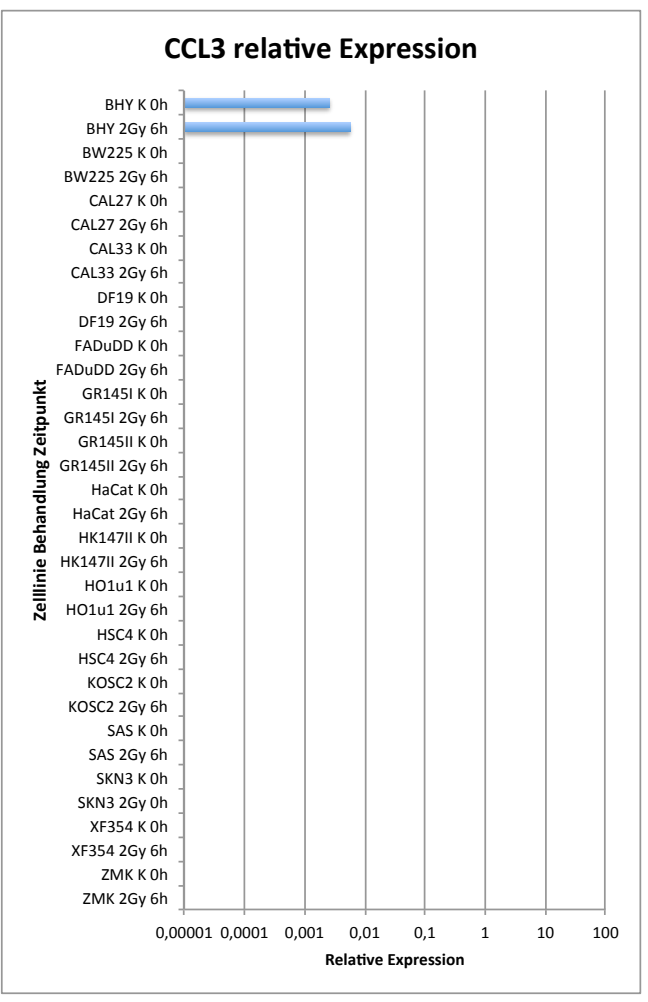

Abbildung 3.1.2: Relative Genexpression CCL3

Der Chemokinligand CCL3 wird allein von der Tumorzelllinie BHY und in Relation zu den Housekeepinggenen insgesamt nur schwach exprimiert. Zum Zeitpunkt 6 h nach der Bestrahlung der Zellen mit 2 Gy zeigt sich eine signifikante Expressionssteigerung des Chemokins CCL3 in der Tumorzelllinie. 


\subsubsection{Genexpression des Chemokinliganden CCL5}

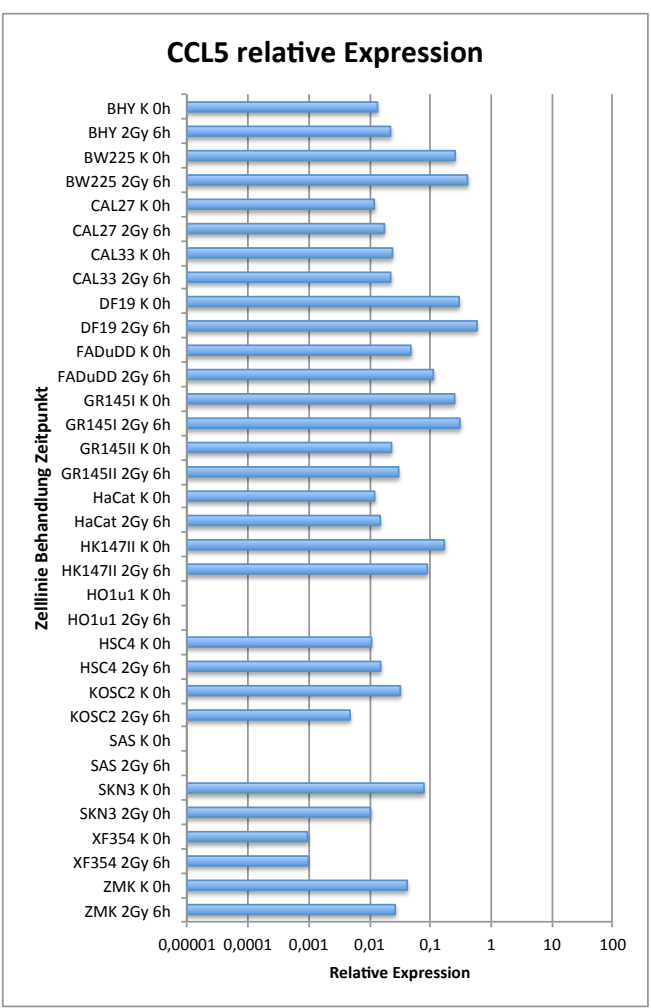

Abbildung 3.1.3: Relative Genexpression CCL5

Die Expression des Chemokins CCL5 ist bei allen Zelllinien, bezogen auf die Housekeepinggene, geringer. Nach Bestrahlung der Zellen mit 2 Gy zeigt sich bei den meisten Zellinien eine Expressionssteigerung. Eine Minderung der Genexpression des Chemokinligandens CCL5 zeigten die Zelllinien CAL33, HK 147, ZMK1, KOSC2, und SKN3. Die Genexpression des CCL5 Chemokins ist nur für die beiden Zelllinien KOSC2 und SKN3 signifikant gemindert. Die Expression des CCL5 Chemokins ist bei den zwei Tumorzelllinien HO1u1 und SAS nicht nachzuweisen. 


\subsubsection{Genexpression des Chemokinliganden CCL20}

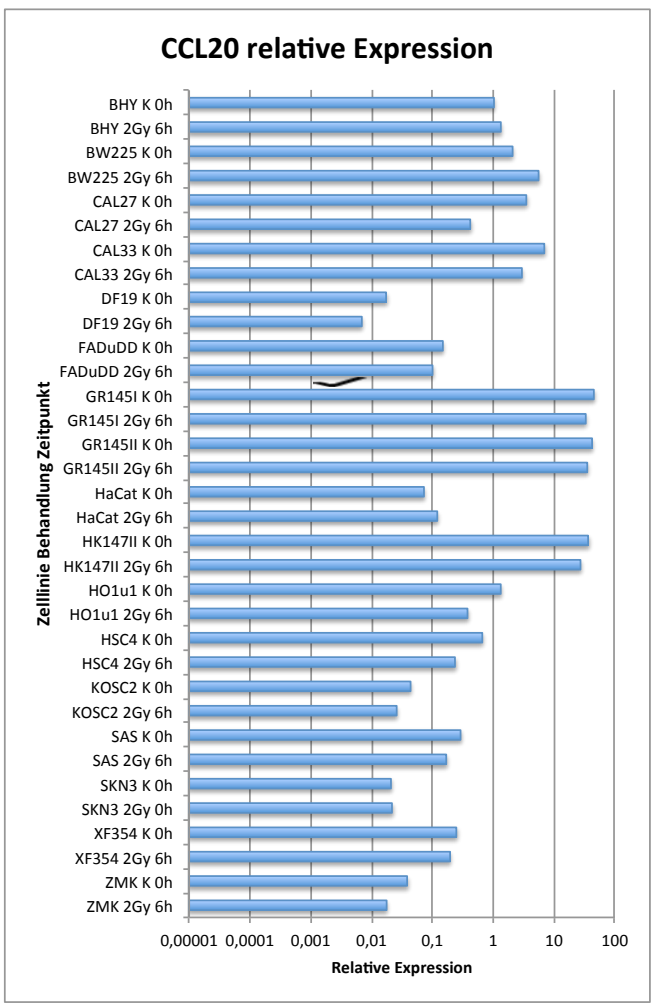

Abbildung 3.1.4: Relative Genexpression CCL20

Die Abbildung 3.1.4 zeigt die Genexpression des CCL20 Chemokins in den untersuchten Zelllinien. Alle untersuchten Zelllinien exprimieren den Chemokinliganden CCL20, wobei die Mehrzahl der Zelllinien eine geringere Genexpression des Chemokins in Relation zu den Housekeepinggenen zeigt. Die Zelllinen GR145 I, GR145 II und HK 147 hingegen exprimieren den Chemokinliganden CCL20 in Relation vermehrt. Nach Bestrahlung der Zellen mit 2 Gy zeigt sich eine Expressionssteigerung bei den Zelllinien BHY, BW225 und HaCat, die für BW225 signifikant ist. Bei den übrigen untersuchten Zelllinien lässt sich eine Minderung der Genexpression nach Bestrahlung der Zellen mit 2 Gy feststellen. Die Zellinien CAL27, CAL33, DF19, Ho1u1, HSC4 und ZMK1 zeigen eine signifikante Expressionsminderung nach Bestrahlung der Zellen mit $2 \mathrm{~Gy}$. 


\subsubsection{Genexpression des Chemokinrezeptors CCR1}

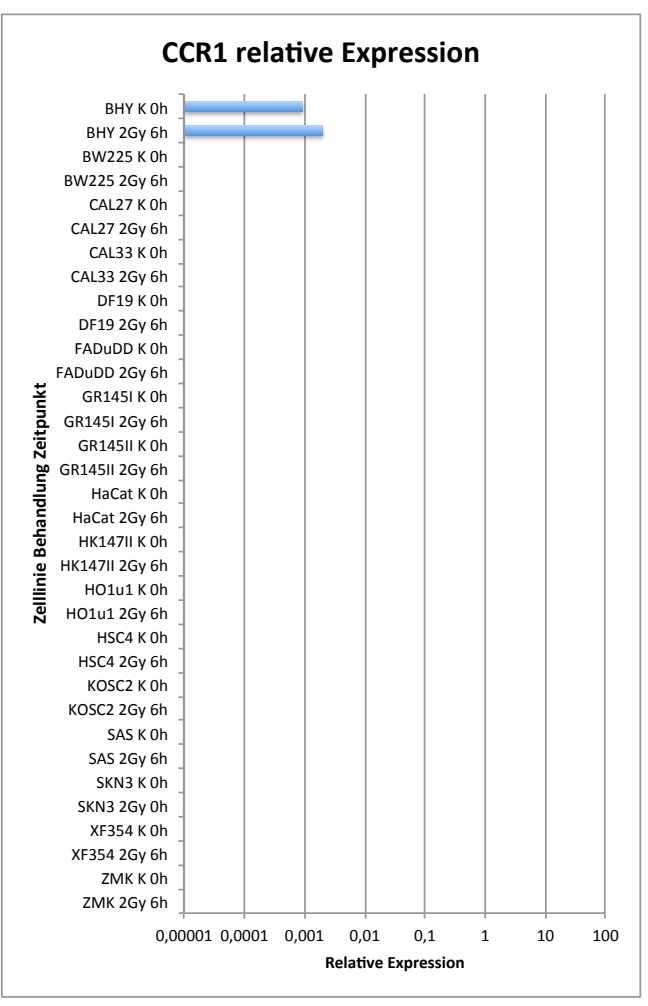

\section{Abbildung 3.1.5: Relative Genexpression CCR1}

Die Abbildung 3.1.5 zeigt die relative Genexpression des Chemokinrezeptors CCR1 in den untersuchten Zelllinien. Der Chemokinrezeptor CCR1 wird nur von der Tumorzelllinie BHY und in Relation zu den Housekeepinggenen nur schwach exprimiert. Es zeigt sich eine deutliche Expressionssteigerung $6 \mathrm{~h}$ nach der Bestrahlung der Zellen mit 2 Gy. 


\subsubsection{Genexpression des Chemokinrezeptors CCR3}

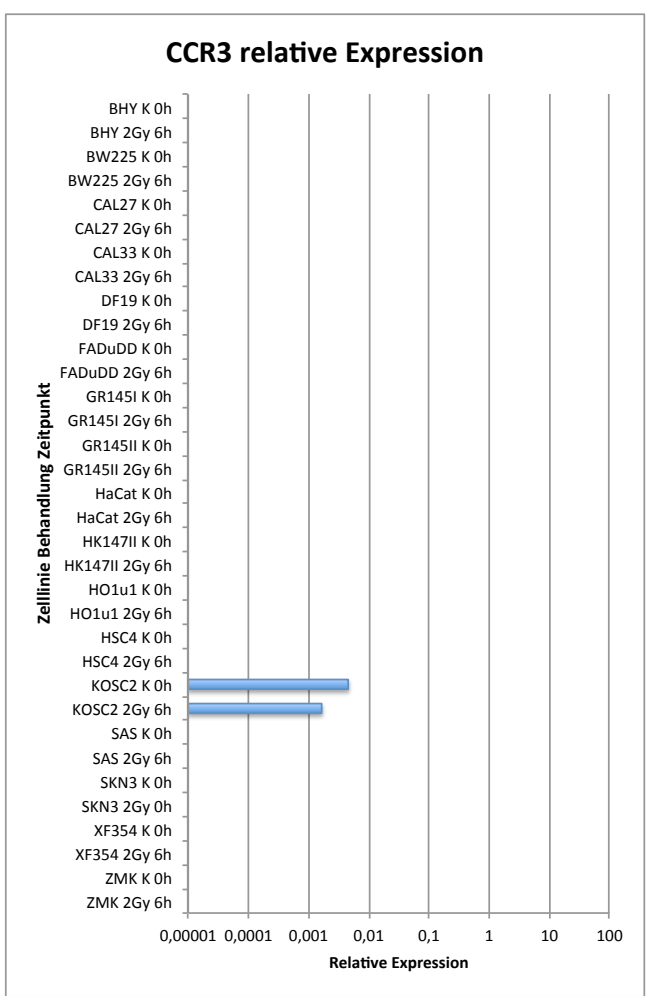

\section{Abbildung 3.1.6: Relative Genexpression CCR3}

Die Abbildung 3.1.6 zeigt die relative Genexpression des Chemokinrezeptors CCR3 in den untersuchten Zelllinien. Der Chemokinrezeptor CCR3 wird alleinig von der Tumorzelllinie KOSC2 und in Relation zu den Housekeepinggenen schwach exprimiert. Zu dem Zeitpunkt $6 \mathrm{~h}$ nach Bestrahlung der Zellen wird die Expression des Chemokinrezeptors CCR3 in der Tumorzellinie signifikant gemindert. 


\subsubsection{Genexpression des Chemokinrezeptors CCR6}

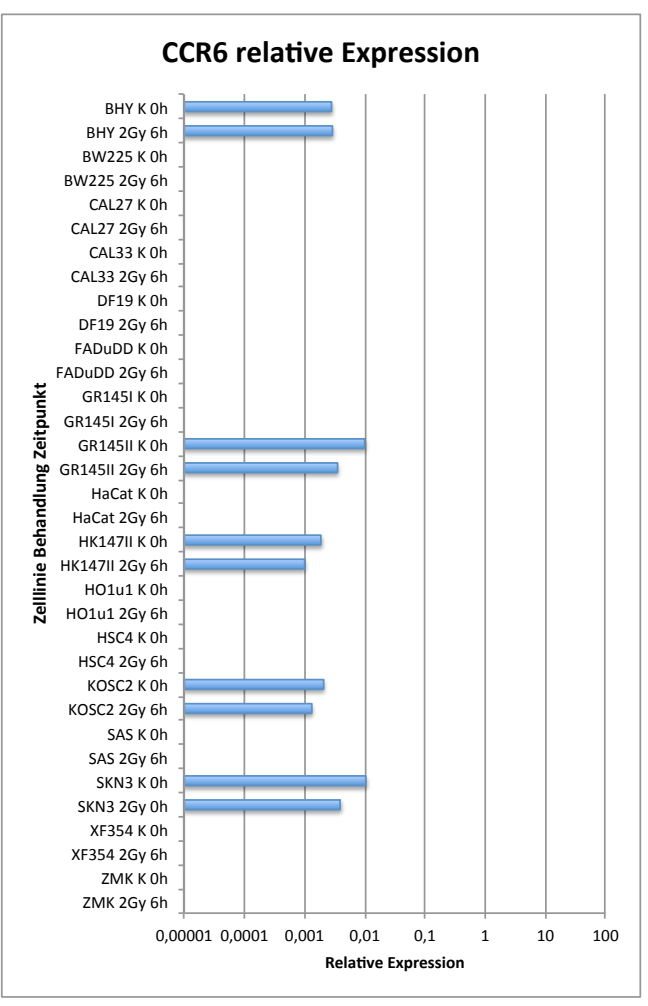

\section{Abbildung 3.1.7: Relative Genexpression CCR6}

Die Abbildung 3.1.7 zeigt die relative Genexpression des Chemokinrezeptors CCR6 der untersuchten Zelllinien. Die relative Expression des Chemokinrezeptors CCR6 ist in den untersuchten Zelllinien insgesamt schwach ausgeprägt. Die Bestrahlung der Zellen mit 2 Gy zeigt eine Herunterregulierung der Expression des Rezeptors in allen exprimierenden Zelllinien, die für GR145 II und SKN3 signifikant sind. Der CCRezeptor 6 ist die Bindungsstelle für den Liganden CCL20. Der Chemokinligand 20 wird allerdings von allen untersuchten Zelllinien exprimiert. Die Expression des Chemokinrezeptors 6 und seines Liganden zeigt in den untersuchten Zellinien vergleichbare Ergebnisse, nämlich eine vorherrschende Herunterregulierung der Expression in bestrahlten Zellen. 


\subsubsection{Genexpression des Chemokinrezeptors CCR7}

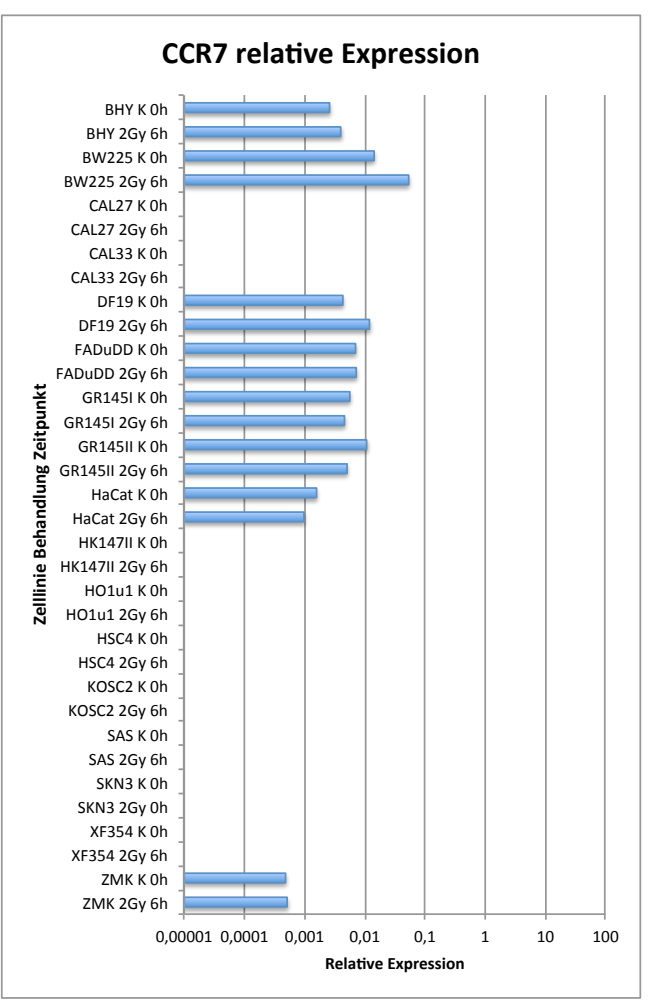

\section{Abbildung 3.1.8: Relative Genexpression CCR7}

Die Abbildung 3.1.8 zeigt die relative Genexpression des Chemokinrezeptors CCR7 der untersuchten Zelllinien. Der vielbeschriebene CC-Rezeptor 7 wird von einigen Tumorzelllinien wie BHY, BW225 oder FaDuDD nach Bestrahlung der Zellen mit 2 Gy gesteigert exprimiert. Die Zelllinien BW225 und DF19 zeigen eine signifikante Steigerung der Expression nach Bestrahlung der Zellen mit 2 Gy. Die Expression des Chemokinrezeptors ist nach Bestrahlung der Zellen bei der Tumorzellinie GR145 II signifikant vermindert. 


\subsubsection{Genexpression des Chemokinliganden CXCL1}

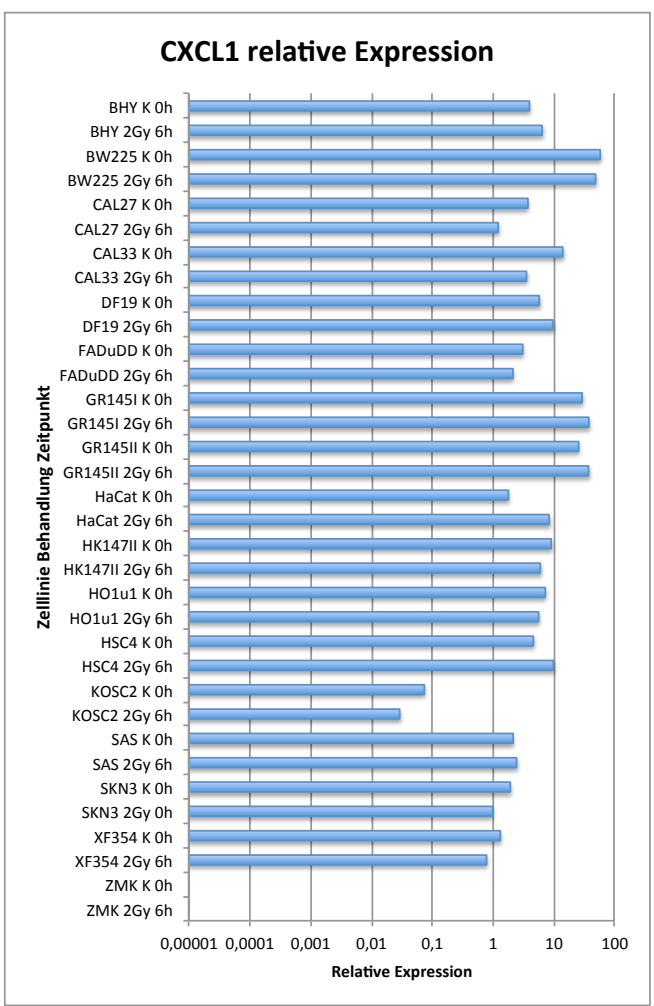

\section{Abbildung 3.1.9: Relative Genexpression CXCL1}

Die Abbildung 3.1.9 zeigt die relative Genexpression des Chemokins CXCL1 in untersuchten Zelllinien. In Relation zu den Housekeepinggenen ist die Expression des Chemokinligandens insgesamt vermehrt. Die Expression nach Bestrahlung der Zellen mit 2 Gy, im Vergleich zu der unbestrahlten Kontrolle, ist in den Zelllinien CAL27, CAL33 und KOSC2 allerdings signifikant reduziert. Die Zelllinien HaCat und HSC4 zeigen eine signifikant gesteigerte Expression nach Bestrahlung der Zellen mit 2 Gy. 


\subsubsection{Genexpression des Chemokinliganden CXCL2}

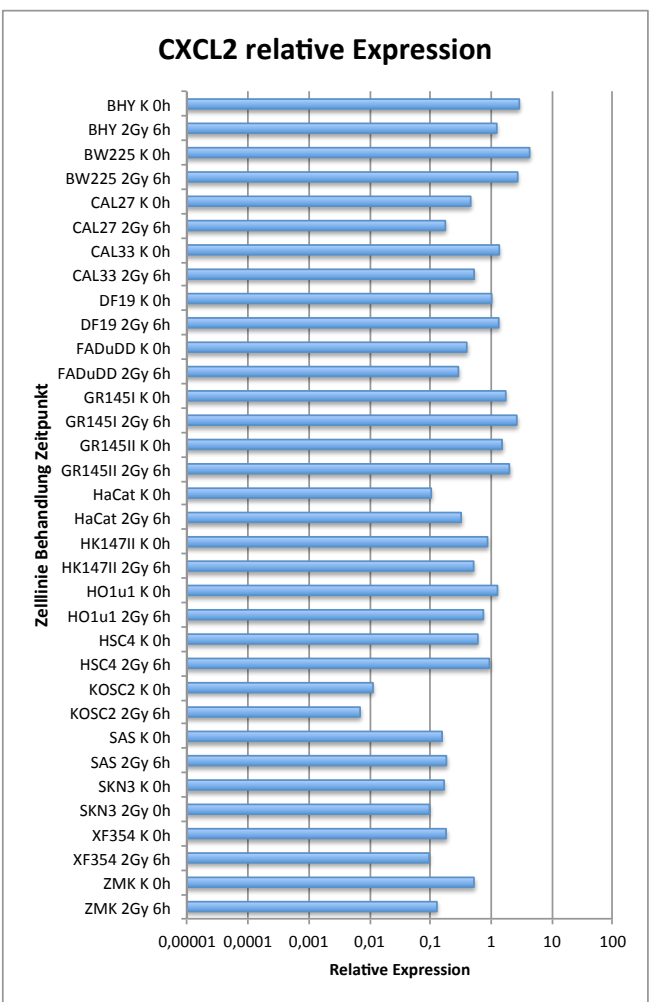

\section{Abbildung 3.1.10: Relative Genexpression CXCL2}

In der Abbildung 3.1.10 ist die relative Genexpression des CXCL2-Chemokins der untersuchten Zelllinien aufgezeigt. Der Chemokinligand wird von allen Zelllinien exprimiert. In Relation zu den Housekeepinggenen ist die Genexpression in den Zelllinien BHY, BW225, GR145 I oder GR145 II vermehrt. Eine verminderte Expression ist in den Zelllinien HaCat, XF345, SAS und KOSC2 zu beobachten. Nach Bestrahlung der Zellen mit 2 Gy wird die Expression in den Zelllinien BHY, CAL27, CAL33 und ZMK1 signifikant herunter reguliert. Von der Zelllinie HaCat wird das Chemokin CXCL2 nach Bestrahlung der Zellen signifikant verstärkt exprimiert. 


\subsubsection{Genexpression des Chemokinliganden CXCL3}

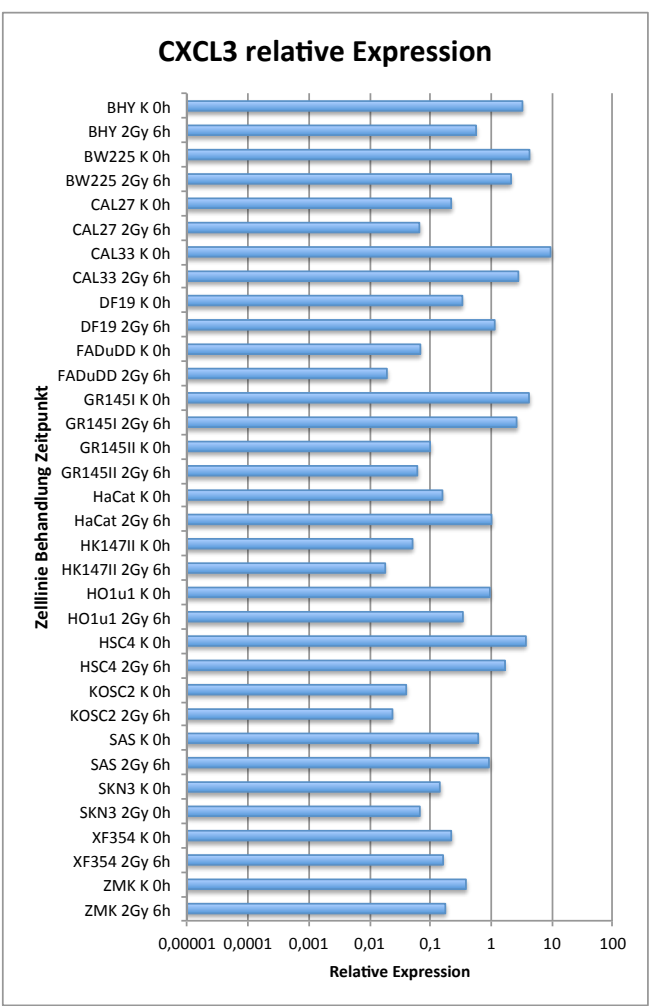

\section{Abbildung 3.1.11: Relative Genexpression CXCL3}

Die Abbildung 3.1.11 zeigt die relative Genexpression des CXCL3-Chemokins der untersuchten Zelllinien. Alle Zelllinien exprimieren den Chemokinliganden und zeigen nach Bestrahlung mit 2 Gy eine breite Varianz der Expressionsänderungen. Die relative Expression des Chemokins CXCL3 ist in den Zelllinien BHY, BW225, GR145 I oder GR145 II herauf reguliert. Die Zelllinien BHY, BW225, CAL27, CAL33, FaDuDD, HK 147, HO1u1 HSC4, SKN3 und ZMK1 zeigen eine signifikante Expressionsminderung des Chemokinliganden CXCL3 nach Bestrahlung der Zellen mit 2 Gy. Von den Normalgewebszelllinien DF19 und HaCat wird das Chemokin CXCL3 nach Bestrahlung der Zellen signifikant verstärkt exprimiert.

Die Chemokine CXCL1, CXCL2 und CXCL3 werden von allen Zellinien in hohem Ausmaß exprimiert. Die einzige Ausnahme ist die fehlende Expression des CXCLiganden 1 in der ZMK1 Tumorzelllinie. Die Genexpression der drei Chemokine ist nach Bestrahlung mit 2 Gy in den untersuchten Zelllinien ähnlich, unterliegt aber Schwankungen. 


\subsubsection{Genexpression des Chemokinliganden CXCL9}

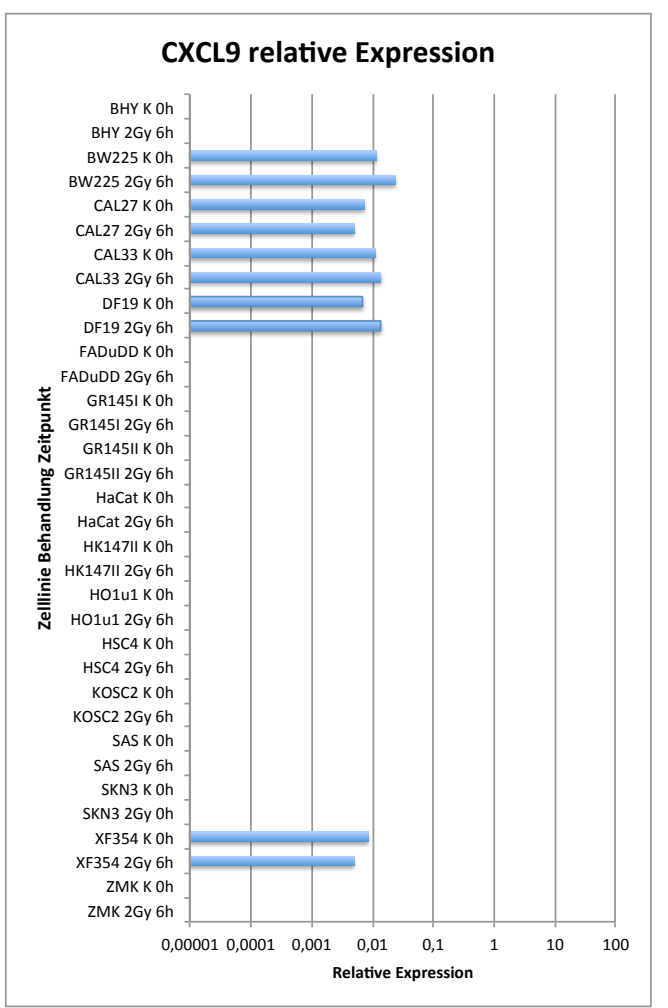

\section{Abbildung 3.1.12: Relative Genexpression CXCL9}

Die Genexpression des CXCL9 Chemokins in den untersuchten Zelllinien wird in der Abbildung 3.1.12 dargestellt. Der CXC-Ligand 9 bildet mit den Chemokinen CXCL10 und CXCL11 eine Gruppe homologer Chemokine und wird von dem Rezeptor CXCR3 gebunden. Die Expression des Chemokins CXCL9 ist in Relation zu den Housekeepinggenen schwach und beschränkt auf einzelne Zelllinien. Die Genexpression des Chemokins CXCL9 wird nach Bestrahlung der Zellen mit 2 Gy in den Zelllinien BW225, DF19 und CAL33 gesteigert. Die Zelllinien CAL27 und XF354 exprimieren das Chemokin CXCL9 nach Bestrahlung vermindert, wobei die Expressionsänderungen der Zelllinien nicht signifikant sind. 


\subsubsection{Genexpression des Chemokinliganden CXCL10}

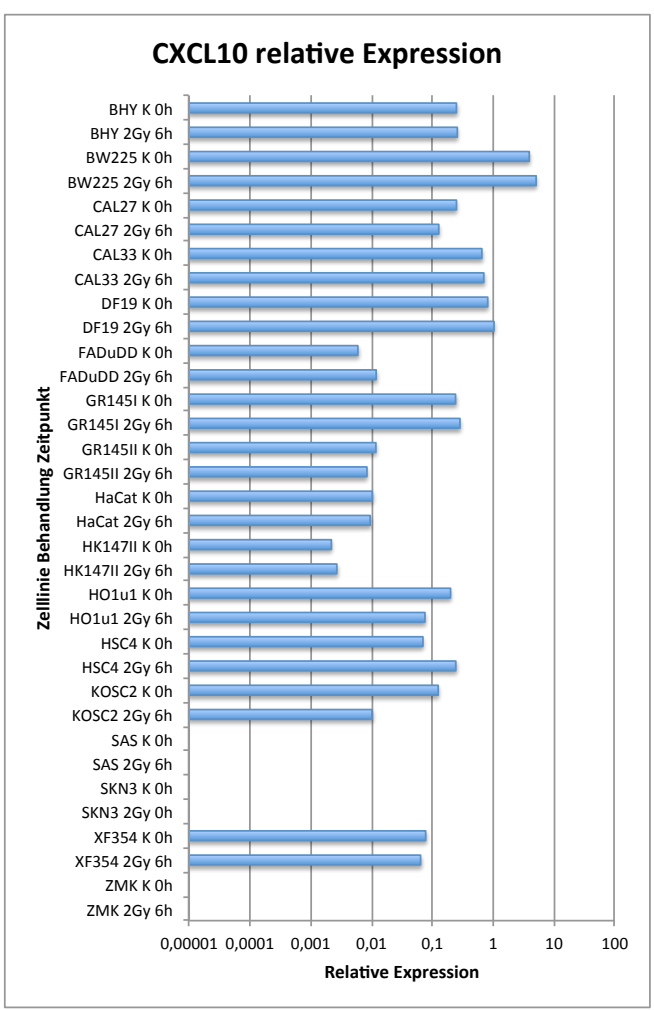

\section{Abbildung 3.1.13: Relative Genexpression CXCL10}

Die Abbildung 3.1.13 zeigt die relative Genexpression des CXCL10 Chemokins in den untersuchten Zelllinien. Der Chemokinligand CXCL10 bildet eine homologe Gruppe mit den Chemokinen CXCL9 und CXCL11 und bindet ebenso an den CXCRezeptor 3. Das CXCL10 Chemokin wird in mehr Zelllinien als das homologe Chemokin CXCL9 exprimiert. Die Expression ist bei dem Großteil der untersuchten Zelllinien in Relation $z u$ den Housekeepinggenen vermindert. Einzig die Tumorzelllinie BW225 exprimiert das Chemokin CXCL10 in Relation gesteigert. Die Expression zeigt weiterhin variable Expressionssänderungen nach Bestrahlung der Zellen mit 2 Gy. Bei den Zelllinien Ho1u1 und KOSC2 ist eine signifikant verminderte Expression, bei den Zelllinien FaDuDD und HSC4 eine signifikant gesteigerte Expression des Chemokinliganden CXCL10 zu beobachten. 


\subsubsection{Genexpression des Chemokinliganden CXCL11}

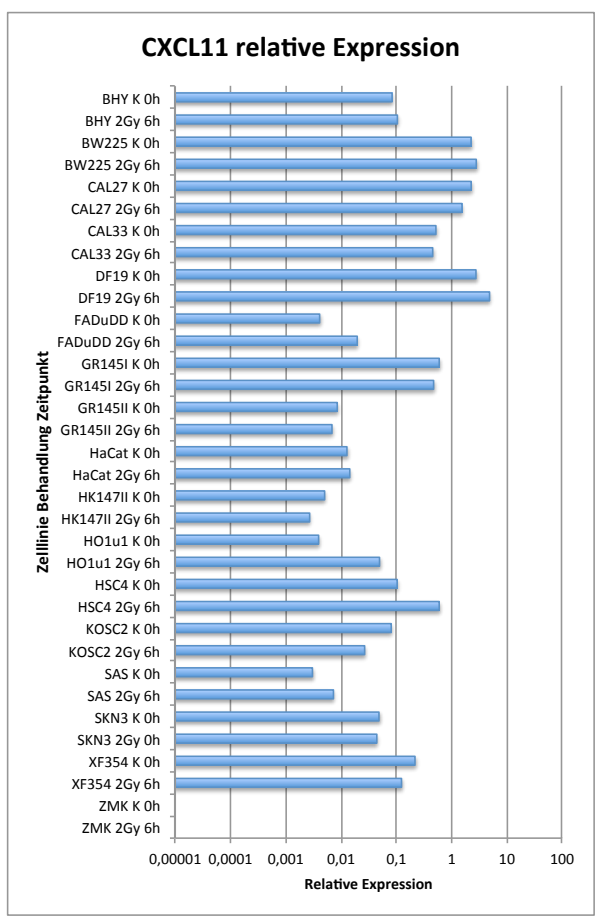

\section{Abbildung 3.1.14: Relative Genexpression CXCL11}

Die Abbildung 3.1.14 zeigt die relative Genexpression des CXCL11 Chemokins der untersuchten Zelllinien. Alle Zellinien mit Ausnahme der Tumorzelllinie ZMK1 exprimieren den Liganden und zeigen nach Bestrahlung mit 2 Gy eine breite Varianz in der Expression. In Relation zu den Housekeepinggenen zeigt die Genexpression eher eine schwache Expression. Die Genexpression ist in den Zelllinien FaDuDD, Ho1u1, HSC4 und SAS nach Bestrahlung mit 2 Gy signifikant gesteigert. Die Expression des Chemokins CXCL11 ist in der Zelllinie KOSC2 nach Bestrahlung der Zellen mit 2 Gy signifikant vermindert. 


\subsubsection{Genexpression des Chemokinliganden CXCL12}

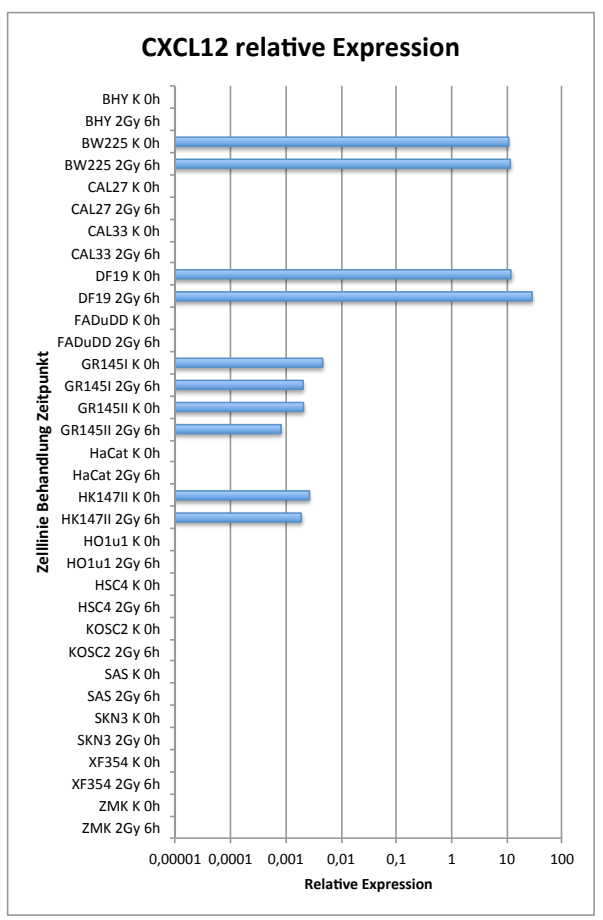

\section{Abbildung 3.1.15: Relative Genexpression CXCL12}

Die Abbildung 3.1.15 zeigt die relative Genexpression des CXCL12 Chemokins der untersuchten Zelllinien. Die Expression des Chemokins ist in den Zelllinien BW225 und DF19 in Relation zu den Housekeepinggenen erhöht. Die Expression wird nach Bestrahlung mit 2 Gy in der Normalgewebszelllinie DF19 signifikant gesteigert. Die beiden Zelllinien GR145 I und GR145 II zeigen eine signifikante Minderung der Expression des Chemokins CXCL12 nach Bestrahlung der Zellen mit 2 Gy. 


\subsubsection{Genexpression des Chemokinrezeptors CXCR1}

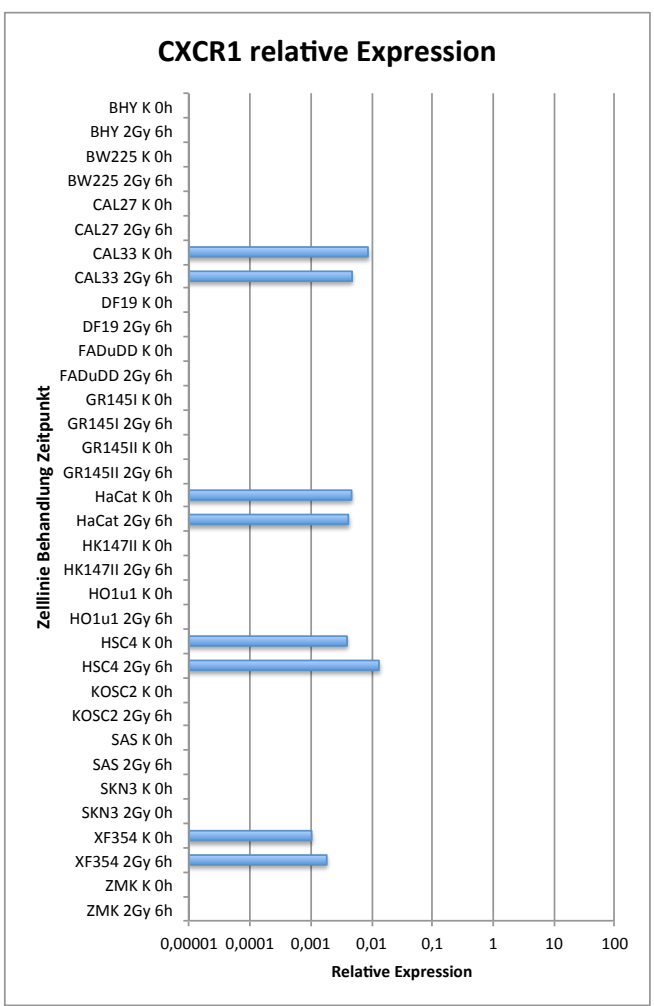

\section{Abbildung 3.1.16: Relative Genexpression CXCR1}

Die Abbildung 3.1.16 zeigt die relative Genexpression des Chemokinrezeptors CXCR1 der untersuchten Zelllinien. Die Expression des Chemokinrezeptors CXCR1 ist in Relation zu den Housekeepinggenen insgesamt nur schwach ausgeprägt. Die Tumorzelllinie CAL33 sowie die Normalgewebszelllinie HaCat zeigen eine Herunterregulierung der Expression nach der Bestrahlung. Die Zelllinien HSC4 und XF354 zeigen eine Steigerung der Expression 6 h nach Bestrahlung der Zellen mit 2 Gy, wobei nur die Expression der Zelllinie HSC4 signifikant gesteigert ist. Der CXCRezeptor 1 ist Bindungsstelle für die Chemokinliganden CXCL1, CXCL2 und CXCL3, die insgesamt von mehreren Zelllinien exprimiert werden. 


\subsubsection{Genexpression des Chemokinrezeptors CXCR4}

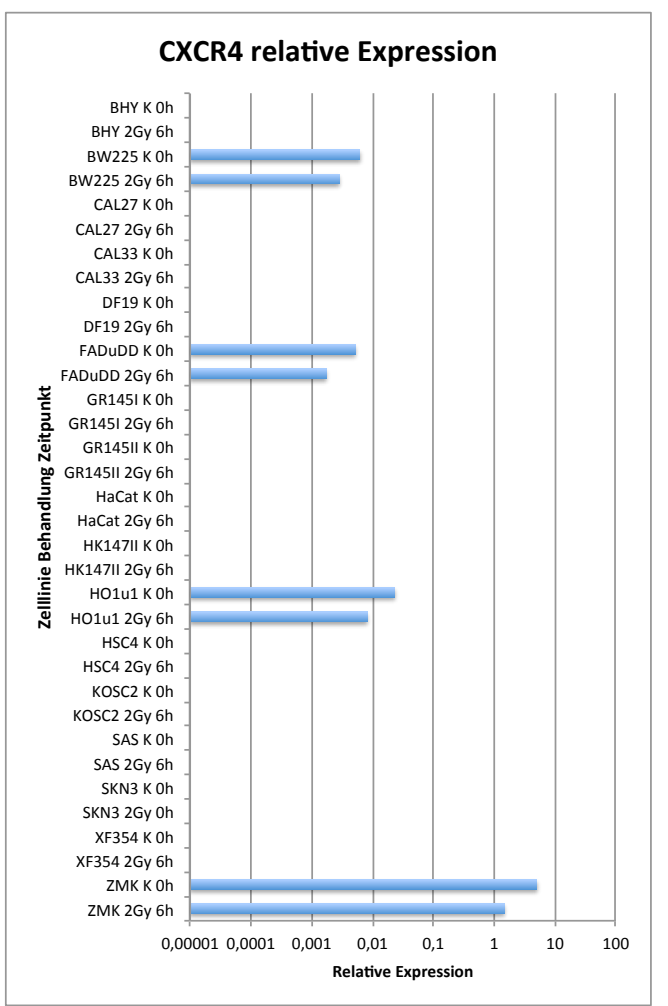

Abbildung 3.1.17: Relative Genexpression des Rezeptors CXCR4

Die Abbildung 3.1.17 zeigt die relative Genexpression des Chemokinrezeptors CXCR4 der untersuchten Zelllinien. Die Expression des Chemokinrezeptors CXCR4 ist in Relation zu den Housekeepinggenen bei drei Zelllinien vermindert und in der Tumorzellinie ZMK1 gesteigert. Bei allen exprimierenden Zelllinien zeigt sich eine signifikante Minderung der Expression zu dem Zeitpunkt $6 \mathrm{~h}$ nach Bestrahlung der Zellen mit 2 Gy. Der CXC-Rezeptor 4 ist Bindungsstelle für den Chemokinliganden CXCL12. Während die Expression des Liganden nach Bestrahlung eine Varianz zeigt, ist die Herunterregulierung der Expression nach Bestrahlung der Zellen mit 2 Gy bei dem Rezeptor CXCR4 vorherrschend. 


\subsection{Kinetik der strahleninduzierten Expressionsänderungen}

Nach der Analyse der Genexpression der Chemokine und Chemokinrezeptoren in den 17 Normal- und Tumorgewebszelllinien wurde für die Genexpression bestimmter Chemokine und Chemokinrezeptoren eine Kinetik bestimmt. Es wurden die Chemokine und deren Rezeptoren ausgewählt, die in der ersten Analyse von vielen Zelllinien exprimiert oder in der Literatur genauer beschrieben wurden. Die zuvor nicht oder nur vereinzelt exprimierten Chemokine und Chemokinrezeptoren wurden nicht weiter untersucht. In der erneuten Analyse wurde sich auf die Chemokine CCL20, CXCL1, CXCL2, CXL3, CXCL12 sowie die Chemokinrezeptoren CCR7, CCR6, CXCR1 und CXCR4 beschränkt. Weiterhin wurden nur die Normalgewebszelllinien DF19 und HaCat sowie die Kopf-Hals-Karzinomzelllinien BHY, BW225, GR145 I, GR145 II, FaDuDD und ZMK1 analysiert. Die Zellen der ausgewählten Zelllinien wurden wie in der ersten Analyse mit $2 \mathrm{~Gy}$ bestrahlt und anschließend die Expression der Chemokine und Chemokinrezpetoren mittels PCR nachgewiesen. Die Ergebnisse wurden erneut in Relation zu den Werten der Housekeepinggene und zusätzlich zu den nicht bestrahlten Kontrollwerten gesetzt. Es kann daher die Expressionsänderungen der Chemokine und deren Rezeptoren nach Bestrahlung im Verlauf analysiert werden. Die Abbildungen 3.2.1.1 bis 3.2.8.2 zeigen also den zeitlichen Verlauf strahleninduzierter Expressionsänderungen der untersuchen Chemokine und Chemokinrezeptoren. Auf der Ordinate sind jeweils die verschiedenen Zeitpunkte nach der Bestrahlung der Zellen mit 2 Gy aufgeführt. Die Abszisse stellt die relative Expression des Chemokinligandens bzw. Chemokinrezeptors bezogen auf die Housekeepinggene und die unbestrahlte Kontrolle dar. Die ermittelten Werte sind doppelt bestimmt worden. Eine Expression von 1 bedeutet in den aufgeführten Abbildungen, dass keine strahleninduzierte Änderung der Expression zu beobachten ist.

Die Bestrahlung der Zellen mit 2 Gy zeigt strahleninduzierte Steigerungen und Minderungen der Genexpression der Chemokine und Chemokinrezeptoren in den untersuchten Zelllinien. Die homologe Gruppe der Chemokine CXCL1, CXCL2 und CXCL3 (Abb. 3.1.9 - Abb. 3.1.11) zeigt in den beiden Normalgewebszelllinien ein ähnliches Muster der strahleninduzierten Expressionsänderung nach Bestrahlung der Zellen mit 2 Gy. Die strahleninduzierte Expression dieser Chemokinliganden ist in 
den Normalgewebszelllinien stärker ausgeprägt, als in den untersuchten Tumorzelllinien. Die Expression des Chemokins CCL20 (Abb. 3.1.4), die mit der Immunantwort und inflammatorischen Prozessen einhergeht, kann in allen untersuchten Gewebszelllinien analysiert werden. Bei den Normal- und Tumorzellinien steht vor allem eine frühe Hochregulierung der strahleninduzierten Expression des Chemokinligandens CCL20 im Vordergrund. Das Chemokin CCL20 ist Ligand für den Chemokinrezeptor CCR6. Die Expression des Rezeptors CCR6 kann nur in den zwei Tumorgewebszellinien 145 II und BHY analysiert werden (Abb. 3.1.7). Die strahleninduzierte Expression unterscheidet sich in den beiden Tumorzelllinien allerdings deutlich. Die Zelllinie GR145 II zeigt nur schwache strahleninduzierte Expressionsänderungen des Chemokins CCL20, dafür aber signifikante Minderung der Expression des dazugehörigen Rezeptors CCR6 nach Bestrahlung mit 2 Gy. Der Chemokinrezeptor CCR7 wird nach Bestrahlung von den beiden Tumorzelllinien BHY und ZMK1 anfangs gemindert und zu späteren Zeitpunkten gesteigert exprimiert (Abb. 3.1.8). Die Normalgewebszelllinie DF19 zeigt ein umgekehrtes Bild mit einer strahleninduzierte Expressionssteigerung des Chemokinsrezeptors CCR7 zu frühen Zeitpunkten und einer folgenden strahleninduzierten Expressionsminderung. Der Rezeptor CXCR1 (Abb. 3.1.16) wird nur von der Zelllinie HaCat exprimiert und zeigt eine deutliche strahleninduzierte Minderung der Expression, wobei die Expression in dieser Zelllinie nur teilweise analysiert werden kann. Das CXCR4/CXCL12 Rezeptor Liganden Paar wird von der Tumorzelllinie BW225 exprimiert. Hier zeigt sich ein ähnliches strahleninduziertes Expressionsmuster des Chemokins CXCL12 (Abb. 3.1.15) und dessen Rezeptors CXCR4 (Abb. 3.1.17), welches aber nicht identisch ist.

\subsubsection{Zeitlicher Verlauf der Genexpression des Chemokins CCL20 nach Bestrahlung}

Die Genexpression des Chemokins CCL20 konnte in der vorliegenden Arbeit in den Normalgewebszellinien HaCat und DF19 sowie den Kopf-Hals-Karzinomzelllinien BHY, BW225, FaDuDD, GR145 I und GR145 II sowie ZMK1 detektiert werden. Die Normalgewebszelllinie HaCat zeigt eine signifikante strahleninduzierte Expressionssteigerung zu den Zeitpunkten $1 \mathrm{~h}$ und $3 \mathrm{~h}$ nach Bestrahlung der Zellen 
mit 2 Gy in Relation zu der unbestrahlten Kontrolle. Zu späteren Zeitpunkten nach Bestrahlung zeigt sich eine Expressionsminderung, wobei die Expression in Relation zu der unbestrahlten Kontrolle trotzdem leicht erhöht blieb. Vergleichbare Werte der strahleninduzierten Expressionssteigerung zeigt die Tumorzelllinie BHY. Die Zellen der Fibroblastenzelllinie DF19 zeigen eine inhomogene Expression mit deutlichen Schwankungen in der Kinetik nach Bestrahlung der Normalgewebszellen. Bei der Tumorzelllinie GR145 I ist ebenso eine strahleninduzierte Expressionssteigerung mit anschließender Expressionsminderung und erneuter starker Steigerung zu beobachten. Bei der Tumorzellinie GR145 II wird in Relation zur unbestrahlten Kontrolle eine leichte strahleninduzierte Expressionsminderung des Chemokins CCL20 beobachtet.

\subsubsection{Strahleninduzierte relative Genexpressionsänderungen des Chemokinliganden CCL20 in der Zelllinie DF19}

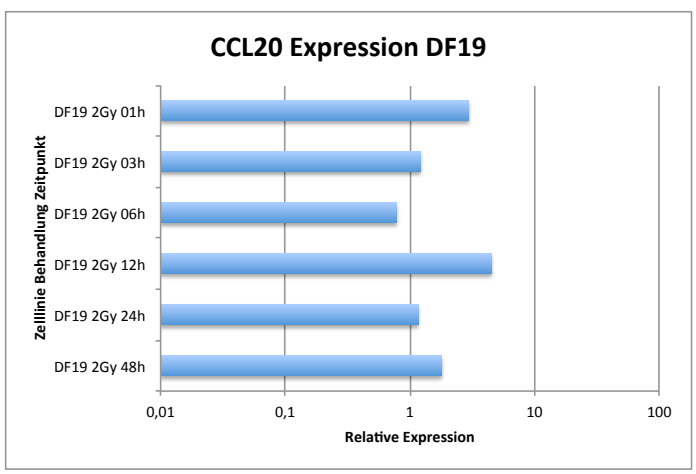

\section{Abbildung 3.2.1.1: Relative Genexpression CCL20 der Zelllinie DF19}

Es ist eine gesteigerte Expression des Chemokinliganden CCL20 in der Zellinie DF19 zu den Zeitpunkten 01 h, 03 h, 12 h, 24 h und 48 h nach Bestrahlung in Relation zu der unbestrahlenten Kontrolle zu beobachten. Die relative Genexpression ist zu den Zeitpunkten $01 \mathrm{~h}$ und $12 \mathrm{~h}$ nach Bestrahlung signifikant herauf reguliert. 


\subsubsection{Strahleninduzierte relative Genexpressionsänderungen des}

Chemokinliganden CCL20 in der Zelllinie HaCat

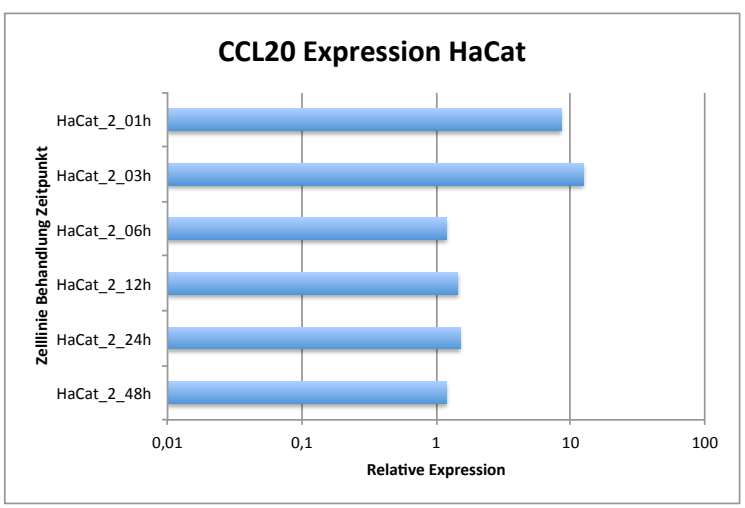

\section{Abbildung 3.2.1.2: Relative Genexpression CCL20 der Zelllinie HaCat}

Die Normalgewebszelllinie HaCat zeigt eine strahleninduzierte Steigerung der Genexpression des Chemokins CCL20 zu allen Zeitpunkten nach Bestrahlung der Zellen mit 2 Gy in Relation zu der unbestrahlten Kontrolle. Es zeigt sich insgesamt eine verstärkt strahleninduziert gesteigerte Expression des Chemokinligandens CCL20 zu frühen Zeitpunkten und Abnahme der Expression zu späteren Zeitpunkten nach Bestrahlung der Zellen mit 2 Gy. Die in Relation zu der unbestrahlten Kontrolle herauf regulierte Genexpression ist zu den Zeitpunkten $1 \mathrm{~h}$ und $3 \mathrm{~h}$ nach Bestrahlung signifikant.

\subsubsection{Strahleninduzierte relative Genexpressionsänderungen des} Chemokinliganden CCL20 in der Zelllinie BHY

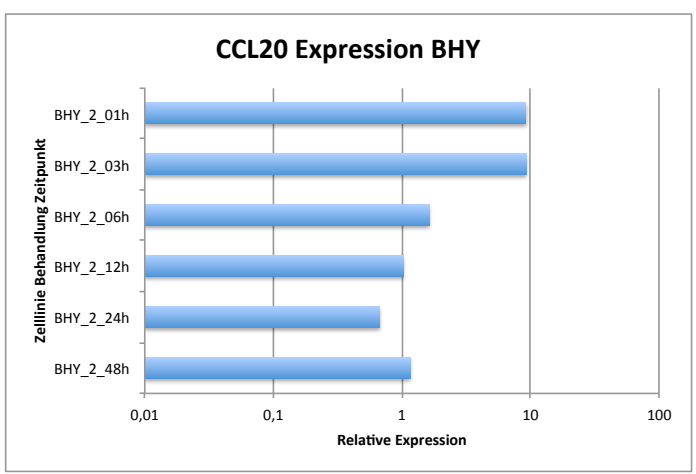

Abbildung 3.2.1.3: Relative Genexpression CCL20 der Zelllinie BHY 
Die strahleninduzierte Genexpression des Chemokins CCL20 in der Tumorzellinie BHY wird zu den Zeitpunkten $1 \mathrm{~h}$ und $3 \mathrm{~h}$ nach Bestrahlung der Zellen mit $2 \mathrm{~Gy}$ in Relation zu der unbestrahlten Kontrolle signifikant gesteigert. Unter Reduktion der Expression im zeitlichen Verlauf zeigt sich eine erneute relative Steigerung der Expression zum Zeitpunkt $48 \mathrm{~h}$ nach Bestrahlung.

\subsubsection{Strahleninduzierte relative Genexpressionsänderungen des} Chemokinliganden CCL20 in der Zelllinie BW225

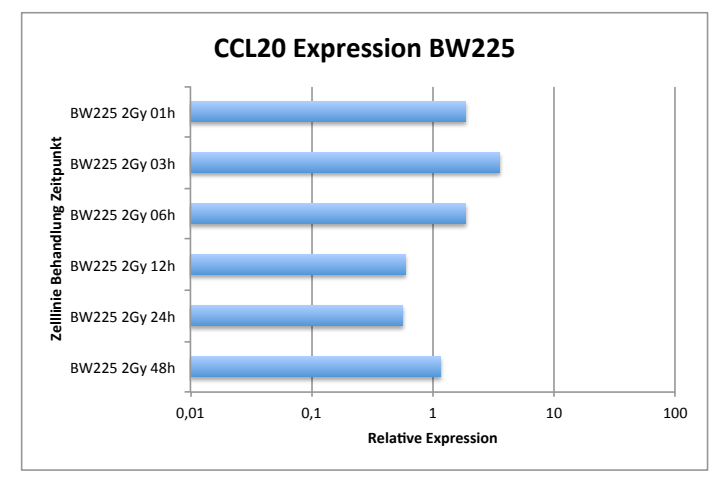

Abbildung 3.2.1.4: Relative Genexpression CCL20 der Zelllinie BW225

Zu den Zeitpunkten 1 h, 3 h, 6 h und 48 h nach Bestrahlung der Zellen mit 2 Gy wird die Expression des Chemokins CCL20 in der Tumorzelllinie BW225 in Relation zu der Kontrolle herauf reguliert. Die strahleninduzierte Expression wird $12 \mathrm{~h}$ und $24 \mathrm{~h}$ nach Bestrahlung vermindert. Die relative Genexpression ist zum Zeitpunkt $3 \mathrm{~h}$ nach Bestrahlung der Zellen signifikant heraufreguliert.

\subsubsection{Strahleninduzierte relative Genexpressionsänderungen des Chemokinliganden CCL20 in der Zelllinie FaDuDD}




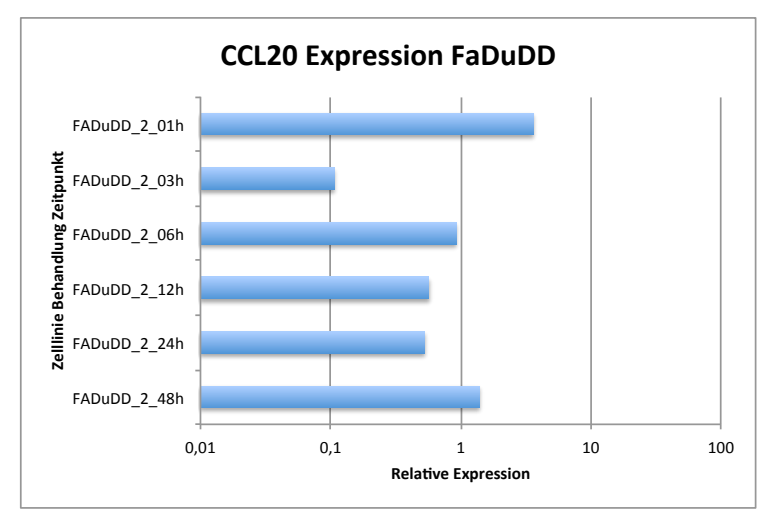

Abbildung 3.2.1.5: Relative Genexpression CCL20 der Zelllinie FaDuDD

Die strahleninduzierte Expression des Chemokinliganden CCL20 wird in Relation zu der unbestrahlten Kontrolle zu den Zeitpunkten $1 \mathrm{~h}$ und $48 \mathrm{~h}$ nach Bestrahlung mit 2 Gy signifikant gesteigert. Zu den Zeitpunkten 3 h, 12 und 24 h nach Bestrahlung ist die Expression des Chemokins CCL20 in der Zelllinie FaDuDD signifikant vermindert.

\subsubsection{Strahleninduzierte relative Genexpressionsänderungen des Chemokinliganden CCL20 in der Zelllinie GR145 I}

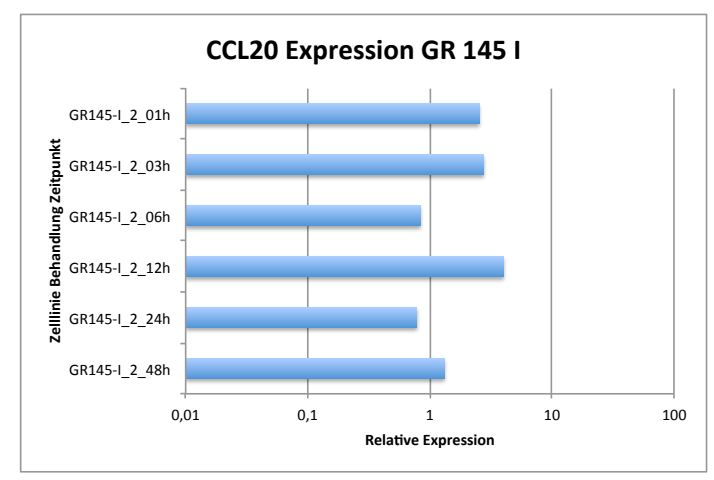

\section{Abbildung 3.2.1.6: Relative Genexpression CCL20 der Zelllinie GR145 I}

Der Chemokinligand CCL20 wird von der Zelllinie GR145 I zu den Zeitpunkten 1 h, 3 h und 12 h nach Bestrahlung mit 2 Gy in Relation zu der unbestrahlten Kontrolle signifikant gesteigert exprimiert. Strahleninduzierte Expressionsminderungen sind im Verlauf nach $6 \mathrm{~h}$ und $24 \mathrm{~h}$ zu beobachten. Die Expression steigt $48 \mathrm{~h}$ nach Bestrahlung der Zellen mit 2 Gy in Relation zur Kontrolle erneut leicht an. 


\subsubsection{Strahleninduzierte relative Genexpressionsänderungen des}

Chemokinliganden CCL20 in der Zelllinie GR145 II

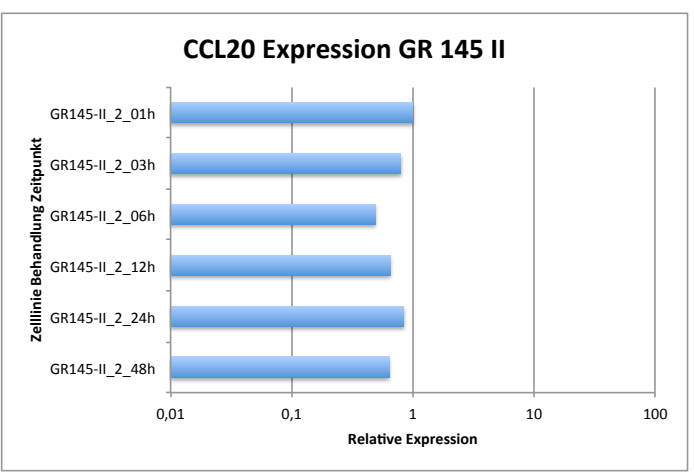

Abbildung 3.2.1.7: Relative Genexpression CCL20 der Zelllinie GR145 II

Der Chemokinligand CCL20 wird von der Zelllinie GR145 II zu allen Zeitpunkten nach der Bestrahlung mit 2 Gy in Relation zu der unbestrahlten Kontrolle vermindert exprimiert. Die strahleninduzierte Genexpression ist zum Zeitpunkt $6 \mathrm{~h}$ nach Bestrahlung signifikant herunter reguliert.

\subsubsection{Strahleninduzierte relative Genexpressionsänderungen des} Chemokinliganden CCL20 in der Zelllinie ZMK1

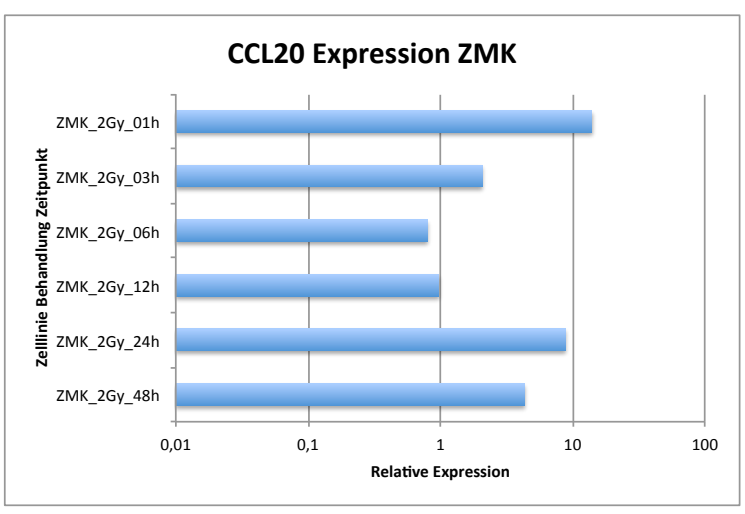

Abbildung 3.2.1.8: Relative Genexpression CCL20 der Zelllinie ZMK1

Das strahleninduzierte Expressionsmuster des Chemokins CCL20 in der Zelllinie ZMK zeigt eine signifikante Heraufregulierung der relativen Expression nach Bestrahlung der Zellen zu den Zeitpunkten 1 h, 3 h, 24 h und 48 h. Zum Zeitpunkt 6 h 
nach Bestrahlung ist allerdings eine deutliche relative Expressionsminderung zu erkennen.

\subsubsection{Zeitlicher Verlauf der Genexpression der Chemokine CXCL1, CXCL2 und CXCL3 nach Bestrahlung}

In den untersuchten Zelllinien kann eine strahleninduzierte Expressionsänderung der CXC-Chemokine nachgewiesen werden. Die Zellen der Fibroblastenzelllinie DF19 zeigen eine Expressionsminderung in Relation zu der unbestrahlten Kontrolle für die Chemokine CXCL1 und CXCL2 zu den Zeitpunkten $01 \mathrm{~h}, 03 \mathrm{~h}, 06 \mathrm{~h}$ nach Bestrahlung und die stärkste Minderung $12 \mathrm{~h}$ nach Bestrahlung mit $2 \mathrm{~Gy}$. Zum Zeitpunkt $12 \mathrm{~h}$ nach Bestrahlung zeigt sich für den Chemokinliganden CXCL3 allerdings eine strahleninduzierte Heraufregulierung der Expression. Bei der Normalgewebszelllinie HaCat zeigt sich in Relation zu der unbestrahlten Kontrolle eine Heraufregulierung der Expression für die drei Chemokine nach Bestrahlung der Zellen mit 2 Gy und anschließender relativer Minderung der Expression. Die Tumorzellinie BHY zeigt eine frühe strahleninduzierte Heraufregulierung der Expression mit anschließender Expressionsminderung der Chemokine CXCL1-3 in Relation zu der unbestrahlten Kontrolle. Die Zelllinie BW225 verhält sich zu der BHY -Zelllinie entgegengesetzt mit deutlicher Zunahme der strahleninduzierten Expression im Verlauf der Kinetik. In der Zellinie FaDuDD zeigt sich ein homologes Genexpressionsmuster der drei Chemokine CXCL1, CXCL2 und CXCL3 mit signifikanter Genexpressionsminderung zu den Zeitpunkten $3 \mathrm{~h}, 6 \mathrm{~h}$ und $12 \mathrm{~h}$ nach Bestrahlung der Zellen mit $2 \mathrm{~Gy}$ in Relation zu den unbestrahlten Zellen der Kontrolle. Bei der Tumorzelllinie GR145 I zeigen sich nur leichte strahleninduzierte Änderungen der Chemokinexpression nach Bestrahlung der Zellen mit $2 \mathrm{~Gy}$. Die Zelllinie GR145 II hingegen zeigt deutlichere strahleninduzierte Expressionsänderungen relativ zur Kontrolle. Die Genexpression der Chemokine CXCL2 und CXCL3 in der Zelllinie ZMK1 ist in Relation zu den Housekeepinggenen und der unbestrahlten Kontrolle der gleichen Zelllinie zu den Zeitpunkten $3 \mathrm{~h}, 6 \mathrm{~h}$ und $12 \mathrm{~h}$ nach Bestrahlung signifikant vermindert und zum Zeitpunkt $24 \mathrm{~h}$ nach Bestrahlung signifikant gesteigert. Die Chemokine CXCL1, CXCL2 und CXCL3 binden an den CXCR2-Rezeptor. Die Expression des CXCR2-Rezeptors konnte in den untersuchten Zelllinien allerdings nicht nachgewiesen werden. 


\subsubsection{Strahleninduzierte relative Genexpressionsänderung der}

Chemokinliganden CXCL1, CXCL2 und CXCL3 in der Zelllinie DF19

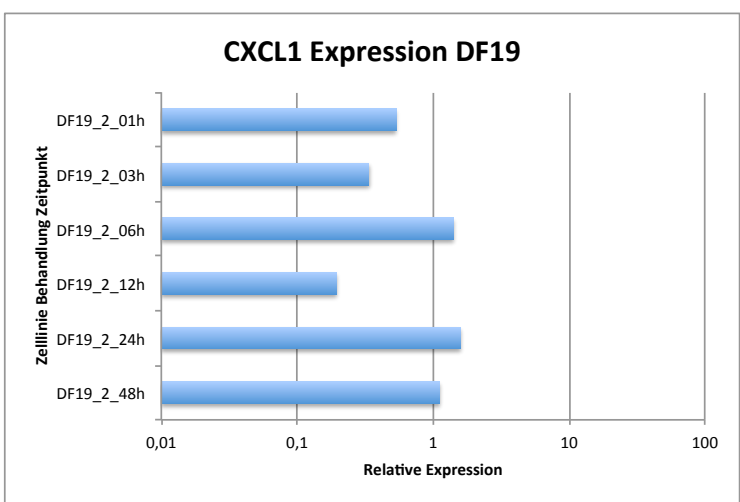

\section{Abbildung 3.2.2.1.1: Relative Genexpression CXCL1 DF19}

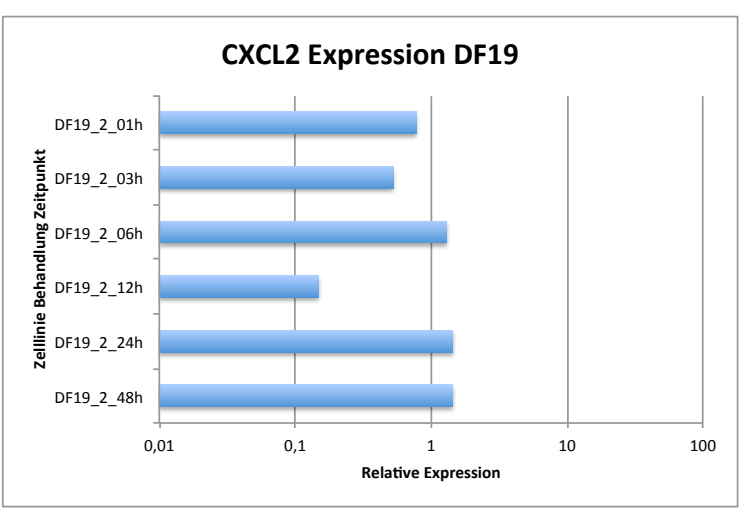

Abbildung 3.2.2.1.2: Relative Genexpression CXCL2 DF19

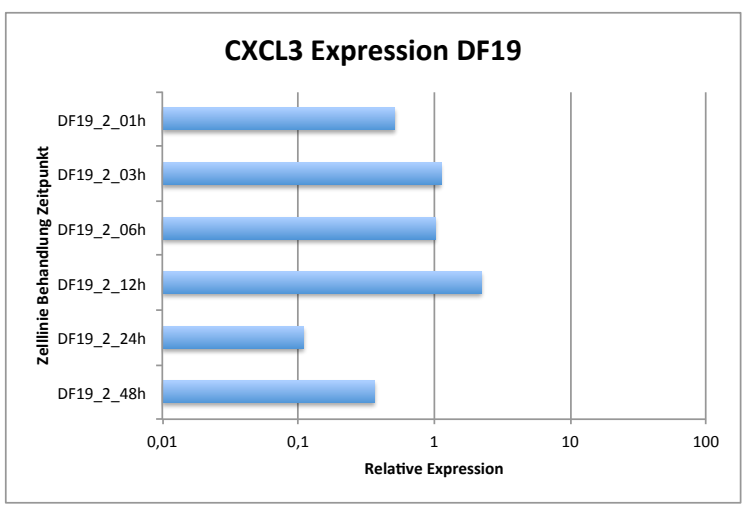

Abbildung 3.2.2.1.3: Relative Genexpression CXCL3 DF19

Das strahleninduzierte Expressionsmuster der Chemokine CXCL1 und CXCL2 der Zelllinie DF19 ist vergleichbar. Bei den beiden Chemokliganden steht die signifikante 
strahleninduzierte Herunterregulierung der Expression $12 \mathrm{~h}$ nach Bestrahlung der Zellen mit 2 Gy in Relation zu der unbestrahlten Kontrolle im Vordergrund. Die Expression der beiden Chemokine CXCL1 und CXCL2 ist zu den Zeitpunkten 6 h, 24 $\mathrm{h}$ und $48 \mathrm{~h}$ in Relation zur Kontrolle gesteigert. Das Chemokin CXCL3 wird im Gegensatz zu den Zeitpunkten $3 \mathrm{~h}$ und $24 \mathrm{~h}$ nach Bestrahlung der Zellen heraufreguliert und zum Zeitpunkt $24 \mathrm{~h}$ und $48 \mathrm{~h}$ nach Bestrahlung signifikant vermindert exprimiert.

\subsubsection{Strahleninduzierte relative Genexpressionsänderung der} Chemokinliganden CXCL1, CXCL2 und CXCL3 in der Zelllinie HaCat

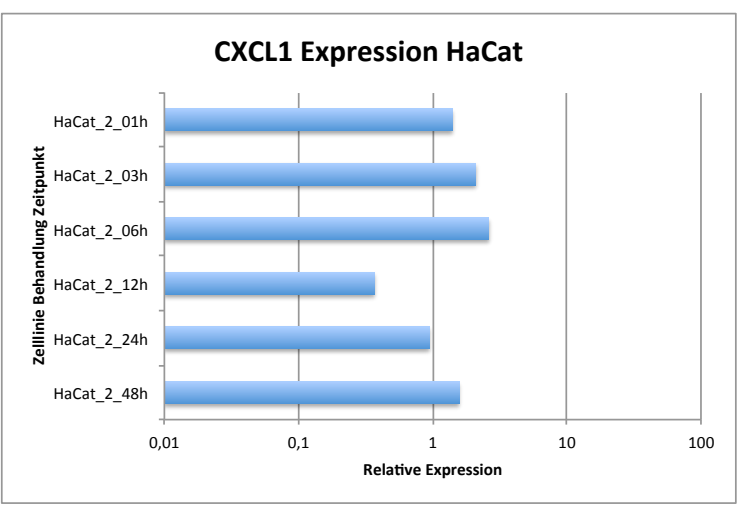

Abbildung 3.2.2.2.1: Relative Genexpression CXCL1 der Zelllinie HaCat

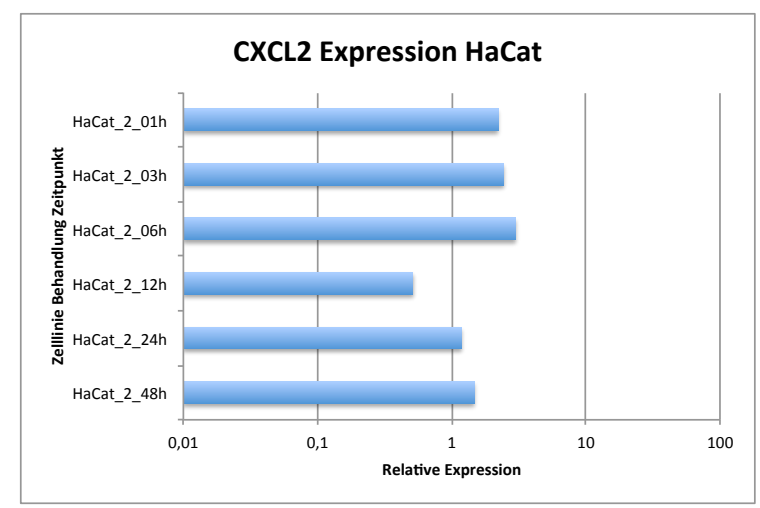

Abbildung 3.2.2.2.2: Relative Genexpression CXCL2 der Zelllinie HaCat 


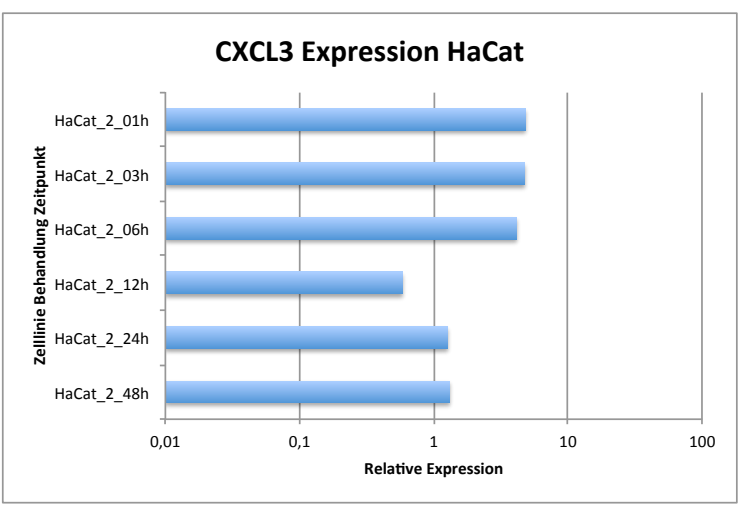

Abbildung 3.2.2.2.3: Relative Genexpression CXCL3 der Zelllinie HaCat

Bei der Normalgewebszellinie HaCat zeigt sich ein vergleichbares strahleninduziertes Expressionsmuster der Chemokinliganden CXCL1-3 mit einer bestrahlungsinduzierten Heraufregulierung der Expression. In Relation zu der unbestrahlten Kontrolle wurde die Expression $1 \mathrm{~h}, 3 \mathrm{~h}$ und $6 \mathrm{~h}$ nach Bestrahlung der Zellen mit 2 Gy signifikant gesteigert. Die relative Expression des Chemokins CXCL1 wird 12 h nach Bestrahlung mit 2 Gy signifikant reduziert.

\subsubsection{Strahleninduzierte relative Genexpressionsänderung der} Chemokinliganden CXCL1, CXCL2 und CXCL3 in der Zelllinie BHY

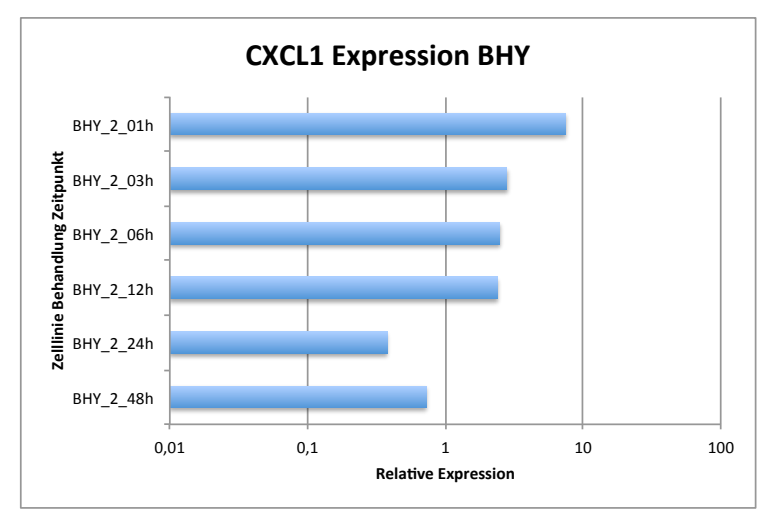

Abbildung 3.2.2.3.1: Relative Genexpression CXCL1 der Zelllinie BHY 


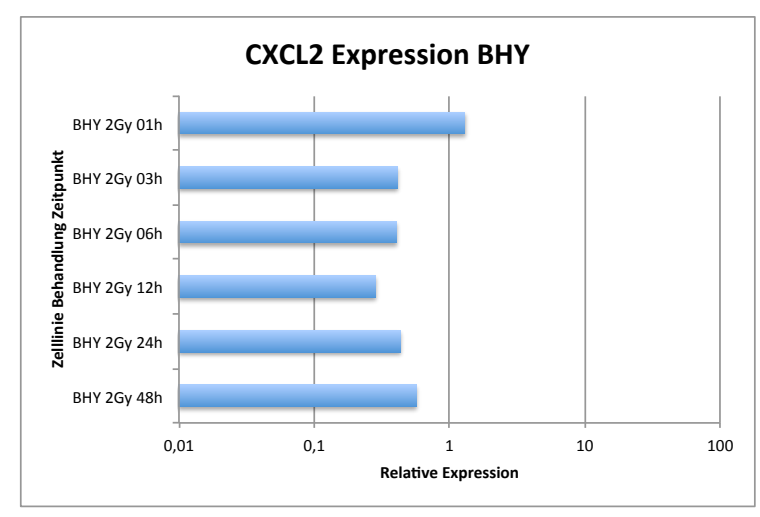

Abbildung 3.2.2.3.2: Relative Genexpression CXCL2 der Zelllinie BHY

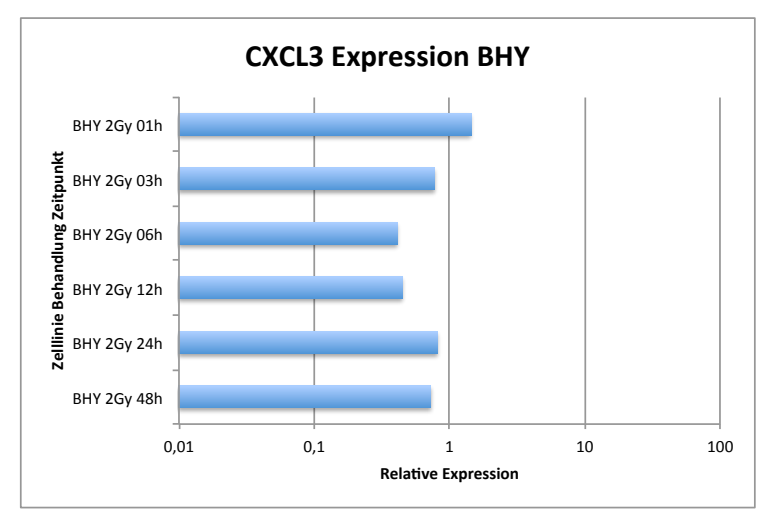

\section{Abbildung 3.2.2.2.3: Relative Genexpression CXCL3 der Zelllinie BHY}

In der Kopf-Hals-Karzinomzelllinie BHY zeigt sich die relative Expression der drei Chemokinliganden CXCL1, CXCL2 und CXCL3 mit einer Expressionssteigerung zum Zeitpunkt $1 \mathrm{~h}$ nach Bestrahlung der Zellen mit 2 Gy. Anschließend ist eine strahleninduzierte Expressionsminderung der Chemokine CXCL2 und CXCL3 in Relation zu der unbestrahlten Kontrolle zu den Zeitpunkten 3 h, 6 h, 12 h, 24 h und $48 \mathrm{~h}$ nach Bestrahlung zu beobachten. In Relation zu der unbestrahlten Kontrolle wird die Expression des Chemokins CXCL1 sinifikant zu den Zeitpunkten $1 \mathrm{~h}, 3 \mathrm{~h}, 6$ $\mathrm{h}$ und $12 \mathrm{~h}$ signifikant herauf reguliert. Zu den Zeitpunkten $24 \mathrm{~h}$ und $48 \mathrm{~h}$ nach Bestrahlung der Tumorzellen ist die Expression auf Bezug zu der Kontrolle gemindert. Das Chemokin CXCL2 wird zu Zeitpunkten 3 h, 6 h, 12 h und 24 h nach Bestrahlung in Relation signifikant vermindert exprimiert. Die Expression des Chemokins CXCL3 ist signifikant $6 \mathrm{~h}$ und $12 \mathrm{~h}$ nach Bestrahlung herunter reguliert. Insgesamt lässt sich bei der Expression der Zelllinie BHY eine frühe strahleninduzierte Steigerung und danach strahleninduzierte signifikante Minderung für die Gruppe der Chemokine CXCL1, CXCL2 und CXCL3 feststellen. 


\subsubsection{Strahleninduzierte relative Genexpressionsänderung der}

Chemokinliganden CXCL1, CXCL2 und CXCL3 in der Zelllinie BW225

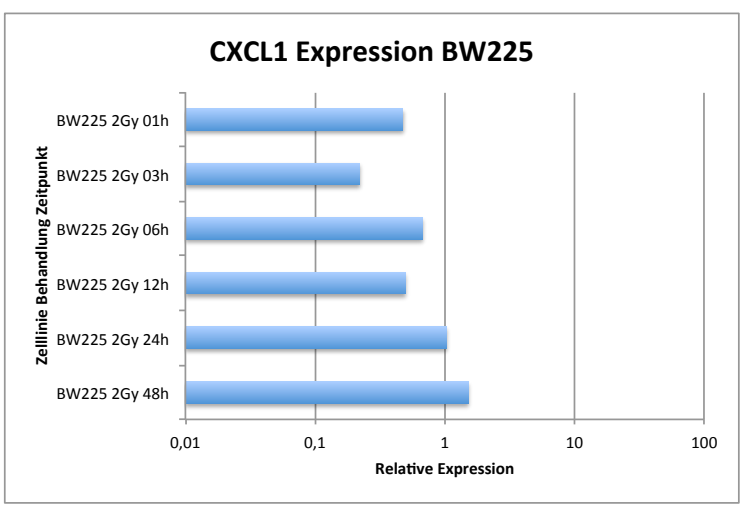

Abbildung 3.2.2.4.1: Relative Genexpression CXCL1 der Zelllinie BW225

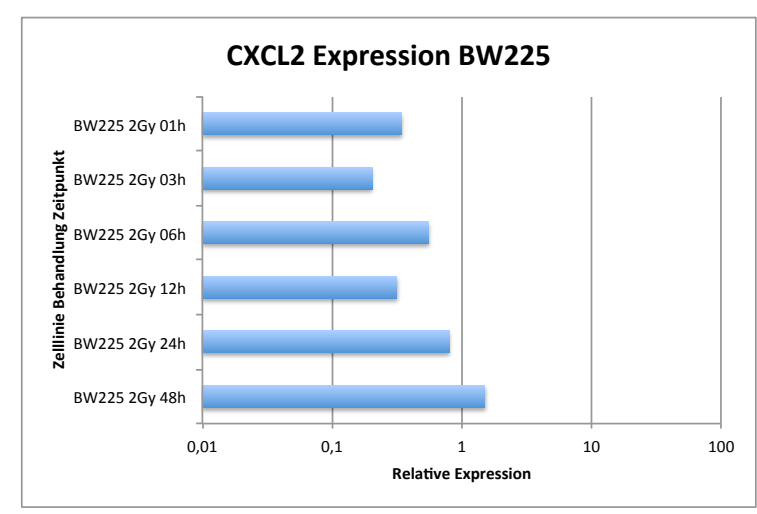

Abbildung 3.2.2.4.2: Relative Genexpression CXCL2 der Zelllinie BW225

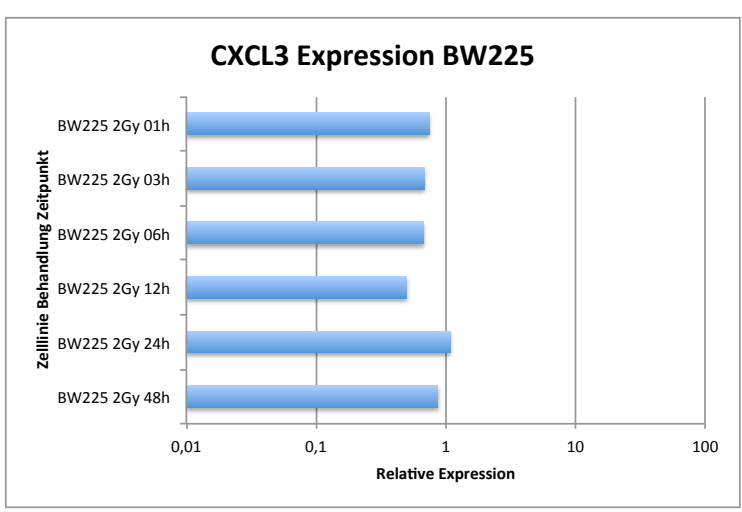

Abbildung 3.2.2.4.3: Relative Genexpression CXCL3 der Zelllinie BW225

Die Genexpression der Chemokine wird 1 h, 3 h, 6 h und 12 h nach Bestrahlung der Zellen der Zellinie BW225 in Relation zu der Kontrolle herunter reguliert. Die relative 
Expression der Chemokine CXCL1 und CXCL2 ist $1 \mathrm{~h}, 3 \mathrm{~h}$ und $12 \mathrm{~h}$ nach Bestrahlung signifikant herunterreguliert. Es zeigte sich eine Steigerung der relativen Expression zu den Zeitpunkten $24 \mathrm{~h}$ und $48 \mathrm{~h}$ nach Bestrahlung der Zellen.

Insgesamt ist eine strahleninduzierten Heraufregulierung der Genexpression nach signifikanter Minderung für die Chemokine CXCL1, CXCL2 und CXCL3 in der Zelllinie BW225 zu erkennen.

\subsubsection{Strahleninduzierte relative Genexpressionsänderung der} Chemokinliganden CXCL1, CXCL2 und CXCL3 in der Zelllinie FaDuDD

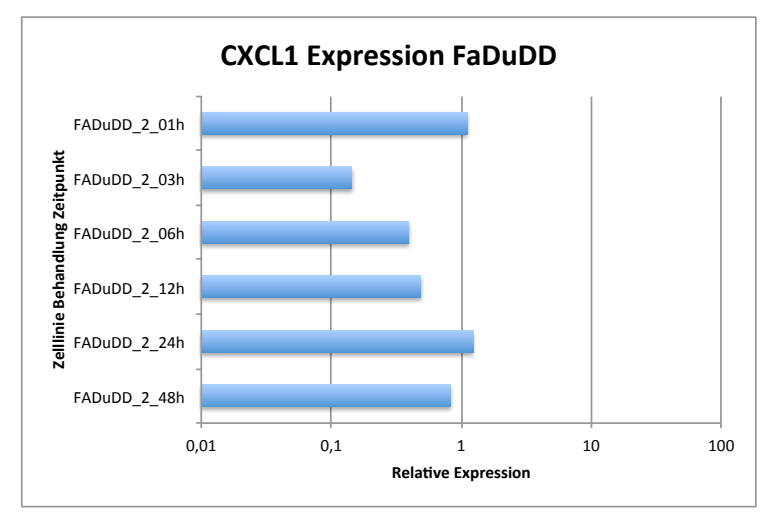

Abbildung 3.2.2.5.1: Relative Genexpression CXCL1 der Zelllinie FaDuDD

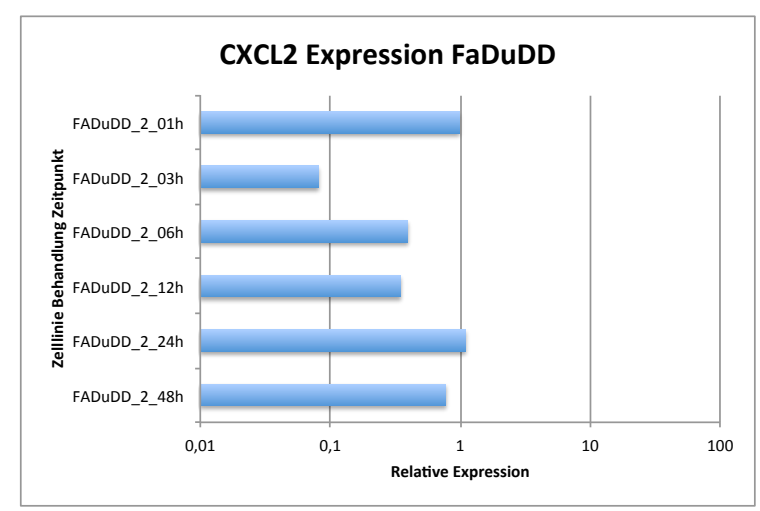

Abbildung 3.2.2.5.2: Relative Genexpression CXCL2 der Zelllinie FaDuDD 


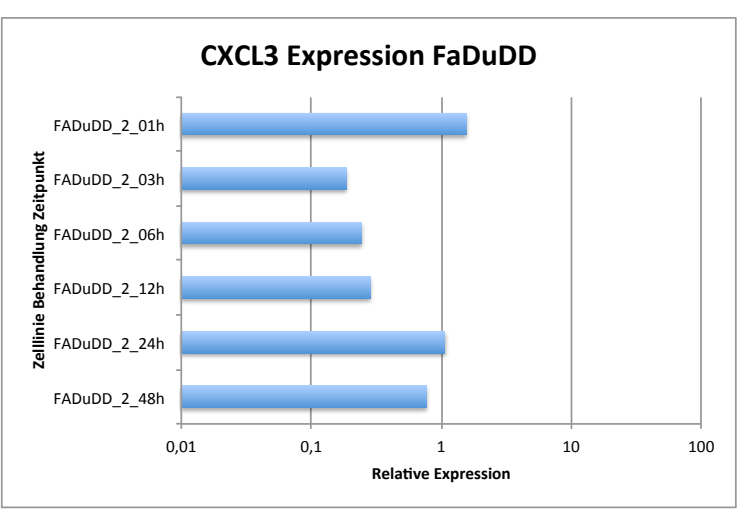

Abbildung 3.2.2.5.3: Relative Genexpression CXCL3 der Zelllinie FaDuDD

In der Zelllinie FaDuDD zeigt sich ein homogenes strahleninduziertes Genexpressionsmuster der drei Chemokine CXCL1, CXCL2 und CXCL3 mit signifikanter Genexpressionsminderung zu den Zeitpunkten 3 h, 6 h und 12 h nach Bestrahlung Zellen mit 2 Gy in Bezug auf die unbestrahlte Kontrolle.

3.2.2.6 Strahleninduzierte relative Genexpressionsänderung der Chemokinliganden CXCL1, CXCL2 und CXCL3 in der Zelllinie GR145 I

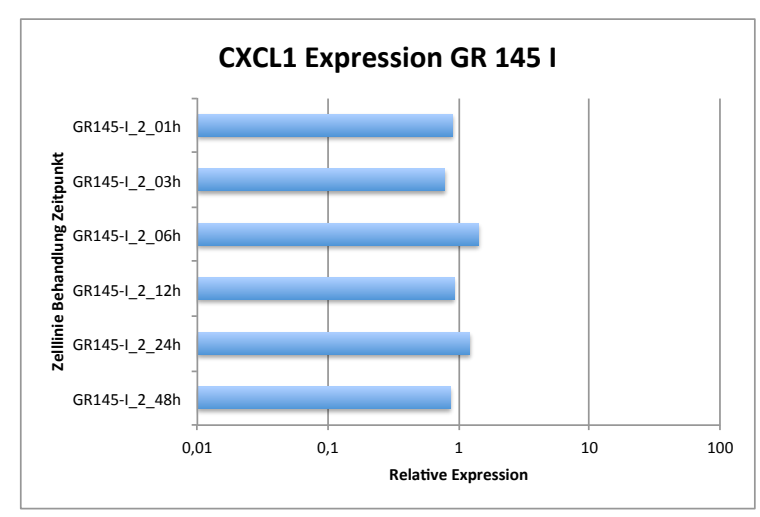

Abbildung 3.2.2.6.1: Relative Genexpression CXCL1 der Zelllinie GR145 I 


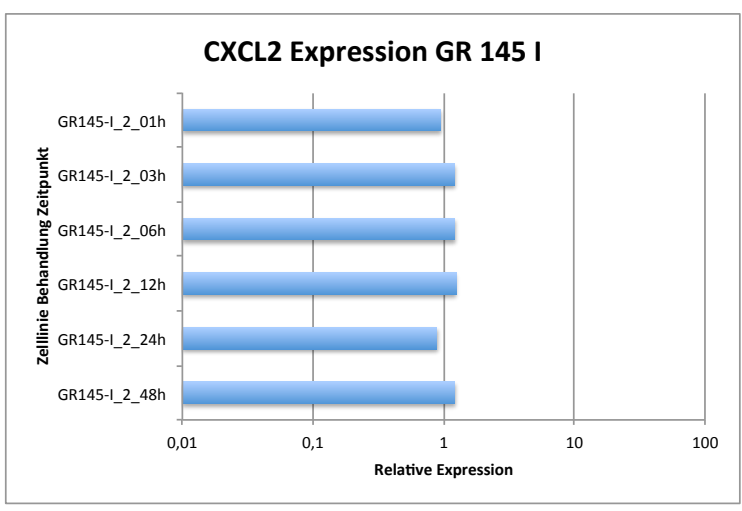

Abbildung 3.2.2.6.2: Relative Genexpression CXCL2 der Zelllinie GR145 I

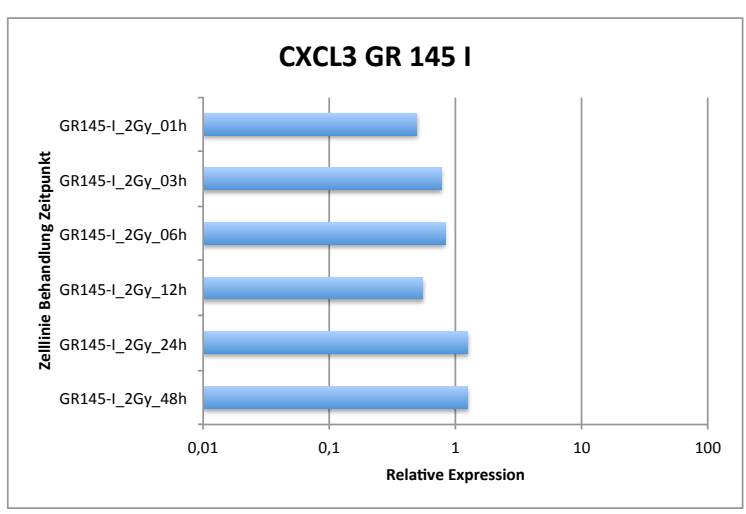

Abbildung 3.2.2.6.3: Relative Genexpression CXCL3 der Zelllinie GR145 I

Die relative Genexpression der Chemokine CXCL1, CXCL2 und CXCL3 der Zelllinie GR145 I zeigt nach Bestrahlung mit 2 Gy in Bezug auf die Kontrolle keine signifikanten Änderungen. Es sind nur leichte strahleninduzierte Expressionsänderungen der drei Chemokinliganden nach Bestrahlung der Zellen mit 2 Gy in Relation zu den nicht bestrahlten Zellen zu beobachten. 
3.2.2.7 Strahleninduzierte relative Genexpressionsänderungen der

Chemokinliganden CXCL1, CXCL2 und CXCL3 in der Zelllinie GR145 II

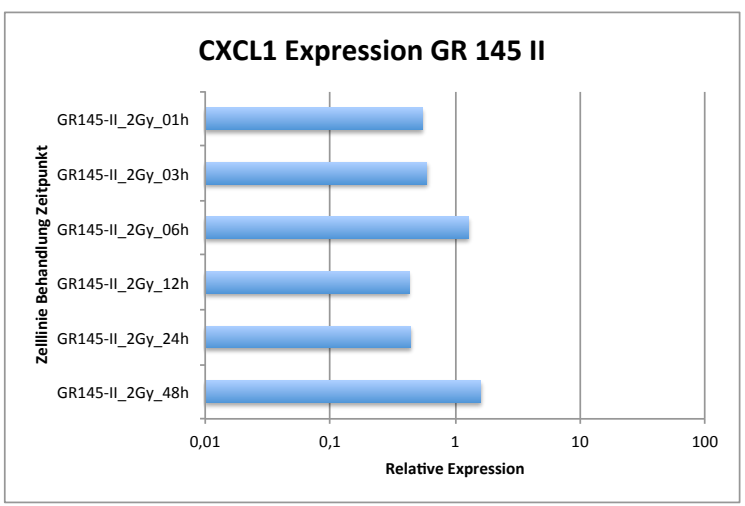

Abbildung 3.2.2.7.1: Relative Genexpression CXCL1 der Zelllinie GR145 II

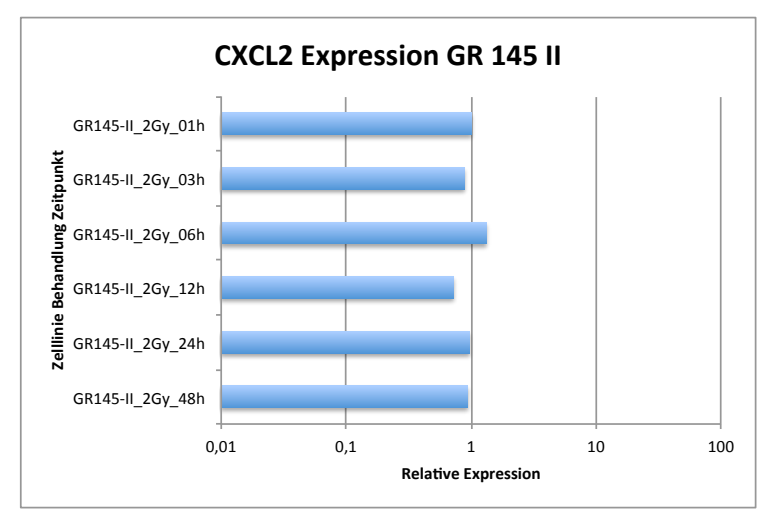

Abbildung 3.2.2.7.2: Relative Genexpression CXCL2 der Zelllinie GR145 II

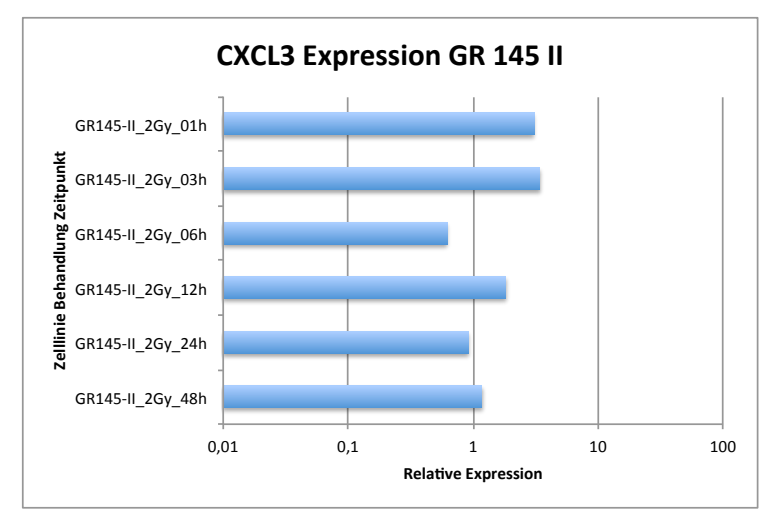

Abbildung 3.2.2.7.3: Relative Genexpression CXCL3 der Zelllinie GR145 II

Bei der Tumorzellinie GR145 II zeigt sich eine unterschiedliche strahleninduzierte Genexpressionen der Chemokine CXCL1, CXCL2 und CXCL3. Für die Chemokine 
CXCL1 und CXCL2 wird die relative Expression zu den Zeitpunkten $1 \mathrm{~h}, 3 \mathrm{~h}, 12 \mathrm{~h}$ und $24 \mathrm{~h}$ nach Bestrahlung der Zellen mit 2 Gy in Bezug auf die Kontrolle herunter reguliert. Die Expression des Chemokins CXCL1 zu den erwähnten Zeitpunkten war in Relation zu der unbestrahlten Kontrolle signifikant vermindert. Zum Zeitpunkt $6 \mathrm{~h}$ nach Bestrahlung der Zellen ist die strahleninduzierte Expression herauf reguliert. Die relative Expression des Chemokinliganden CXCL3 ist demgegenüber zu den Zeitpunkten $1 \mathrm{~h}, 3 \mathrm{~h}, 12 \mathrm{~h}$ und $24 \mathrm{~h}$ nach Bestrahlung herauf reguliert und zu den Zeitpunkten $6 \mathrm{~h}$ und $24 \mathrm{~h}$ in Relation zur Kontrolle vermindert. Die strahleninduzierte Expressionsänderung des Chemokins CXCL3 unterscheidet sich also von den Chemokinen CXCL1 und CXCL2 in der Tumorzellinie GR145 II.

\subsubsection{Strahleninduzierte relative Genexpressionsänderungen der} Chemokinliganden CXCL2 und CXCL3 in der Zelllinie ZMK1

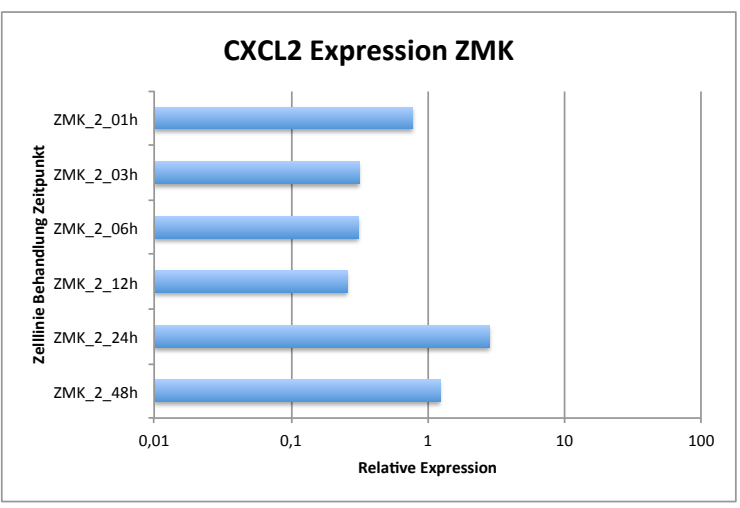

Abbildung 3.2.2.8.1: Relative Genexpression CXCL2 der Zelllinie ZMK1

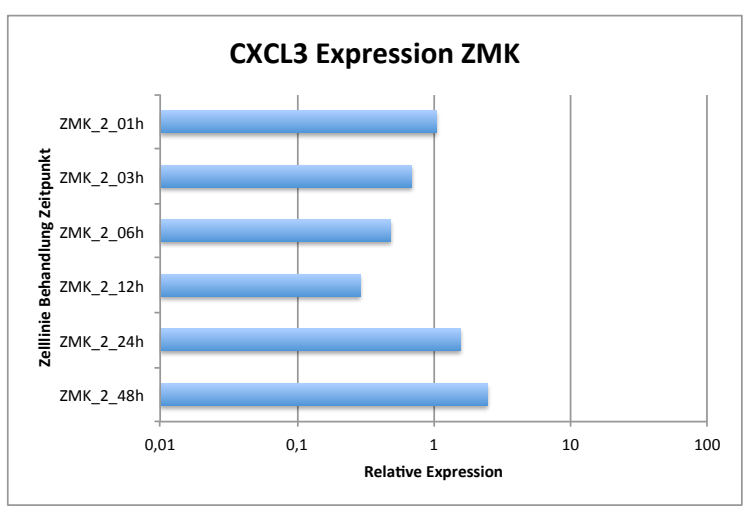

Abbildung 3.2.2.8.2: Relative Genexpression CXCL3 der Zelllinie ZMK1 
In der Zelllinie ZMK1 zeigt sich ein homogenes strahleninduziertes

Genexpressionsmuster der Chemokine CXCL2 und CXCL3. Die Genexpression des Chemokins CXCL2 wird in Bezug auf die unbestrahlte Kontrolle zu den Zeitpunkten 3 h, $6 \mathrm{~h}$ und $12 \mathrm{~h}$ nach Bestrahlung signifikant vermindert und zum Zeitpunkt $24 \mathrm{~h}$ nach Bestrahlung signifikant gesteigert. Die strahleninduzierte Genexpression des Chemokins CXCL3 wird in Relation zu der Kontrolle zu den Zeitpunkten $6 \mathrm{~h}$ und $12 \mathrm{~h}$ nach Bestrahlung der Zellen mit 2 Gy signifikant herunter reguliert und $48 \mathrm{~h}$ nach Bestrahlung signifikant herauf reguliert.

\subsubsection{Zeitlicher Verlauf der Genexpression des Chemokinrezeptors CCR6 nach Bestrahlung}

Die strahleninduzierte Genexpressionsänderung des Rezeptors CCR6 wurde nur in den zwei Tumorgewebszelllinien BHY und GR145 II nachgewiesen. In Relation zur unbestrahlten Kontrolle unterscheidet sich die strahleninduzierte Genexpression in den beiden Tumorzelllinien. Die strahleninduzierte Chemokinrezeptorexpression wird in der Zelllinie BHY in Relation zu der unbestrahlten Kontrolle herauf reguliert, wohingegen in der Zelllinie GR145 II die Expression nach Bestrahlung vermindert wird.

3.2.3.1 Strahleninduzierte relative Genexpressionsänderungen des Chemokinrezeptor CCR6 in der Zelllinie BHY

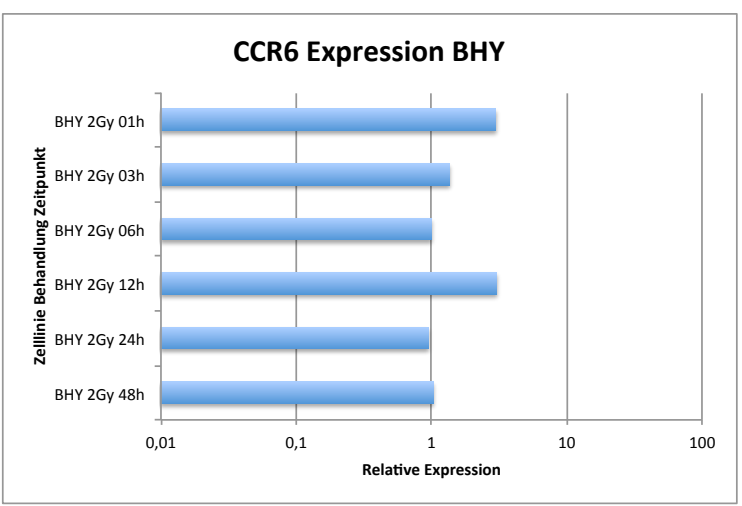

Abbildung 3.2.3.1: Relative Genexpression CCR6 der Zelllinie BHY 
Die strahleninduzierte Genexpression des Chemokinrezeptors CCR6 in der Zelllinie BHY wurde zu den Zeitpunkten 1 h, 3 h, 12 h und 48 h nach Bestrahlung der Zellen mit 2 Gy in Relation zur unbestrahlten Kontrolle gesteigert. Die Genexpression ist zu den Zeitpunkten $1 \mathrm{~h}$ und $12 \mathrm{~h}$ nach Bestrahlung signifikant erhöht.

\subsubsection{Strahleninduzierte relative Genexpressionsänderungen des Chemokinrezeptor CCR6 in der Zelllinie GR145 II}

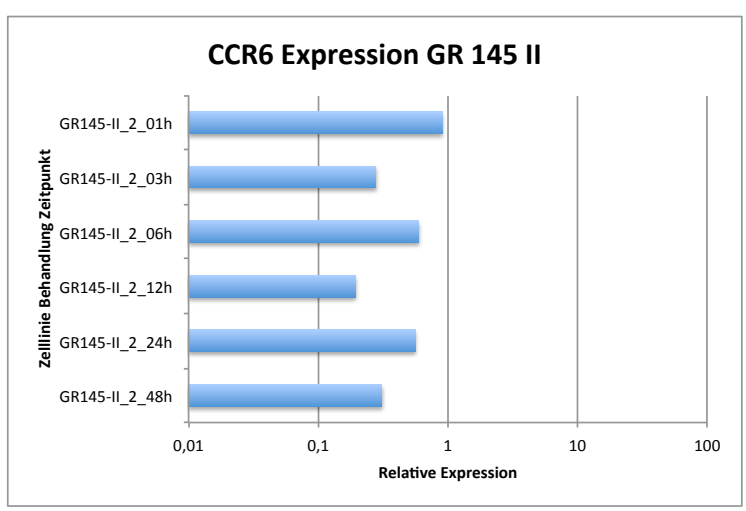

\section{Abbildung 3.2.3.2: Relative Genexpression CCR6 der Zelllinie GR145 II}

Die strahleninduzierte Genexpression des Chemokinrezeptors CCR6 in der Tumorzellinie GR145 II wird nach Bestrahlung der Zellen mit 2 Gy in Relation zur unbestrahlten Kontrolle herunter reguliert. Zu den Zeitpunkten 3 h, 12 h und 48 h nach Bestrahlung der Zellen ist die Genexpression signifikant gemindert. Die Genexpression des Rezeptors CCR6 konnte in der verwandten Tumorzelllinie GR145 I nicht nachgewiesen werden.

\subsubsection{Zeitlicher Verlauf der Genexpression des Chemokinrezeptors CCR7 nach Bestrahlung}

Der Chemokinrezeptor CCR7 wird von den Normalgewebszelllinien DF19 und HaCat sowie den Tumorzellen BHY und ZMK1 exprimiert. Die Genexpression des Chemokinrezeptors 7 wird in der Normalgewebszellinie DF19 nach Bestrahlung der Zellen mit 2 Gy in Relation zu der unbestrahlten Kontrolle gesteigert. Die Zelllinien $\mathrm{BHY}$ und HaCat zeigen im Verlauf eine strahleninduzierte Expressionsminderung nach Bestrahlung und eine Steigerung der Genexpression. 


\subsubsection{Strahleninduzierte relative Genexpressionsänderungen des} Chemokinrezeptor CCR7 in der Zelllinie DF19

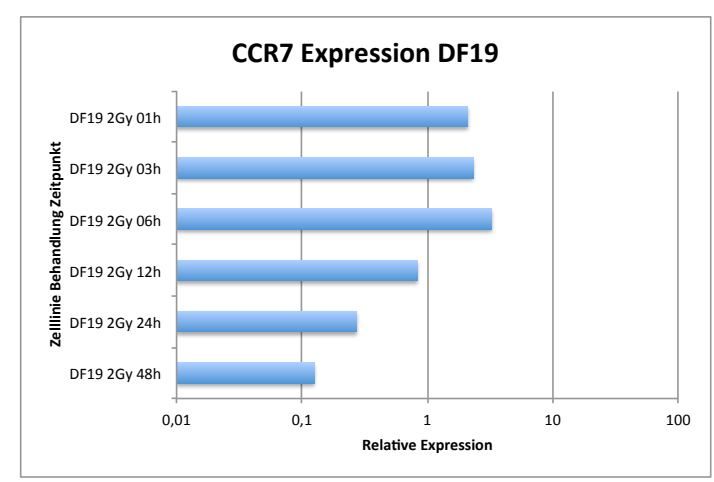

Abbildung 3.2.4.1: Relative Genexpression CCR7 der Zelllinie DF19

Die strahleninduzierte Expression des Rezeptors CCR7 wurde in der Zelllinie DF19 zu den Zeitpunkten $1 \mathrm{~h}, 3 \mathrm{~h}$ und $6 \mathrm{~h}$ nach Bestrahlung mit 2 Gy in Relation zu der Kontrolle signifikant gesteigert. Eine verminderte Genexpression ist zu den Zeitpunkten $12 \mathrm{~h}, 24 \mathrm{~h}$ und $48 \mathrm{~h}$ nach Bestrahlung zu beobachten. Die strahleninduzierte Expression $24 \mathrm{~h}$ und $48 \mathrm{~h}$ nach Bestrahlung der Zellen ist signifikant herunter reguliert. 


\subsubsection{Strahleninduzierte relative Genexpressionsänderungen des}

Chemokinrezeptors CCR7 in der Zelllinie HaCat

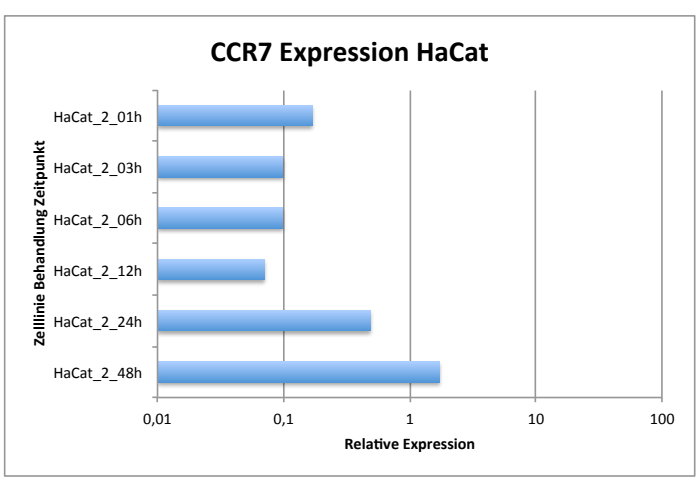

Abbildung 3.2.4.2: Relative Genexpression CCR7 der Zelllinie HaCat

Der Rezeptor CCR7 wird nach Bestrahlung der Zellen in Relation zur unbestrahlten Kontrolle in der Zelllinie HaCat stark vermindert exprimiert. Bei der Normalgewebszelllinie HaCat ist eine signifikante relative Expressionsminderung zu den Zeitpunkten 1 h, 3 h, 6 h und 12 h nach Bestrahlung der Zellen mit 2 Gy zu beobachten. Die strahleninduzierte Genexpression wird $48 \mathrm{~h}$ nach Bestrahlung signifikant gesteigert.

\subsubsection{Strahleninduzierte relative Genexpressionsänderungen des} Chemokinrezeptor CCR7 in der Zelllinie BHY

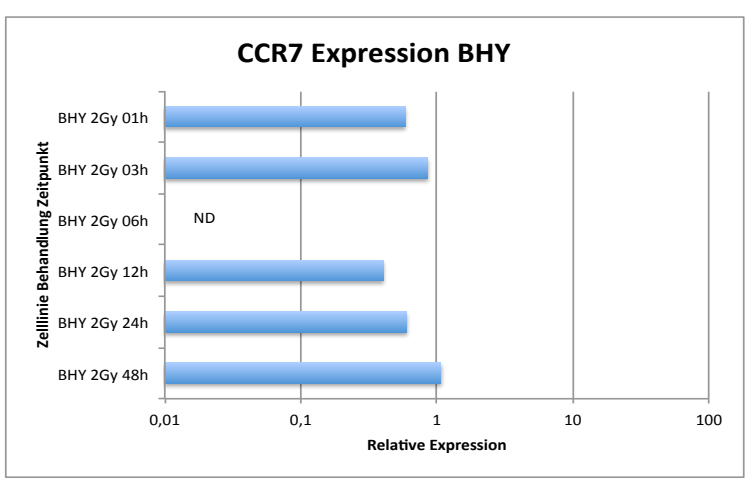

Abbildung 3.2.4.3: Relative Genexpression CCR7 der Zelllinie BHY 
Die Expression des Chemokinrezeptors CCR7 in der Zelllinine BHY wird nach Bestrahlung mit $2 \mathrm{~Gy}$ in Relation zur unbestrahlten Kontrolle herunterreguliert. Die strahleninduzierte Expression wird zum Zeitpunkt $12 \mathrm{~h}$ nach Bestrahlung signifikant gemindert. Die Genexpression zum Zeitpunkt $6 \mathrm{~h}$ nach Bestrahlung konnte nicht analysiert werden.

\subsubsection{Strahleninduzierte relative Genexpressionsänderungen des Chemokinrezeptors CCR7 in der Zelllinie ZMK1}

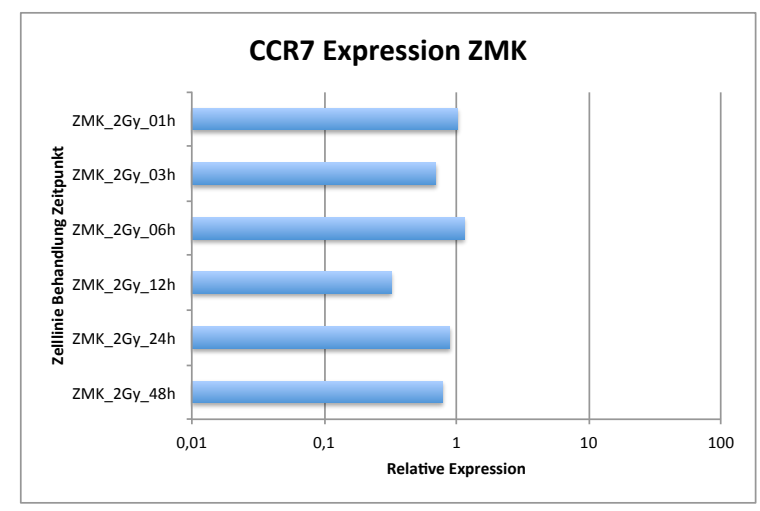

Abbildung 3.2.4.4: Relative Genexpression CCR7 der Zelllinie ZMK1

Die Tumorzellinie ZMK1 exprimiert den Rezeptor zu den Zeitpunkten $3 \mathrm{~h}, 12 \mathrm{~h}, 24 \mathrm{~h}$ und $48 \mathrm{~h}$ nach Bestrahlung mit $2 \mathrm{~Gy}$ in Relation zu der unbestrahlten Kontrolle vermindert. Die strahleninduzierte Expressionsminderung des Rezeptors CCR7 ist zum Zeitpunkt $12 \mathrm{~h}$ nach Bestrahlung signifikant. Die Genexpression wird in Relation zur Kontrolle zum Zeitpunkt 6 h gesteigert.

\subsubsection{Zeitlicher Verlauf der Genexpression des Chemokinrezeptors CXCR1 nach Bestrahlung}

Der Rezeptor CXCR1 wird nur von der Zelllinie HaCat exprimiert. Die Expression konnte zudem nur teilweise analysiert werden und ist in Relation zu der Kontrolle zu den Zeitpunkten $6 \mathrm{~h}$ und $12 \mathrm{~h}$ nach Bestrahlung signifikant herunterreguliert. 


\subsubsection{Strahleninduzierte relative Genexpressionsänderungen des} Chemokinrezeptor CXCR1 in der Zelllinie HaCat

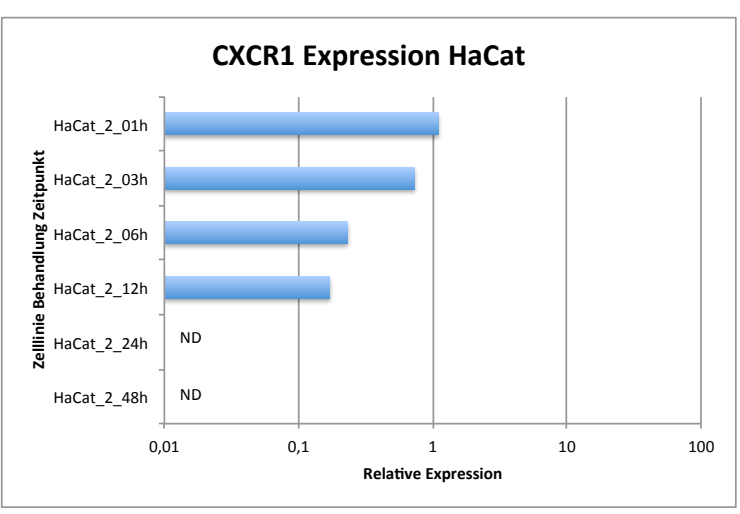

Abbildung 3.2.5.1: Relative Genexpression CXCR1 der Zelllinie HaCat

In der Zellinie HaCat nimmt die Genexpression des Rezeptors CXCR1 nach Bestrahlung der Zellen mit 2 Gy zu den Zeitpunkten 3 h, 6 h und 12 h kontinuierlich ab. In Relation zur unbestrahlten Kontrolle ist die Expression zu den Zeitpunkten $6 \mathrm{~h}$ und $12 \mathrm{~h}$ signifikant vermindert. Die Genexpression zu den Zeitpunkten $24 \mathrm{~h}$ und 48 $\mathrm{h}$ nach Bestrahlung konnte nicht analysiert werden.

\subsubsection{Zeitlicher Verlauf der Genexpression des Chemokinrezeptors CXCR4 nach Bestrahlung}

Der Chemokinrezeptor CXCR4 wird von den Tumorzelllinien BW225 (Abb. 3.2.8.1.1), FaDuDD (Abb. 3.2.6.1) und ZMK1 (Abb. 3.2.6.2) exprimiert. Die strahleninduzierte Expressionsänderung des Rezeptors CXCR4 in der Zelllinie FaDuDD zeigt nach Bestrahlung deutliche Schwankungen. So sind in der Zelllinie strahlenbedingte Steigerungen sowie strahleninduzierte Expressionsminderungen zu beobachten. Die Tumorzellinie ZMK1 zeigt eine eher gesteigerte strahleninduzierte Genexpression des CXCR4. Beide Zellinien exprimieren den Liganden (CXCL12) des Rezeptors CXCR4 nicht.

Die Zelllinie BW225 exprimiert den Rezeptor CXCR4 und den Chemokinliganden CXCL12. Die Expression des Rezeptors wurde nach Bestrahlung der Zellen mit 2 Gy in Relation zur unbestrahlten Kontrolle sowohl gemindert als auch gesteigert (Abb. 3.2.8.1.1). 


\subsubsection{Strahleninduzierte relative Genexpressionsänderungen des}

Chemokinrezeptor CXCR4 in der Zelllinie FaDuDD

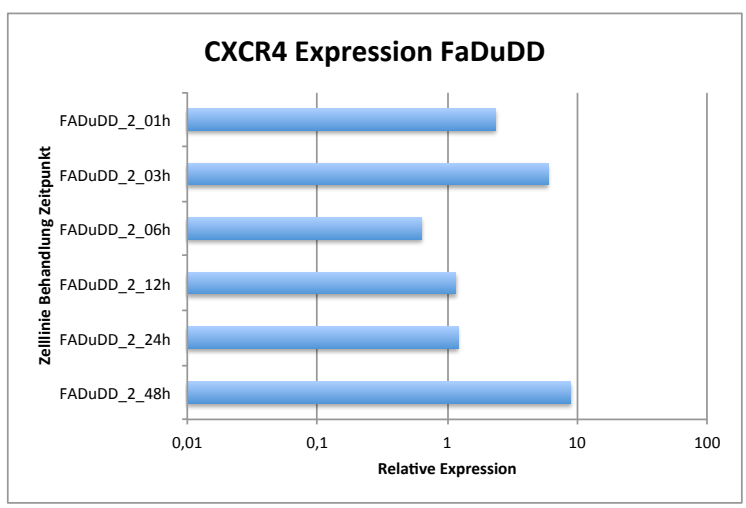

Abbildung 3.2.6.1: Relative Genexpression CXCR4 der Zelllinie FaDuDD

Die Expression des Rezeptors CXCR4 in der Tumorzelllinie FaDuDD wird zu den Zeitpunkten $1 \mathrm{~h}, 3 \mathrm{~h}$ und $48 \mathrm{~h}$ nach Bestrahlung mit 2 Gy in Relation zu der unbestrahlten Kontrolle signifikant gesteigert.

\subsubsection{Strahleninduzierte relative Genexpressionsänderungen des}

Chemokinrezeptor CXCR4 in der Zelllinie ZMK1

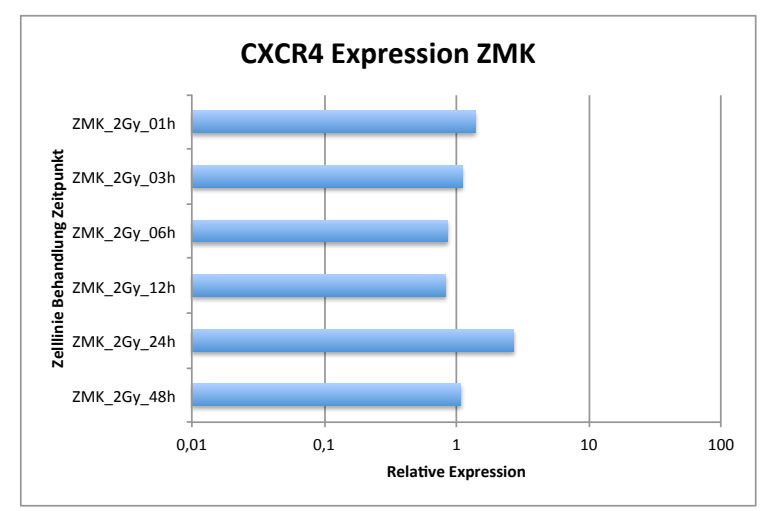

Abbildung 3.2.6.2: Relative Genexpression CXCR4 der Zelllinie ZMK1

Die Genexpression des Chemokinrezeptors CXCR4 in der Zelllinie ZMK1 wird nach Bestrahlung der Zellen mit 2 Gy in Relation zu der unbestrahlten Kontrolle zu den Zeitpunkten 1 h, 3 h, 24 h und 48 h nach Bestrahlung gesteigert, zu den Zeitpunkten 
$6 \mathrm{~h}$ und $12 \mathrm{~h}$ hingegen relativ vermindert. Zum Zeitpunkt $24 \mathrm{~h}$ nach Bestrahlung ist die strahleninduzierte Genexpression signifikant erhöht.

\subsubsection{Zeitlicher Verlauf der Genexpression des Chemokinliganden CXCL12 nach Bestrahlung}

Der Chemokinligand CXCL12 wird von den Tumorzelllinien BW225, GR145 I sowie der Normalgewebszelllinie DF19 exprimiert. In der Zelllinie GR145 I konnte die Expression nur zu einzelnen Zeitpunkten nachgewiesen werden. Die Cycle Threshold Werte lagen bei der Zelllinie GR145 I über 35, daher war eine gesicherte Analyse nicht möglich. Des Weiteren ist die strahleninduzierte Expression zu den unterschiedlichen Zeitpunkten variabel.

\subsubsection{Strahleninduzierte relative Genexpressionsänderungen des}

Chemokinliganden CXCL12 in der Zelllinie DF19

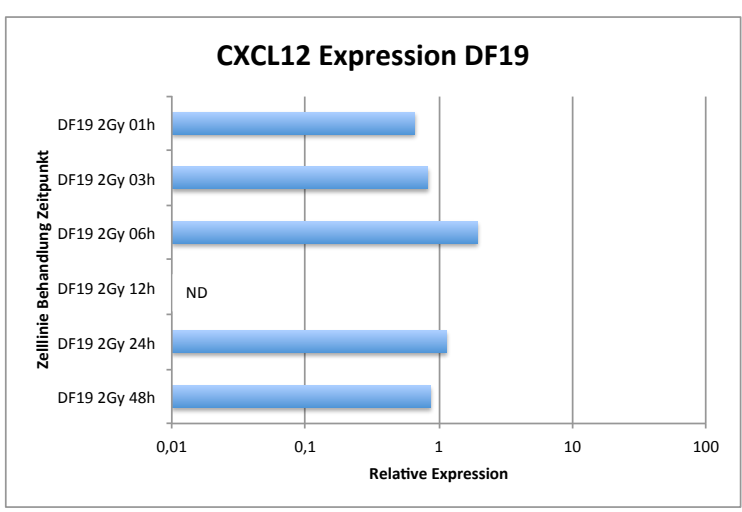

Abbildung 3.2.7.1: Relative Genexpression CXCL12 der Zelllinie DF19

Die strahleninduzierte Expression des Chemokinliganden CXCL12 in der Normalgewebszellinie DF19 zeigt nach Bestrahlung der Zellen mit 2 Gy keine signifikanten Änderungen. Die Genexpression wird zu den Zeitpunkten $1 \mathrm{~h}, 3 \mathrm{~h}$ und $48 \mathrm{~h}$ nach Bestrahlung in Relation zu der Kontrolle gemindert. Die Genexpression des Chemokins CXCL12 zum Zeitpunkt $12 \mathrm{~h}$ nach Bestrahlung konnte nicht analysiert werden. 


\subsubsection{Strahleninduzierte relative Genexpressionsänderungen des Chemokinliganden CXCL12 in der Zelllinie GR145 I}

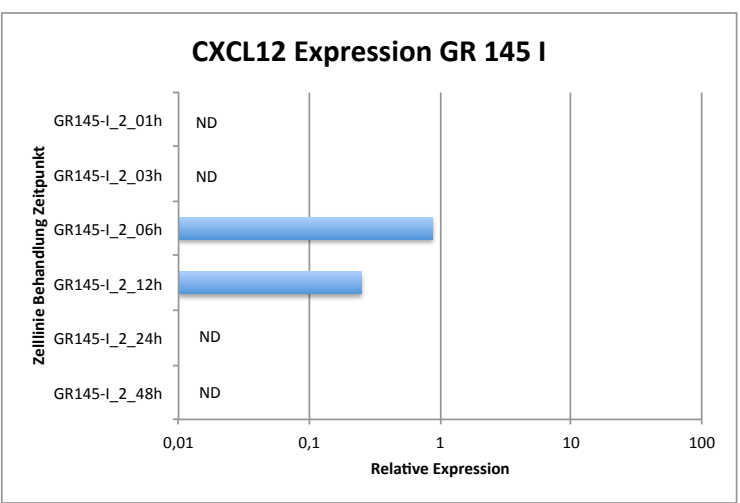

Abbildung 3.2.7.2: Relative Genexpression CXCL12 der Zelllinie GR145 I

Die Genexpression des Chemokinliganden CXCL12 in der Zelllinie GR145 I wird zu den Zeitpunkten $6 \mathrm{~h}$ und $12 \mathrm{~h}$ nach Bestrahlung der Zellen mit 2 Gy in Relation zu der Kontrolle herunterreguliert. Eine signifikante strahleninduzierte Expressionsminderung des Chemokinliganden zeigt sich $12 \mathrm{~h}$ nach Bestrahlung der Zellen mit 2 Gy. Die weiteren Zeitpunkte der Genexpression konnten in der Zelllinie nicht analysiert werden.

\subsubsection{Zeitlicher Verlauf der Genexpression des Rezeptor-Liganden-Paar CXCR4/CXCL12 nach Bestrahlung}

Das CXCR4/CXCL12-Rezeptor-Liganden-Paar wird nur von der Tumorzellinie BW225 exprimiert. Die relative Genexpression des Rezeptors CXCR4 und des entsprechenden Liganden CXCL12 zeigt in der Tumorzelllinie BW225 ein ähnliches strahleninduziertes Expressionsmuster, ist aber nicht identisch. 


\subsubsection{Strahleninduzierte relative Genexpressionsänderungen des Rezeptor-} Liganden-Paares CXCR4/CXCL12 in der Zelllinie BW225

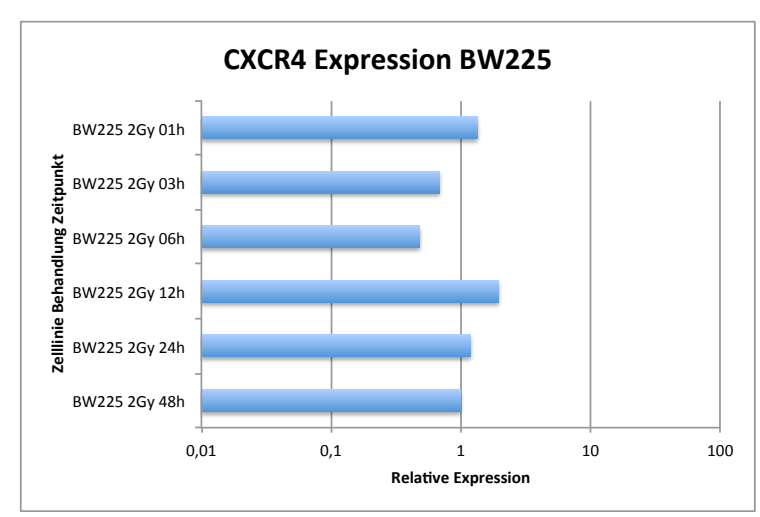

Abbildung 3.2.8.1.1: Relative Genexpression CXCR4 der Zelllinie BW225

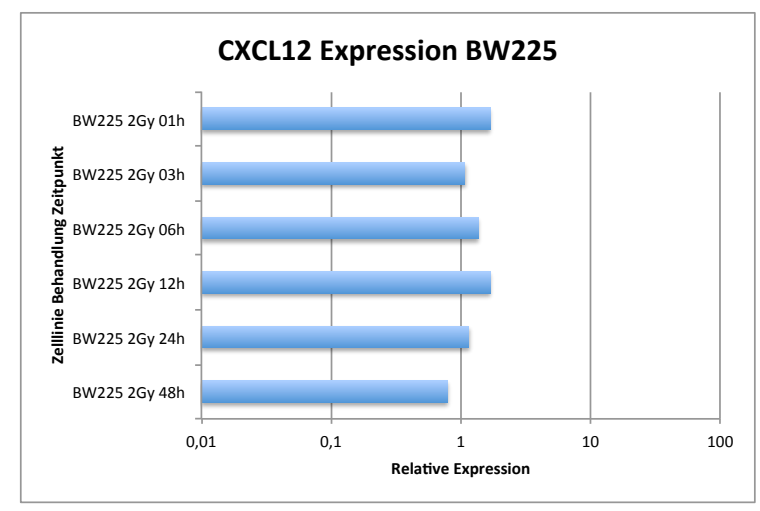

Abbildung 3.2.8.1.2: Relative Genexpression CXCL12 der Zelllinie BW225

Die strahleninduzierten Expressionen des Chemokinrezeptors CXCR4 und des Chemokinliganden CXCL12 zeigen in der Zelllinie BW225 ein ähnliches strahleninduziertes Expressionsmuster. Auffallend sind die strahleninduzierten Genexpressionssteigerungen des Rezeptor-Liganden-Paar zu den Zeitpunkten $1 \mathrm{~h}$, $12 \mathrm{~h}$ und $24 \mathrm{~h}$ nach Bestrahlung mit $2 \mathrm{~Gy}$ in Bezug zur unbestrahlten Kontrolle. Die Expression des CXC-Liganden 12 wurde $3 \mathrm{~h}, 6 \mathrm{~h}$ und $48 \mathrm{~h}$ nach Bestrahlung gemindert. Zum Zeitpunkt $6 \mathrm{~h}$ nach Bestrahlung wird die Expression des Rezeptors in Relation zur der unbestrahlten Kontrolle gemindert und die strahleninduzierte Expression des Liganden gesteigert. 


\subsection{Enzyme-Linked Immunosorbent Assay (ELISA)}

Um zu testen, ob das isolierte RNA-Transkript aus den untersuchten Zellen der verschiedenen Zelllinien in die Proteinexpression übersetzt wurde, wurden die Proteine der Chemokine CXCL1 und CXCL12 in den Zellkulturüberständen der untersuchten Zelllinien durch ELISA bestimmt. Die Abbildungen 3.5.1 und 3.5.2 zeigen, dass die Proteinexpression mit dem RNA-Transkript in den untersuchten Zelllinien übereinstimmt. Allerdings wurden keine signifikanten Unterschiede zwischen bestrahlten und nicht-bestrahlten Zellen detektiert.

\subsubsection{Proteinexpression des Chemokins CXCL1}

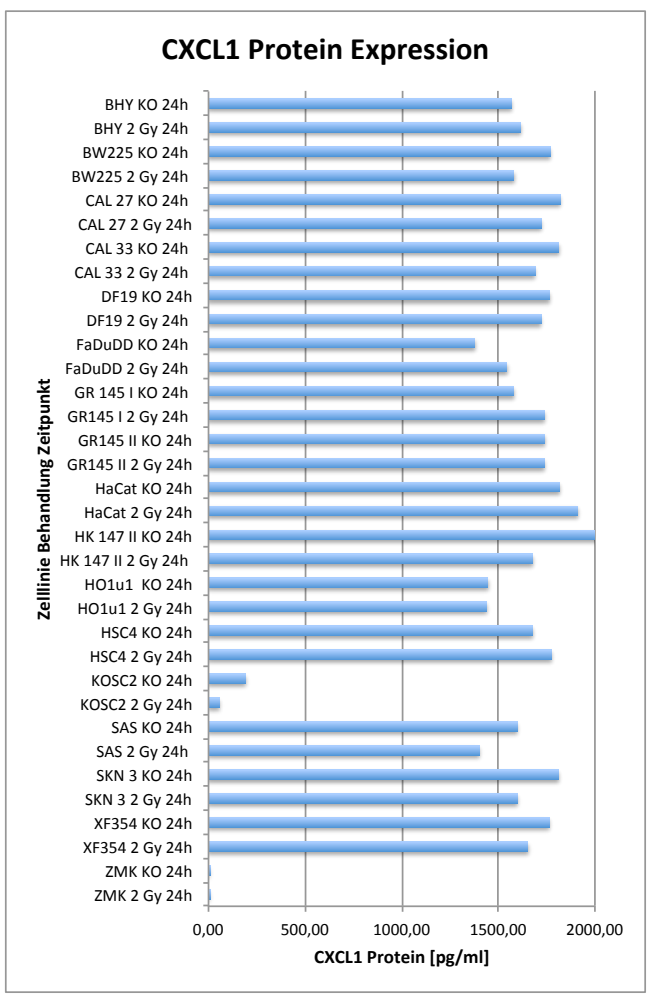

\section{Abbildung 3.3.1: Proteinexpression des Chemokins CXCL1 in den Zellüberständen aller untersuchten Zelllinien.}

Die Abbildung 3.3.1 zeigt die Proteinexpression des CXCL1 Chemokins in den untersuchten Zelllinien. Auf der Ordinate sind die verschiedenen Zelllinien zum Zeitpunkt Oh ohne Bestrahlung und $6 \mathrm{~h}$ nach Bestrahlung der Zellen mit 2 Gy 
aufgeführt. Die Abszisse stellt die Proteinexpression des Chemokins CXCL1 in pg/ml im Zellüberstand dar. Die Zellüberstände der verschiedenen Zelllinien wurden zu den angegebenen Zeitpunkten nach Bestrahlung und vor der Aufbereitung der Zellen für die RNA Asservierung entnommen. Die ermittelten Werte sind doppelt bestimmt worden. Der Chemokinligand CXCL1, der an den Rezeptor CXCR1 bindet, wurde insgesamt stark auf Proteinebene exprimiert und sezerniert. Alle Zelllinien, mit Ausnahme der Tumorzellinien ZMK1 und KOSC2, sezernieren den Liganden in sicher nachweisbaren Mengen. Zudem ist die Proteinexpression in den Zellüberständen mit dem RNA-Transkript der untersuchten Zelllinien vergleichbar.

\subsubsection{Proteinexpression des Chemokins CXCL12}

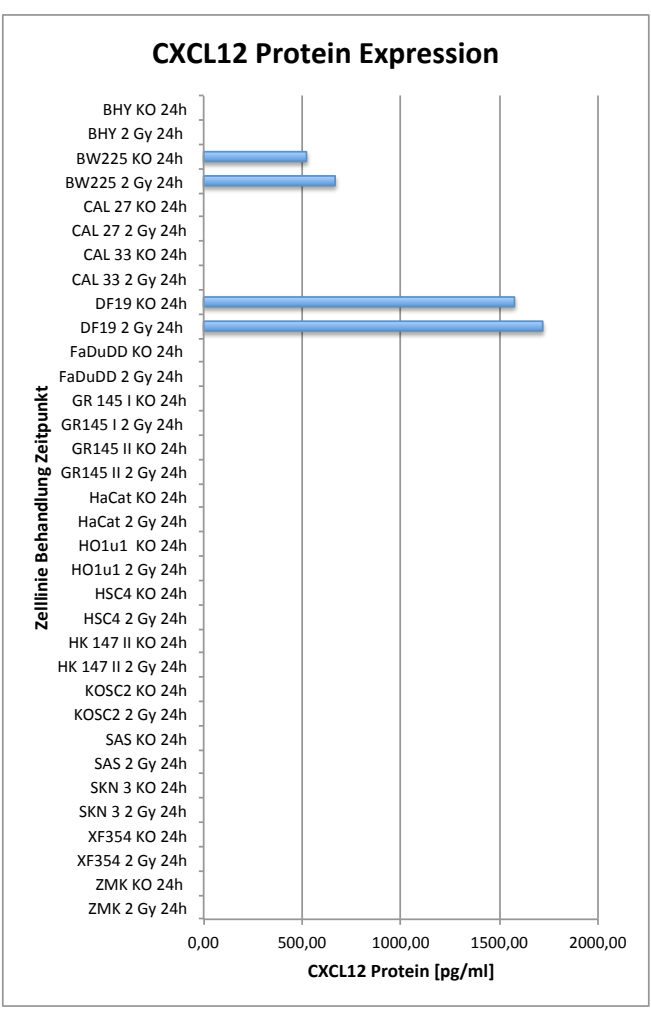

Abbildung 3.3.2: Proteinexpression des Chemokins CXCL12 in den Zellüberständen aller untersuchten Zelllinien

Die Abbildung 3.3.2 zeigt die Proteinexpression des CXCL12 Chemokins in den untersuchten Zelllinien. Auf der Ordinate sind die verschiedenen Zelllinien zum Zeitpunkt Oh ohne Bestrahlung und $6 \mathrm{~h}$ nach Bestrahlung der Zellen mit 2 Gy 
aufgeführt. Die Abszisse stellt die Proteinexpression des Chemokins CXCL12 in $\mathrm{pg} / \mathrm{ml}$ im Zellüberstand dar. Die Zellüberstände der verschiedenen Zelllinien wurden zu den angegebenen Zeitpunkten nach Bestrahlung und vor der Aufbereitung der Zellen für die RNA Asservierung entnommen. Die ermittelten Werte sind doppelt bestimmt worden. Der Chemokinligand CXCL12, der an den Rezeptor CXCR4 bindet, wird nur in den Zellüberständen der Zelllinien DF19 und den BW225 nachgewiesen. Die Proteinexpression in den Zellüberständen der Zelllinie BW225 ist schwächer ausgeprägt als in der Normalgewebszellinie DF19.

\subsection{Dosis-Effekt Kurven}

Das Überleben der Zellen nach Bestrahlung wurde mittels eines standardisierten Koloniebildungstests ermittelt. Es wurde daher die Koloniebildungsfähigkeit der Zellen der untersuchen Zellinien nach unterschiedlichen Strahlendosen bewertet. Der Koloniebildungstest ist ein Maß für die intrinsische Strahlensensitivität und misst das klonogene Zellüberleben bzw. das Langzeitüberleben der untersuchten Zellen nach Strahleneinwirkung. Der Koloniebildungstest hat somit eine starke Aussagekraft über das Wachstum der Zellen in vivo unter den in der Analyse gegebenen Bedingungen. Die Strahlendosen wurden gegen das Gesamtüberleben der Kolonien in den folgenden Abbildungen dargestellt. Auf der Abszisse der Abbildungen ist die zunehmende Dosis in Gray linear dargestellt, auf der Ordinate wird das relative Überleben bezogen auf die auf 1 normierte und nicht bestrahlte Kontrolle logarithmisch aufgetragen. Die unbestrahlten Kontrollproben entsprechen daher definitionsgemäß einer Überlebensrate von $100 \%$ der Zellen. Es ist zu erkennen, dass die für die Expressionsanalysen benutzten Strahlendosen von $2 \mathrm{~Gy}$ zwar einen deutlichen Effekt auf das Überleben von Zellen haben, aber keinesfalls letal für die Zellen sind. Die Zellen der Zelllinie BHY konnten trotz mehrfachen Kultivierens nicht dem Koloniebildungstest unterzogen werden. 


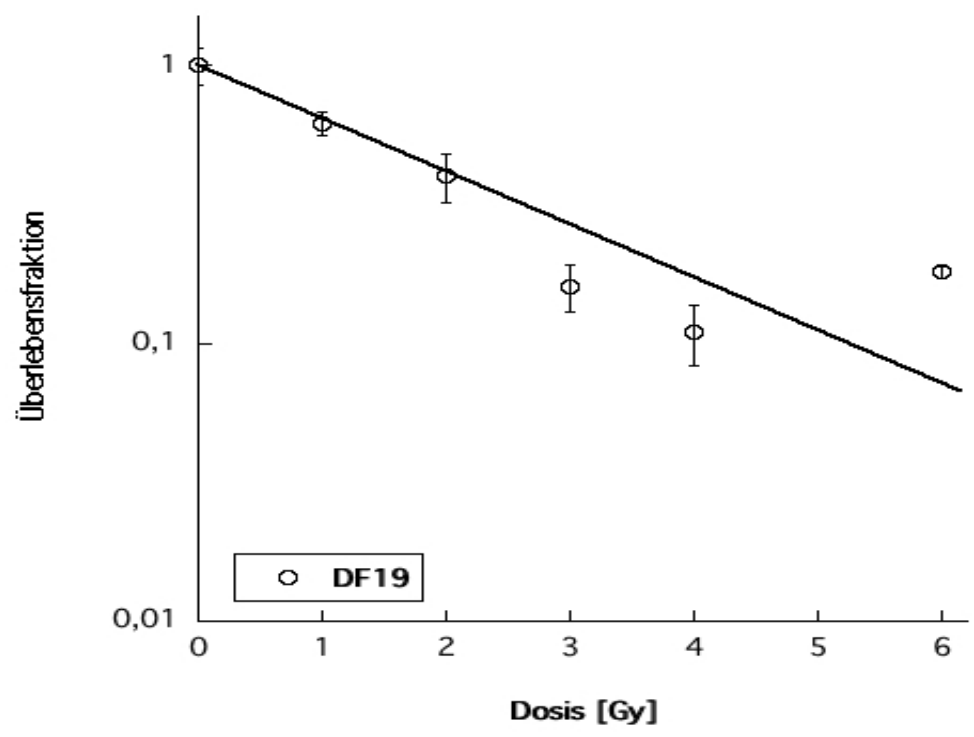

Abbildung 3.4.1: Zellüberleben der Normalgewebszelllinie DF19 nach Bestrahlung

Die Abbildung 3.4.1. zeigt die Dosis-Effekt-Kurve der Normalgewebszellinie DF19. Die Zellen der Normalgewebszelllinie DF19 reagieren auf die Steigerung der Bestrahlungsintensität. Nach Bestrahlung der Zellpopulation mit 2 Gy hatten sich die Kolonien im Mittel auf 39,42\% des Ausgangswerts vermindert. Nach Bestrahlung mit 3 Gy waren es 16,02\% und nach 6 Gy nur noch 1,76\% des Ausgangswerts der Koloniebildungen. 


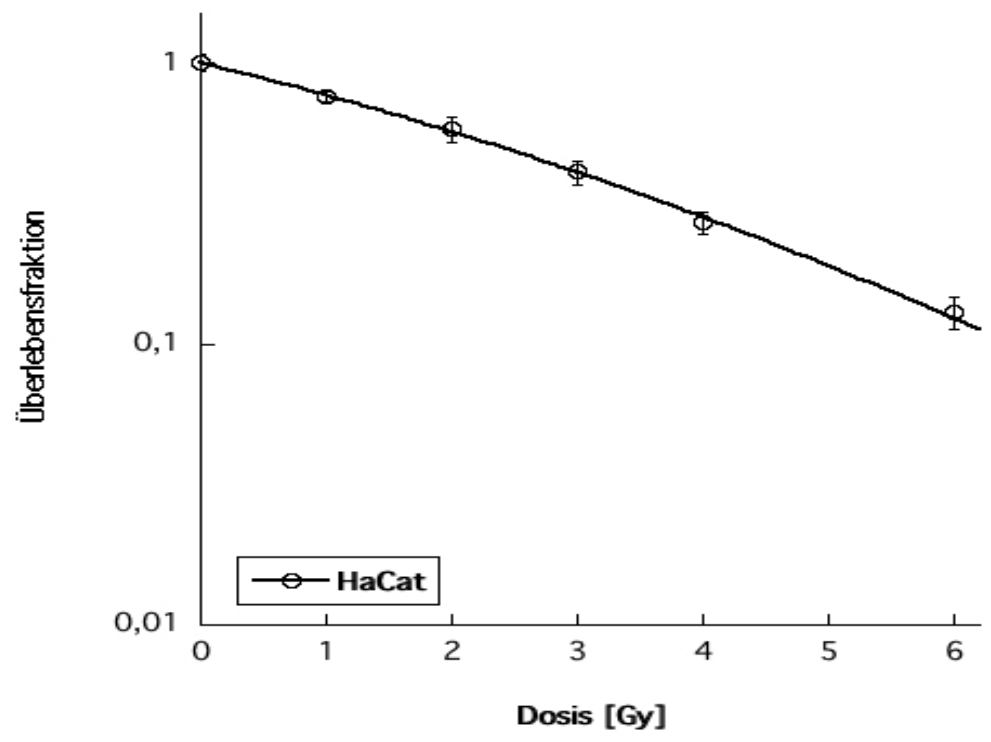

\section{Abbildung 3.4.2: Zellüberleben der Normalgewebszelllinie HaCat nach Bestrahlung}

Die Abbildung 3.4.2 zeigt die Dosis-Effekt-Kurve der Normalgewebszellinie HaCat. Die Zellen der Normalgewebszellinie HaCat sprechen weniger stark auf die Steigerung der Bestrahlungsintensität an. Nach Bestrahlung der Zellpopulation mit 2 Gy hatten sich die Kolonien im Mittel auf 58,15\% des Ausgangswerts der Kontrolle ohne Bestrahlung vermindert. Nach Bestrahlung mit 3 Gy waren es noch $41,04 \%$ und nach 6 Gy nur noch 13,25\% des Ausgangswerts der Koloniebildungen. 


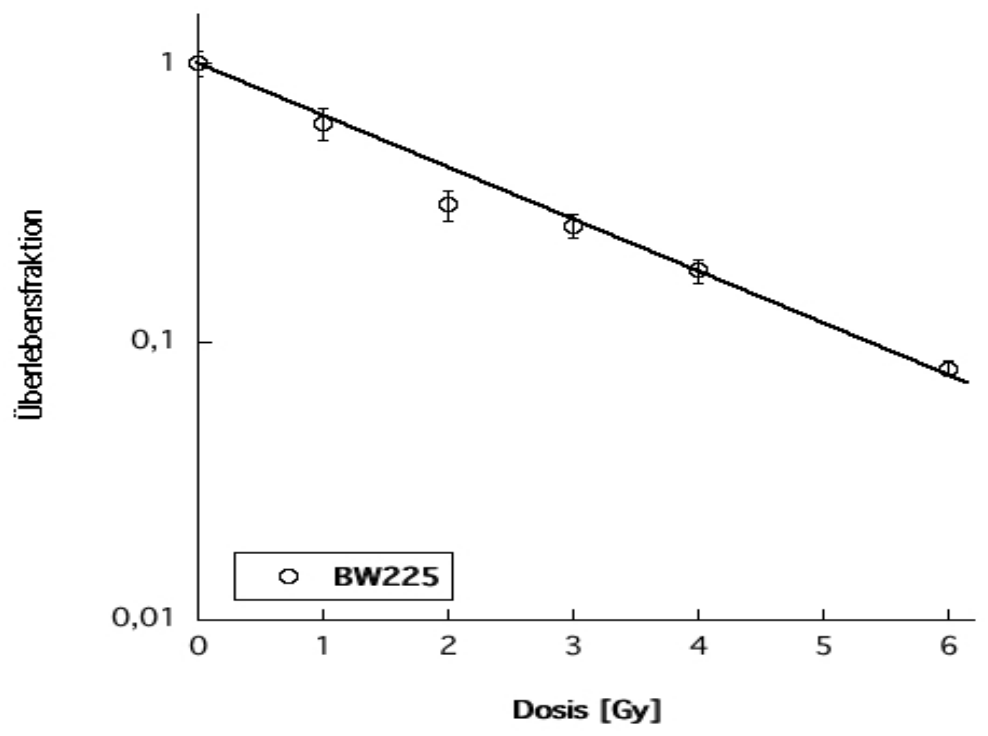

Abbildung 3.4.3: Zellüberleben von der Tumorzelllinie BW225 nach Bestrahlung

Die Abbildung 3.4.3 zeigt die Dosis-Effekt-Kurve der Zellen der Tumorzellinie BW225. Die Zellen der Tumorgewebszelllinie BW225 zeigen in allen Dosisbereichen eine starke Minderung der Koloniebildungen nach Bestrahlung. Nach Bestrahlung der Zellpopulation mit 2 Gy hatten sich die Kolonien im Mittel auf 31,33\% des Ausgangswerts der Kontrolle ohne Bestrahlung vermindert. Nach Bestrahlung mit 3 Gy waren es noch 25\%. Nach der Bestrahlung der Tumorzellen mit 6 Gy haben sich nur noch 7,53\% der Kolonien im Vergleich zum Ausgangswert gebildet. 


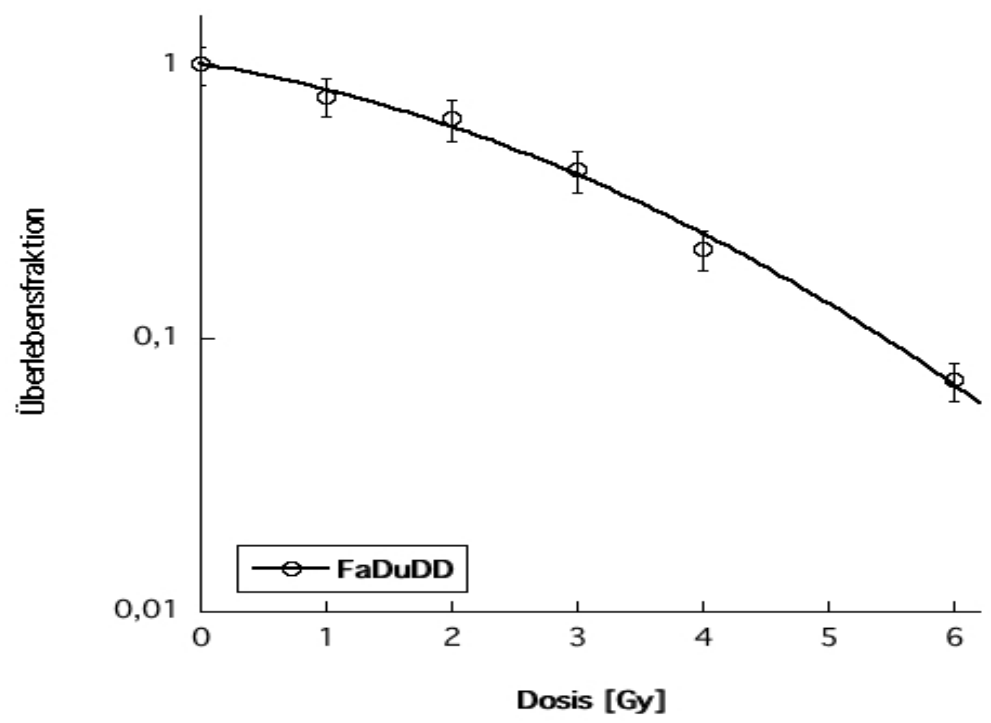

\section{Abbildung 3.4.4: Zellüberleben von der Tumorzellinie FaDuDD nach Bestrahlung}

Die Abbildung 3.4.4 zeigt die Dosis-Effekt-Kurve der Zellen der Tumorzellinie FaDuDD. Die Zellen der Tumorgewebszelllinie FaDuDD zeigen ein weniger empfindliches Ansprechen auf die Steigerung der Bestrahlungsintensität. Nach Bestrahlung der Zellpopulation mit 2 Gy hatten sich die Kolonien im Mittelauf 62,69\% des Ausgangswerts der Kontrolle ohne Bestrahlung vermindert. Nach Bestrahlung mit 3 Gy waren es noch 41,19\%. Nach der Bestrahlung der Tumorzellen mit 6 Gy haben sich nur noch $7,00 \%$ der Kolonien im Vergleich zum Ausgangswert gebildet. 


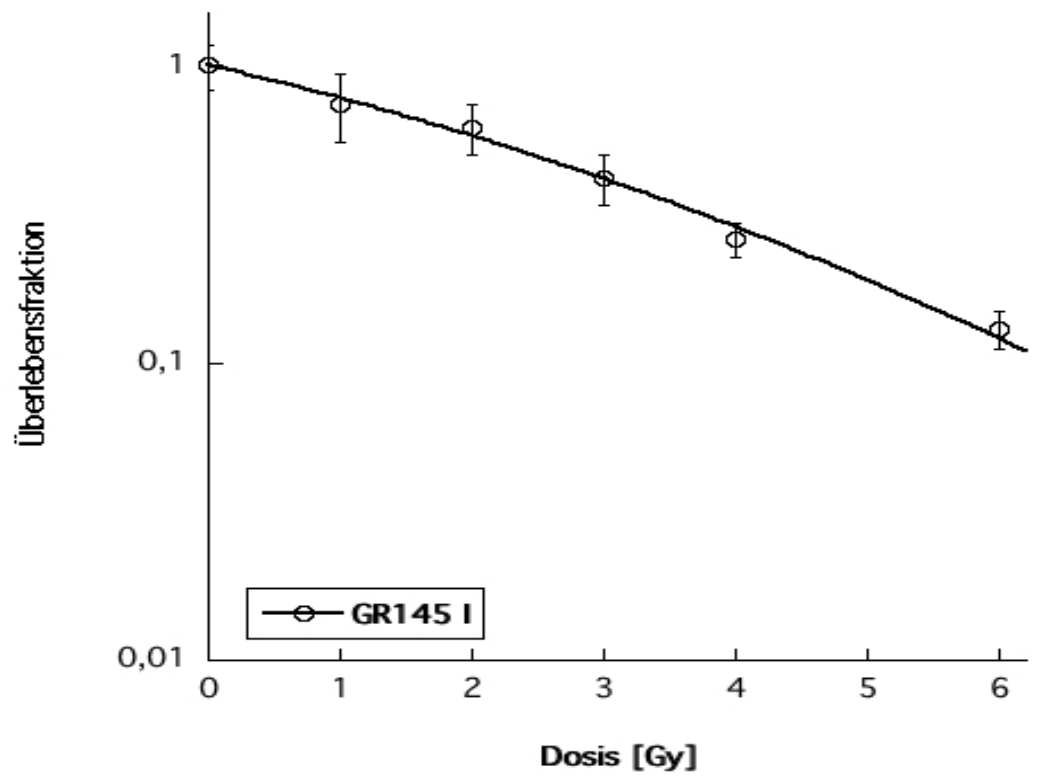

Abbildung 3.4.5: Zellüberleben von der Tumorzellinie GR145 I nach
Bestrahlung

Die Abbildung 3.4.5 zeigt die Dosis-Effekt-Kurve der Zellen der Tumorgewebszelllinie GR145 I. Die Zellen der Tumorgewebszelllinie GR145 I zeigen ein vergleichbares Ansprechen mit den anderen Tumorzellinien auf die Steigerung der Bestrahlungsintensität. Nach Bestrahlung der Zellpopulation mit 2 Gy hatten sich die Kolonien im Mittel auf $61,66 \%$ des Ausgangswerts der Kontrolle ohne Bestrahlung vermindert. Nach Bestrahlung mit 3 Gy sank der Wert auf 41,53\%. Nach der Bestrahlung der Tumorzellen mit 6 Gy haben sich 13,15\% der Kolonien im Vergleich zum Ausgangswert gebildet. 


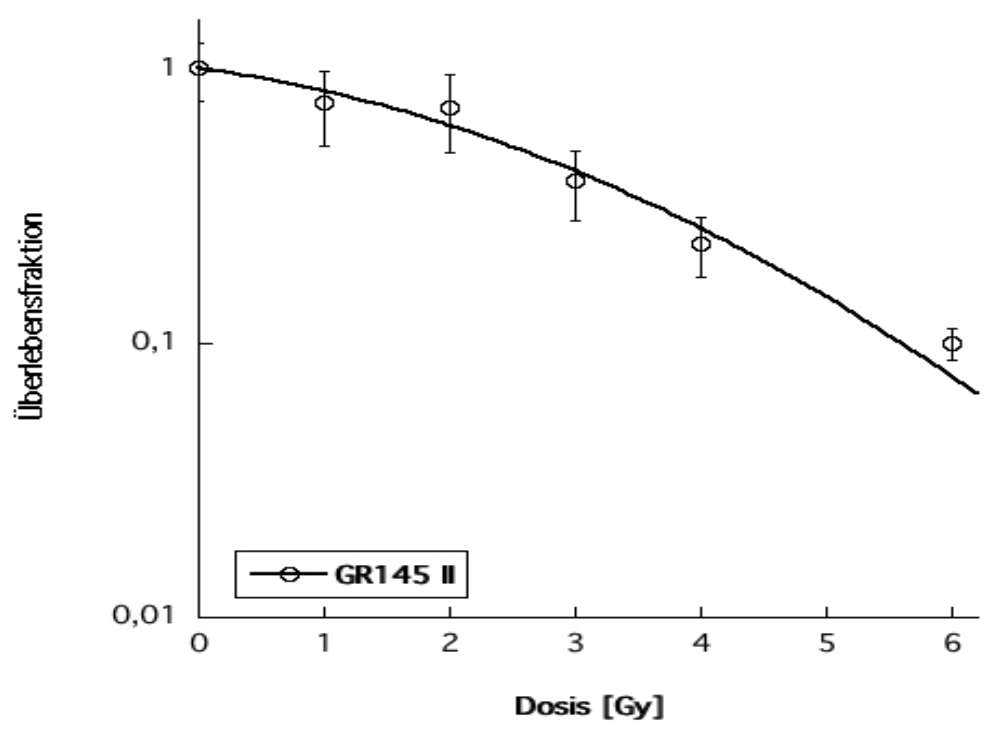

Abbildung 3.4.6: Zellüberleben von der Tumorzelllinie GR145 II nach Bestrahlung

Die Abbildung 3.4.6 zeigt die Dosis-Effekt-Kurve der Zellen der Tumorgewebszelllinie GR145 II. Die Zellen der Tumorgewebszelllinie GR145 II zeigen ein der Zelllinie GR 145 I vergleichbares Ansprechen auf die Steigerung der Bestrahlungsintensität. Nach Bestrahlung der Zellpopulation mit 2 Gy hatten sich die Kolonien im Mittel auf $63,68 \%$ des Ausgangswerts der Kontrolle ohne Bestrahlung vermindert. Nach Bestrahlung mit 3 Gy waren es nur noch 38,95 \% und nach 6 Gy nur noch 10,12\% des Ausgangswerts der Koloniebildungen. 


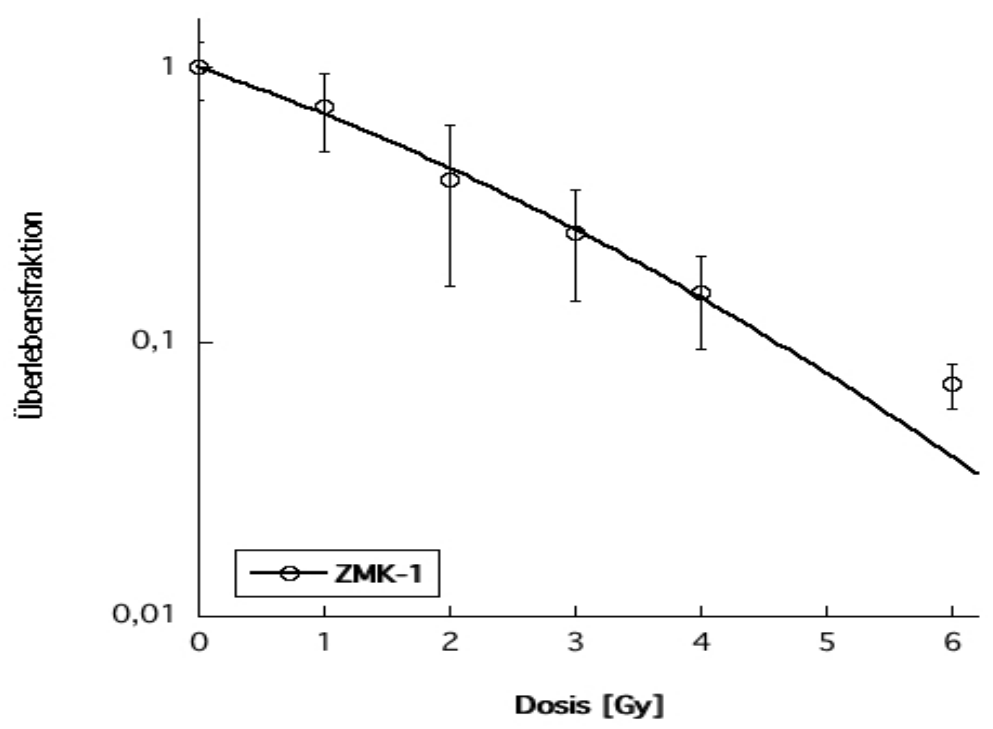

Abbildung 3.4.7: Relatives Zellüberleben von der Tumorzelllinie ZMK1 nach Bestrahlung

Die Abbildung 3.4.7 zeigt die Dosis-Effekt-Kurve der Zellen der Tumorzelllinie ZMK1. Die Zellen der Tumorgewebszellinie ZMK1 zeigen in allen Dosisbereichen eine starke Minderung der Koloniebildungen nach Bestrahlung. Nach Bestrahlung der Zellpopulation mit 2 Gy hatten sich die Kolonien im Mittel auf 41,59\% des Ausgangswerts der Kontrolle ohne Bestrahlung vermindert. Nach Bestrahlung mit 3 Gy waren es noch $32,37 \%$ des Ausgangswerts. Nach der Bestrahlung der Tumorzellen mit 6 Gy haben sich nur noch 10,46\% Kolonien im Vergleich zum Ausgangswert gebildet. 


\section{Diskussion}

Der Einfluss von Chemokinen und ihrer Signalwege über Chemokinrezeptoren hinsichtlich des Wachstums, der Ausbreitung und des Ansprechens von Kopf-HalsKarzinomen auf eine Radiochemotherapie ist noch nicht hinreichend untersucht. Die genauere Kenntnis der Chemokin- oder Chemokinrezeptorexpression in Kopf-HalsKarzinomzelllinien könnte daher einen Beitrag zum besseren Verständnis der oben genannten Parameter leisten.

Ziel der vorliegenden Arbeit war deshalb die Analyse der Expression von Chemokinen und Chemokinrezeptoren in 15 Kopf-Hals-Karzinomzelllinien. Vergleichend zu den Tumorzelllinien wurden zudem zwei Normalgewebszellinien untersucht. Insgesamt wurde die Genexpression der Chemokine CCL2, CCL3, CCL5, CCL20, CXCL1, CXCL2, CXCL3, CXCL9, CXCL10, CXC11, CXCL12 und der Rezeptoren CCR1, CCR3, CCR6, CCR7, CXCR1 und CXCR4 analysiert. Diese Genexpression wurde vor und nach Bestrahlung der Zellen mit 2 Gy ausgewertet und zueinander in Relation gesetzt. Die Zellen der Tumorzellinien entstammen Plattenepithelkarzinomen im Kopf-Hals-Bereich. Eine Ausnahme sind die Zellen der Tumorzellinie XF354, die einer Lymphknotenmetastase eines oralen Plattenepithelkarzinoms entnommen wurden. Die Bestrahlung der Zelllinien erfolgte immer mit der klinischen Einzeldosis von $2 \mathrm{~Gy}$, da die Bestrahlung in diesem therapeutischen Dosisbereich eine wirksame Reaktion der Zelllinien induzieren kann (Demaria und Formenti 2007). Dieses wurde in der vorliegenden Arbeit durch klonogene Tests bestätigt.

In einer ersten Analyse von insgesamt 11 Chemokinen und 6 Chemokinrezeptoren war zu beobachten, dass die Expression der Chemokine in den untersuchten Zelllinien verbreiteter ist als die Expression der untersuchten Chemokinrezeptoren. Auch war die Expression im Vergleich zu den untersuchten Housekeepinggenen (HPRT, TBP, TUBB) bei den Chemokinliganden stärker als bei den Chemokinrezeptoren. Des Weiteren fiel auf, dass es zum Zeitpunkt $6 \mathrm{~h}$ nach der Bestrahlung zu Expressionsänderungen der untersuchten Chemokine und 
Chemokinrezeptoren kommt. Dabei wurden für alle Chemokine sowohl Expressionssteigerungen als auch Expressionsminderungen beobachtet. Kein Chemokin wies in allen exprimierenden Zellen eine gleichsinnige Expressionsänderung nach Bestrahlung auf. Allerdings wurde die Expression der CC-Chemokinliganden (CCL2, CCL3, CCL5, CCL20) und die häufig co-exprimierten CXC-Liganden 1 und 2 (Accharyya et al. 2012) durch die Bestrahlung vorwiegend gemindert (18 signifikante Minderungen verglichen mit 6 Steigerungen). Bei den als homologe Gruppe beschriebenen CXC-Liganden 9, 10 und 11 (Zlotnik et al. 2000) waren 6 Stunden nach der Bestrahlung sechs gesteigerte Expressionen im Vergleich zu nur drei verminderten Expressionen sichtbar. Das vieluntersuchte Chemokin CXCL12 zeigte in den Tumorzellinien 6 Stunden nach Bestrahlung mit 2 Gy allerdings eine verminderte Expression. Bei den untersuchten Normalgewebszellen DF-19 und HaCat zeigten sich insgesamt weniger Expressionsveränderungen als bei den Tumorzellinien. Diese stellten sich dann allerdings überwiegend als Expressionssteigerungen dar. Die Chemokinrezeptoren wurden insgesamt weniger häufig, in geringerer Stärke und hauptsächlich von den Tumorzelllinien exprimiert. Auch hier kam es 6 Stunden nach der Bestrahlung mit 2 Gy überwiegend zu Expressionsminderungen. Signifikante Steigerungen nach der Bestrahlung wurden nur einmal für CCR7 und einmal für CXCR1 beobachtet. Letztgenannte Rezeptoren waren auch die Einzigen, die in den Normalgewebszellen nachgewiesen wurden. Die Expression der beiden Rezeptoren wurde allerdings in den Normalgewebszelllinien durch die Bestrahlung mit 2 Gy nicht verändert.

Im Anschluss an die erste Analyse wurde die Genexpression erneut an einer Auswahl von Zelllinien und Chemokinen sowie Chemokinrezeptoren untersucht. In dieser zweiten Analyse lag der Schwerpunkt auf der Expressionskinetik nach der Bestrahlung. Hierfür wurden die Chemokine und deren Rezeptoren ausgewählt, die in der ersten Analyse stark exprimiert waren oder die in der Literatur bereits genauer beschrieben wurden. Die erneute Analyse der strahleninduzierten Genexpression umfasste die Chemokine CXCL1, CXCL2, CXCL3, CCL20, CXCL12 sowie die Chemokinrezeptoren CCR7, CCR6, CXCR1 und CXCR4. Die Analysen wurden an den Normalgewebszelllinien DF19 und HaCat sowie den Kopf-HalsKarzinomzellinien BHY, BW225, GR145 I, GR145 II, FaDuDD und ZMK1 durchgeführt. 
Dafür wurde in dieser erneuten Analyse der zeitliche Verlauf der strahleninduzierten Genexpressionsänderung in Relation zu der unbestrahlten Kontrolle gesetzt.

Es bestätigten sich hier zunächst die Ergebnisse der ersten Analyse, da die strahleninduzierte Expressionskinetik der Chemokine und Chemokinrezeptoren zum Zeitpunkt 6 Stunden nach der Bestrahlung mit den Ergebnissen der ersten Analyse vergleichbar waren. Allerdings muss hier auch erwähnt werden, dass die Werte nicht absolut identisch waren. Zudem ist der zeitliche Verlauf der strahleninduzierten Expressionsänderungen der Chemokine und Chemokinrezeptoren nicht immer gleichsinnig, wenn die unterschiedlichen Zelllinien verglichen werden. Hier zeigten sich vereinzelt Abweichungen der Genexpression.

So kommt es in der ersten Analyse zum Zeitpunkt 6 Stunden nach Bestrahlung größtenteils zu einer strahleninduzierten Expressionsminderungen der CXCLiganden 1, 2 und 3. In der anschließenden Analyse des zeitlichen Verlaufs der Expression nach der Bestrahlung ist in 4 Zelllinien zwar ebenfalls eine Genexpressionsminderung zu beobachten, allerdings ist in zwei Zelllinien die Expression nach Bestrahlung gesteigert.

Für den Chemokinliganden CCL20 lässt sich ebenfalls eine Differenz zwischen der Expression zum Zeitpunkt 6 Stunden nach der Bestrahlung und der anderen Zeitpunkte feststellen. Bei insgesamt sechs Zelllinien liegt hier eine strahleninduzierte Steigerung der Expression im zeitlichen Verlauf vor, obwohl in der ersten Analyse zum Zeitpunkt 6 Stunden nach der Bestrahlung eine Minderung der Genexpression zu beobachten ist. Ebenso ist bei dem CC-Rezeptor 6 eine strahleninduzierte Minderung der Expression in der Zelllinie GR145 I zu beobachten, wobei die Zelllinie $\mathrm{BHY}$ eine Expressionssteigerung im zeitlichen Verlauf zeigt. Zudem ist die Abweichung des CXCR4/CXCL12-Rezeptor-Liganden-Paar, welches nur von der Tumorzelllinie BW225 exprimiert wird, zu erwähnen. Hier wird zum Zeitpunkt 6 Stunden nach der Bestrahlung die Expression des Liganden gesteigert und die des Rezeptors gemindert. Es gibt also durchaus Divergenzen in der Genexpression zum Zeitpunkt 6 Stunden nach Bestrahlung und dem weiteren zeitlichen Verlauf nach der Bestrahlung. Die strahleninduzierten Expressionsänderungen lassen sich im zeitlichen Verlauf also nicht komplett übereinstimmend aus den Werten zum Zeitpunkt 6 Stunden nach Bestrahlung ableiten. 
Allerdings konnten die Ergebnisse der Einzeitanalyse bestätigt werden, und es besteht zwischen den beiden unabhängigen Versuchsreihen eine gute Übereinstimmung der Ergebnisse zum Zeitpunkt $6 \mathrm{~h}$ nach Bestrahlung. Aufgrund der hohen Deckungsgleichheit in den beiden Analysen zum Zeitpunkt 6 Stunden nach Bestrahlung und der meist gleichsinnigen strahleninduzierten Expressionsänderung im zeitlichen Verlauf, kann der Zeitpunkt 6 Stunden nach Bestrahlung also gut zur Analyse der Expression von Chemokinen und deren Rezeptoren genutzt werden.

Die Ergebnisse der gemessenen Genexpression wurden ebenso auf Proteinebene für die Chemokine CXCL1 und CXCL12 untersucht. Die Proteinexpression der Chemokine entspricht im Wesentlichen dem mRNA Transkript. Allerdings wurden auf Proteinebene keine signifikanten strahleninduzierten Expressionsänderungen nachgewiesen.

Die Ergebnisse der untersuchten Chemokine und ihrer Rezeptoren in der vorliegenden Arbeit lassen sich hinsichtlich ihrer möglichen klinischer Relevanz wie folgt einordnen.

Der Chemokinligand CCL2 wurde in der alle Zelllinien umfassenden Analyse von den Normalgewebszelllinien und einigen Tumor-Zelllinien exprimiert. Die beiden Normalgewebszelllinien DF19 und HaCat sowie die Karzinomzellinie BW225 exprimieren den Chemokinliganden CCL2 in Relation zu den Housekeeping Genen verstärkt. Andere Tumorzellen exprimieren den Chemokinliganden hingegen vermindert. Die Chemokinexpression wurde nach der Bestrahlung eher herunter reguliert. Bei Kopf-Hals-Karzinomen, Mamma-Karzinomen und auch Prostatakarzinomen wurde die Expression und Sekretion des Chemokins CCL2 sowie die damit verbundene Tumorausbreitung und Metastasierung bereits beschrieben (Ben-Baruch et al. 2006; Buettner et al. 2007; Marcus et al. 2004; Loberg et al. 2007). Hohe Expression des Chemokins CCL2 ging zudem in der Studie von Ferreira et al. 2008 mit einem verminderten Gesamtüberleben von Patientin mit Kopf-Hals-Karzinomen einher. Des Weiteren beeinflusst die zielgerichtete Therapie von Prostatakarzinomen mit CCL2-Antikörpern das Wachstum und die Ausbreitung dieser Tumoren (Loberg et al. 2007). Die Expression von CCL2 könnte daher therapeutisch genutzt werden oder ein sinnvoller Parameter für das Ansprechen einer Therapie von Kopf-Hals-Karzinomen bzw. dessen Verlauf sein. 
Das Chemokin CCL3 wurde in der alle Zelllinien umfassenden Analyse alleinig von der Tumorzellinie BHY und in Relation zu den Housekeeping Genen insgesamt nur gering exprimiert. Die Expression des Chemokins wurde allerdings nach der Bestrahlung der Zellen mit 2 Gy signifikant gesteigert. Die Expression des Chemokinliganden CCL3 steht in Verbindung mit der gerichteten Ausbreitung von Tumorzellen in Lymphknoten oder anderer Organe. Des Weiteren sind inflammatorische Prozesse über die Expression von CCL3 gesteuert (Nath et al. 2006; Wu et al. 2008). Die Ergebnisse der Arbeit von Silva et al. 2007 lassen den Schluss zu, dass sowohl die Ausbreitung als auch die lokale Immunabwehr gegen Tumorzellen über CCL3 reguliert wird.

In der ersten Analyse zeigte sich, dass alle Zellinien den Chemokinliganden CCL20 exprimieren. Nach Bestrahlung der Zellen mit 2 Gy herrschte bei den meisten Zelllinien eine Herunterregulierung der Genexpression vor. Bei der anschließenden Analyse des zeitlichen Verlaufs nach der Bestrahlung wurde die Genexpression des Chemokins CCL20 wiederholt in allen untersuchten Zelllinien detektiert. Hier lagen allerdings sowohl Expressionssteigerungen als auch -minderungen nach der Bestrahlung in den untersuchten Zelllinien vor. Die Expression des Chemokins CCL20 in malignen Tumoren ist wiederholt beschrieben worden (Abiko et al. 2003; Buettner et al. 2007; Chang et al. 2008; Ferreira et al. 2008; Michiels et al. 2009). Das Chemokin CCL20 hat bei der Immunantwort sowie bei der Metastasierung und Entstehung von Tumoren eine besondere Bedeutung (Kleef et al. 1999). Gesteigertes Vorkommen des Chemokinliganden CCL20 steht auch im Zusammenhang mit dem Wachstum von oralen Plattenepithelkarzinomen (Abiko et al. 2003). Hohe Expression von CCL20 korreliert zudem mit einer schlechten Prognose bei Patienten mit Leberzellkarzinomen, da eine hohe CCL20 Expression mit einer größeren Tumormasse und Ausbreitung einhergeht (Yamauchi et al. 2003). In der Arbeit von Chang et al. 2008 zeigte sich bei Nasopharynxkarzinomen eine Korrelation von hoher CCL20 Expression und einem geringeren Überleben von Patienten im Gegensatz zur Kontrollgruppe. Eine erhöhte CCL20 Expression korreliert zudem mit einem posttherapeutischen Rezidiv eines Leberzellkarzinoms (Ding et al. 2012). Auch in Pankreaskarzinomzellen ist die CCL20 Expression gegenüber normalen Pankreaszellen deutlich erhöht (Kleef et al. 1999). Allerdings ist das Ansprechen der CCL20 Expression auf eine Radiotherapie widersprüchlich und müsste weiter untersucht werden. So könnte die gesteigerte CCL20 Expression auch 
mit einer Immunantwort in Verbindung stehen (Ben-Baruch 2006; Chen et al. 2010). Der Chemokinligand könnte daher auch eine klinische Bedeutung als Marker von malignen Tumorerkrankungen im Verlauf der Therapie und der Prognose sowie für das Überleben nach der Therapie haben.

Weiter wird eine Expressionssteigerung des Chemokins CCL20 und dessen Rezeptor CCR6 nach Chemotherapie bei Patienten mit kolorektalen Karzinomen festgestellt. Diese Expressionssteigerung wird in Zusammenhang mit Metastasierung durch die erhöhte Proliferation der Tumorzellen gestellt (Chen et al. 2010; Ghadjar et al. 2009). Daher könnte eher eine strahleninduzierte Herunterregulierung der Genexpression des Chemokins mit einem Tumorreduktion und einer niedrigeren Rezidivrate in Verbindung stehen.

Die Expression des Chemokinliganden CCL5, welche ebenso mit inflammatorischen Prozessen (Buettner et al. 2007; Ben-Baruch 2006) sowie dem Wachstum und der Metastasierung bei Oral-, Ovarial- und Mammakarzinomzellen in Zusammenhang steht (Chuang et al. 2009: Egunsola et al. 2012; Soria et al. 2009), konnte im Großteil der untersuchten Zelllinien detektiert werden. Nach Bestrahlung der Zellen mit 2 Gy zeigte sich bei den meisten Zelllinien eine Steigerung der Chemokinexpression von CCL5.

Das Chemokin CCL5 ist ein Mediator bei inflammatorischen Prozessen, daher könnte die gesteigerte Expression von CCL5 als Immunreaktion auf die Bestrahlung gewertet werden (Soria et al. 2009). Da der Chemokinligand CCL5 an die CCRezeptoren 1, 3 und 5 bindet, könnte eine gesteigerte Expression des Chemokins auch über den Chemokinrezeptor 5 inflammatorisch und somit tumorbekämpfend wirken. In der Arbeit von Chakraborty et al. 2012 wurde eine signifikante Hochregulation der CCR5 Expression sowie der Sekretion des entsprechenden Liganden durch den Immunmodulator IFNa2b in Plattenepithelkarzinomzellen der Zunge und dadurch eine verbesserte Tumorbekämpfung hervorgerufen. Die Ergebnisse von Chuang et al. 2009 zeigen aber andererseits auch den Zusammenhang zwischen hoher CCR5 Expression und einer vermehrten Metastasierung von oralen Karzinomzellen.

Die Chemokinrezeptoren CCR1 und CCR3 sind für viele verschiedene Liganden eine Bindungsstelle. Die Rezeptoren werden vor allem im Rahmen von inflammatorischen Prozessen exprimiert (Heath et al. 1997) und sind mit ihrer Bindungsstelle für viele Liganden in immunmodulatorischen Prozessen eingebunden (Wang et al. 2009). 
In der vorliegenden Arbeit wird der Chemokinrezeptor CCR1 nur von der Tumorzellinie BHY und der Chemokinrezeptor CCR3 alleinig von der Tumorzellinie KOSC2 exprimiert. In Relation zu den Housekeeping Genen ist die Expression vermindert. Es zeigt sich eine deutliche Expressionssteigerung für den Chemokinrezeptor CCR1 und eine signifikante Minderung der Expression des Chemokinrezeptors CCR3 nach Bestrahlung der Zellen mit 2 Gy. Die vereinzelte Expression der beiden Rezeptoren in den untersuchten Zelllinien steht im Einklang mit der Arbeit von (Chuang et al. 2009), die eine Expression des Chemokinrezeptors CCR5, aber nicht der Rezeptoren CCR1 und CCR3 in oralen Karzinomzellen nachweisen konnten. Andererseits ist die Expression von CCR3 in Schilddrüsenkarzinomen sowie malignen Melanomen und Plattenepithelkarzinomen der Haut erhöht (González et al. 2009; Lee et al. 2010). Die Arbeit von González et al. 2009 lässt den Schluss zu, dass erhöhte CCR3 Expression mit einer erhöhten Malignität sowie der Progression von Plattenepithelkarzinomen korrelieren. Auch in der Arbeit von Jöhrer et al. 2005 wird die Anwesenheit des Chemokinrezeptors CCR3 mit dem Malignitätsgrad, hier Nierenzellkarzinomen, korreliert.

Der Rezeptor CCR1 wird von verschiedenen Karzinomzellen exprimiert und korreliert mit der Tumorausbreitung sowie Metastasierung von Karzinomen (Wang et al. 2009; Wu et al. 2007). Die Expression von CCR1 geht zum Beispiel mit einem aggressiveren Phänotyp von nicht-kleinzelligen Lungenkarzinomen einher. Zudem wurde die Invasivität der nicht-kleinzelligen Lungenkarzinome, unter Blockierung von CCR1, signifikant reduziert (Wang et al. 2009). Auch in oralen Plattenepithelkarzinomen ist die CCR1 Expression erhöht und könnte aufgrund der Studie von Silva et al. 2007 bei der lymphogenen Ausbreitung von Plattenepithelkarzinomen eine Funktion innehalten. Die Expression der beiden Chemokinrezeptoren CCR1 und CCR 3 steht also ebenfalls eher in Verbindung mit der Proliferation und Metastasierung von Karzinomzellen.

Der Chemokinrezeptor CCR6 wird von vielen Tumorzellarten exprimiert und steht mit der Proliferation und Metastasierung von Tumorzellen in Zusammenhang (Fusi et al. 2012). Außerdem scheinen die Interaktionen des Rezeptors CCR6 mit dem Liganden CCL20 die Lebermetastasierung zu begünstigen (Ghadjar et al. 2009; Dellacasagrande et al. 2003). In der vorliegenden Arbeit wurde die Expression des Chemokinrezeptors CCR6 in Relation zu den Housekeeping Genen und nach 
Bestrahlung in den untersuchten Zelllinien eher herunter reguliert. Als Ausnahme gilt die Zelllinie BHY, in der eine gesteigerte Expression beobachtet wurde.

Die Expression von Chemokinrezeptor CCR6 steht mit der Ausbreitung von Tumoren in Verbindung, wobei auch eine Herunterregulierung des Rezeptors CCR6 bei potentiell metastasierenden Tumorzelllinien beobachtet wird (Basile et al. 2008). Allerdings zeigt sich in der Arbeit von Dellacasagrande et al. 2003 eine gesteigerte Expression von CCR6 bei diversen metastasierten Tumorzellen. Hier wird die Interaktion des Rezeptor-Liganden-Paares CCR6/CCL20 als möglicher Signalweg für eine Metastasierung in die Leber von Kolon-, Ovarial- und Schilddrüsenkarzinomen gesehen. Daher könnte die geringere Expression von CCR6 nach Bestrahlung der Tumorzellen mit einer geringeren Metastasierungstendenz einhergehen. Die Arbeit von Wang et al. 2005 zeigt eine Herunterregulation des Chemokinrezeptors CCR6 und eine Hochregulation von CCR7 bei metastasierenden Kopf-Hals-Plattenepithelkarzinomzellen. Demzufolge könnte die Expression von CCR6 und CCR7 in KopfHals-Plattenepithelkarzinomzellen zum Metastasierungsprozess beitragen. Im Gegensatz zu den oben erwähnten Ergebnissen von Wang et al. 2005 zeigt sich in der Arbeit von Muller et al. 2006 allerdings kein Unterschied der Chemokinrezeptorexpression bei primären Kopf-Hals-Plattenepithelkarzinomen und entsprechenden Lymphknotenmetastasen. In der durchgeführten Analyse konnte jedoch weder die Expression von CCR6 noch von CCR7 in der einer Metastase entstammenden Zelllinie XF354 nachgewiesen werden.

Der Chemokinrezeptor CCR7 wird in der vorliegenden Arbeit von den untersuchten Zelllinien vor und nach Bestrahlung unterschiedlich exprimiert. Die Tumorzellinien exprimieren den Rezeptor nach Bestrahlung der Zellen mit 2 Gy zumeist gesteigert. Im zeitlichen Verlauf zeigt sich allerdings auch eine Expressionsminderung des Rezeptors CCR7 nach Bestrahlung. Der von vielen Karzinomzellen exprimierte Chemokinrezeptor 7 vermittelt das Überleben und die Invasivität von metastasierten Kopf- und Hals-Plattenepithelkarzinomen in regionale Lymphknoten (Wang et al. 2004; Zlotnik et al. 2006; Ben-Baruch et al. 2008). Weiterhin ist die Metastasierung von nasopharyngealen und oralen Karzinomen mit der Expression des Chemokinrezeptors CCR7 assoziiert (Ou et al. 2006; Shang et al. 2008). Die Zelllinien BW225 und DF19 zeigen eine signifikante Steigerung der Expression des CCR7 nach Bestrahlung der Zellen mit 2 Gy. 
Die Expression des Chemokinrezeptors ist nach der Bestrahlung von Zellen der Tumorzelllinie GR145 II signifikant vermindert. Da sich die Expression in den untersuchten Zelllinien nach Bestrahlung unterschiedlich verhält, kann keine allgemeine Aussage über die Expressionsänderung des Chemokinrezeptors nach der Bestrahlung und dessen Bedeutung gemacht werden. Da die Expression des Chemokinrezeptors CCR7 allerdings in Zusammenhang mit einer Progression von Tumoren (Wang et al. 2008) steht, könnte die Expression des CCR7 zur Abschätzung der Progression von Kopf- und Hals-Plattenepithelkarzinomen genutzt werden (Tsuzuki et al. 2006). Zudem könnte therapeutische Rezeptorinhibition von CCR7 eine Metastasierung von Kopf-Hals-Karzinomen verhindern (Wang et al. 2005; Zhao et al. 2009).

Die Chemokine CXCL1, CXCL2, CXCL3, CXCL10 und CXCL11 wurden von allen oder der Mehrheit der untersuchten Zelllinien vergleichbar exprimiert. Die Expression von CXCL9 und CXCL12 blieb auf einige wenige Kopf-Hals-Karzinomzelllinien und die Fibroblastenzellen der Zelllinie DF19 beschränkt. Die homogene Expression der Chemokine CXCL1, CXCL2 und CXCL3 ist durch deren Lokalisierung auf einem schmalen Bereich von Chromosom 4 und die dadurch bedingte Co-expression erklärbar (Bièche et al. 2007).

Die Chemokine CXCL1, CXCL2 und CXCL3 binden an den CXCR2-Rezeptor, dessen Expression in den untersuchten Zelllinien jedoch nicht nachgewiesen werden konnte. Die Expression der Chemokine CXCL1, CXCL2 und CXCL3 zeigte ein ähnliches strahleninduziertes Muster zum Zeitpunkt 6 Stunden nach Bestrahlung. Die beiden Normalgewebszellinien zeigten eine strahleninduzierte Hochregulation, während bei den Tumorzellinien eine strahleninduzierte Herunterregulierung beobachtet werden konnte. Die Expression der CXC-Chemokine CXCL1, CXCL2 und CXCL3 in den untersuchten Tumorzelllinien steht eventuell mit der Tumorentstehung an sich oder auch mit der Tumorzell-Proliferation in Verbindung (Liu et al. 2006; Shintani et al. 2004). Weiterhin sind die CXC-Chemokine im Metastasierungsprozess mitentscheidend (Gomperts et al. 2006; Ou et al. 2006). Ein vermehrtes Vorkommen von CXCL-Chemokinen bei Patienten mit Tumorerkrankungen geht mit einer schlechteren Überlebensrate bei Kopf-HalsKarzinom (Allen et al. 2007) und Kolorektalzellen einher (Verbeke et al. 2011). Daher könnte eine Minderung der Chemokinexpression für ein Ansprechen auf die Bestrahlung und ein damit einhergehendes verbessertes Therapieergebnis 
sprechen. Auch die Metastasierung von Karzinomzellen ist mit einer vermehrten Expression der Chemokinliganden CXCL1 und CXCL2 verbunden, da eine vermehrte Expression der Chemokinliganden mit einer Metastasierung von Mammakarzinomzellen korreliert (Accharyya et al. 2012).

Eine Expression von CXCL3 wurde bei aggressiven Mammakarzinomen nachgewiesen und steht hier ebenfalls mit Metastasierungsprozessen in Zusammenhang (See et al. 2014). In Kolonkarzinomzellen ist die Expression der Chemokine CXCL2 und CXCL3 im Vergleich zu Normalgewebszellen erhöht, zudem war eine gesteigerte Expression von CXCL3 bei Lebermetastasen zu beobachten (Doll et al. 2010). Da die Expression der CXC-Chemokine mit inflammatorischen Reaktionen in Verbindung steht (Wang et al. 2009), könnte ein Zusammenhang zwischen der Akutreaktion nach Bestrahlung, dem Therapieansprechen auf Bestrahlung von Kopf-Hals-Karzinomen und der Expression von CXC-Chemokinen bestehen (Wolff et al. 2011).

Die Expression der CXC-Chemokine bzw. deren Änderung könnte daher eventuell als Biomarker für das Ansprechen einer Radiochemotherapie bei Patienten mit KopfHals-Karzinomen genutzt werden (Allen et al. 2007; Michiels et al 2009,). Die Expression der CXC-Chemokine könnte sich also durchaus als ein interessanter Parameter oder Angriffspunkt in der Therapie von Kopf-Hals-Karzinomen erweisen (Allen et al. 2007; Gomperts et al. 2006; Michiels et al 2009; Yeudall et al. 2007).

Die Chemokine CXCL9, CXCL10 und CXCL11 bilden eine homologe Gruppe, die im Rahmen von inflammatorischen Prozessen von Makrophagen produziert werden. Die Gruppe der Chemokine CXCL9, CXCL10 und CXCL11 liegt direkt neben der chromosomalen Region 4q21 und wird daher häufig zusammen exprimiert (Zlotnik et al. 2000). Die Chemokine CXCL10 und CXCL11 wurden in der vorliegenden Arbeit in der Mehrheit oder allen Zelllinien exprimiert, während die Expression von CXCL9 auf die Fibroblastenzelllinie DF19 und die Tumorzelllinien BW225, CAL27, CAL33 und XF354 beschränkt blieb. Die Genexpression der Chemokine ist in Relation zu den Housekeepinggenen eher herunter reguliert und wird nach Bestrahlung von den Karzinom- sowie von den Normalgewebszelllinien sowohl gesteigert als auch vermindert exprimiert. Eindeutige strahleninduzierte Expressionsänderungen lassen sich aufgrund der Varianzen der Expressionsänderungen daher nicht einordnen.

Die Chemokine CXCL9, CXCL10 und CXCL11 induzieren Tumorprogression, Invasion und Metastasierung bei Zellen des multiplen Myeloms (Kawada et al. 2004; 
Pellegrino et al. 2004). Allerdings weist die Expression der Chemokine CXCL9, CXCL10 und CXCL11 in Karzinomen des oberen Verdauungstrakts auch einen tumorreduzierenden Effekt auf, der durch die Anziehung von zytotoxischen TLymphozyten und die Hemmung der Angiogenese erklärbar ist (Hensbergen et al. 2005; Verbeke et al. 2012).

Die Expression der Chemokine CXCL9, CXCL10 und CXCL11 zusammen mit ihrem Rezeptor CXCR3 ist ebenso in Basalzellkarzinomen, sowie Ovarial und B-Zell Lymphomen zu finden (Lo et al. 2010). Eine erhöhte CXCL9 Expression in Bezug auf orale Normalgewebszellen zeigt sich außerdem bei oralen Plattenepithelkarzinomen, die mit der Tumorausbreitung korreliert und so als prognostischer Faktor einsetzbar wäre (Chang et al. 2013).

Der Chemokinrezeptor CXCR4 wird nur in den untersuchten Tumorzelllinien BW225, FaDuDD und ZMK1 exprimiert. Bei allen exprimierenden Zelllinien zeigt sich eine signifikante Minderung der Expression des Chemokinrezeptors CXCR4 zu dem Zeitpunkt $6 \mathrm{~h}$ nach Bestrahlung der Zellen mit 2 Gy. Die strahleninduzierten Expressionsänderungen des Rezeptors CXCR4 in der Zelllinie FaDuDD und ZMK1 zeigen im Verlauf aber deutliche Schwankungen. Die beiden Zelllinien FaDuDD und ZMK1 exprimieren den Liganden (CXCL12) des Rezeptors CXCR4 nicht. Die Expression des Chemokinrezeptors CXCR4 könnte als prognostischer Faktor verwendet werden, da auch die lymphogene Metastasierung von Plattenepithelkarzinomen im Kopf-Hals-Bereich über CXCR4 reguliert wird (Uchida et al. 2003; Delilbasi et al. 2004). Eine Herunterregulierung der Genexpression nach Bestrahlung, wie in den Zelllinien BW225, FaDuDD und ZMK1 könnte hier also eventuell mit einer verminderten Metastasierung von Karzinomzellen einhergehen. Allerdings sind die strahleninduzierten Expressionsänderungen des Rezeptors CXCR4 im zeitlichen Verlauf wiederum zu verschiedenen Zeiten gesteigert.

Die Zelllinie BW225 exprimiert sowohl den Chemokinrezeptor CXCR4 als auch den Chemokinliganden CXCL12. Die relative Genexpression des Rezeptors CXCR4 und des entsprechenden Liganden CXCL12 zeigt hier ein ähnliches strahleninduziertes Expressionsmuster mit signifikanter Herunterregulation zum Zeitpunkt 6 h nach Bestrahlung. Bei der Funktion des CXCR4/CXCL12 Rezeptorliganden-Paars sind die Tumorgenese, die Chemotaxis von Leukozyten sowie die Metastasierung von malignen Kopf-Hals-Tumoren zu nennen (Almofti et al. 2004; Delilbasi et al. 2004; Oliveira-Neto et al. 2008; Rehman et al. 2008). Eine verminderte Genexpression von 
CXCR4/CXCL12 nach Bestrahlung könnte also ebenso im Zusammenhang mit einer verminderten Progression oder Metastasierung stehen. Da die Aktivierung von CXCL12 zur Ausbreitung von Kopf-Hals-Karzinomen beiträgt, wie in der retrospektiven Studie von Smirnova et al. 2011 beschrieben wird, könnte hier also ein möglicher Angriffspunkt einer Therapie liegen. In der Studie von Ou et al. 2006 konnte zudem eine vermehrte Expression des Chemokinliganden CXCR4 bei Metastasen von Nasopharyngealen Karzinomen festgestellt werden. Zudem wurde in der Arbeit von Yoon et al. 2007 in einer experimentellen Arbeit am Mausmodell unter Blockierung des Rezeptors CXCR4 ein vermindertes Wachstum und Metastasierung von Kopf-Hals-Karzinomen beobachtet. Der Rezeptor CXCR4 könnte daher in der medikamentösen Therapie von Kopf-Hals-Karzinomen ein möglicher Angriffspunkt sein. Allerdings wird eine gesteigerte Expression des Rezeptors CXCR4 ebenso nach Radiotherapie der nasopharyngealen Karzinomzellen beobachtet (Ou et al. 2006). Da die Expression von CXCL12 und CXCR4 nach Bestrahlung der Zellen mit $2 \mathrm{~Gy}$ in der vorliegenden Arbeit allerdings nicht eindeutig hoch oder herunter reguliert wurde, müssen weitere Analysen zur strahleninduzierten Expression folgen. So ist die Genexpression des Chemokins CXCL12 und des Rezeptors zum Zeitpunkt $6 \mathrm{~h}$ nach Bestrahlung zwar herunter reguliert, allerdings zeigt sich im zeitlichen Verlauf z.B. bei der Zellinie FaDuDD eine Steigerung der Expression zu allen anderen Zeitpunkten. Der Chemokinrezeptor CXCR1 ist laut mehrerer Studien sowohl an der Tumorentstehung selbst (Singh et al. 2009; Varney et al. 2003) als auch der Ausbreitung durch Bindung des Chemokinliganden CXCL8 (Brat et al. 2005; Murphy et al. 2005) beteiligt.

Der Chemokinrezeptor CXCR1 wird von den in dieser Arbeit untersuchten Zellen insgesamt von wenigen Zelllinien und schwach exprimiert. Nach Bestrahlung der Zellen mit $2 \mathrm{~Gy}$ wird die Expression bei der Normalgewebszelllinie HaCat gemindert und bei zwei Karzinomzelllinien gesteigert. Eine gesteigerte Expression des Chemokinrezeptors CXCR1 ist ebenso bei ösophagealen Karzinomen zu beobachten (Milano et al. 2008). Weiterhin scheint eine Antagonisierung von CXCR1 die Lebermetastasierung bei Kolonkarzinomen zu vermindern (Varney et al. 2011). Grundsätzlich ist CXCR1 für die Tumorentstehung sowie für das Wachstum und die Verbreitung von Bedeutung, was die Möglichkeit für eine zukünftige therapeutische Intervention bietet (Singh et al. 2009). 
Die Ergebnisse der untersuchten Genexpressionen sowie der strahleninduzierten Änderungen sind aufgrund der oben beschriebenen Varianz daher nicht ganz eindeutig zu bewerten. Obwohl viele Zelllinien und Chemokine/Chemokinrezeptoren untersucht wurden, können die vorliegenden Ergebnisse nicht direkt auf die Praxis angewendet werden. Allerdings könnten die strahleninduzierten Genexpressionsänderungen der Chemokine oder deren Rezeptoren eventuell nach weiteren Untersuchungen und Bestätigung der vorliegenden Ergebnisse als prognostischer Marker eingesetzt werden.

Es könnte sich daraus die Möglichkeit ergeben, ein mögliches Therapieansprechen zu detektieren oder eine Prognose bzw. den Verlauf einer Tumorerkrankung zu prognostizieren. Daher wären weitere Studien zur Abklärung möglichen Ansprechens einer Radio- bzw. Radiochemotherapie in Bezug auf Chemokinexpression notwendig. Interessant wäre zudem die Untersuchung von Patienten mit Kopf-HalsKarzinom in Bezug auf die Expression verschiedener Chemokine sowie dessen Änderung im therapeutischen Verlauf.

Die Bedeutung von inflammatorischen Prozessen bei Kopf-Hals-Karzinomen und deren Bezug für ein verbessertes Gesamtüberleben bei höhergradigen Akutreaktionen nach Radiochemotherapie ist bei Wolff et al. 2011 beschrieben. Hier könnten die Chemokinexpression Aufschluss auf einen möglichen Wirkmechanismus geben. Auch eine individuellere Therapie könnte im weiteren Sinne aufgrund einer Analyse bzw. dem Verlauf gewisser Chemokinexpression möglich sein. So wäre eine individuelle Dosisfindung bei der Radiotherapie von malignen Kopf-Hals-Karzinomen denkbar. Des Weiteren sind die zum Teil unterschiedlichen Signalwege der untersuchten Chemokine und Chemokinrezeptoren bezogen auf die Expression bzw. deren Änderung noch nicht verstanden. Die therapeutische Bedeutung der Chemokine und deren Rezeptoren sowie deren Wirkungsmechanismus bei Tumorgenese, einschließlich Angiogenese, Tumorwachstum, Invasion und Metastasierung muss daher weiterhin untersucht und diskutiert werden (Vandercappeln et al. 2008). Erst dann ist eine mögliche Anwendung auf verschiedene Therapieschemata denkbar. Allerdings können die Ergebnisse der vorliegenden Arbeit dazu genutzt werden, um in weiteren Arbeitsschritten das Ansprechen von Kopf-Hals-Karzinomen auf die Radio- bzw. Radiochemotherapie weiterführend zu untersuchen. 


\section{$5 \quad$ Zusammenfassung}

In der vorliegenden Arbeit wurde die Genexpression von Chemokinen der CC- bzw. CXC-Klasse und ihren Rezeptoren in Kopf-Hals-Karzinomzellen sowie Normalgewebszellinien untersucht. Die Radiotherapie ist ein wesentlicher Bestandteil bei der Behandlung von malignen Kopf-Hals-Tumoren. Chemokine sind chemotaktische Zytokine, die u.a. inflammatorische Prozesse, Metastasierung sowie das Immunsystem beeinflussen. Die Expression von Chemokinen wird dabei von Zytokinen sowie pathogenen Stimuli induziert, wobei der Einfluss von Chemokinen und ihrer Signalwege über Chemokinrezeptoren hinsichtlich des Wachstums, der Ausbreitung und des Ansprechens von Kopf-Hals-Karzinomen auf eine Radiochemotherapie noch nicht gänzlich verstanden ist. Zudem ist der Effekt der Bestrahlung auf die Expression von Chemokinen und Chemokinrezeptoren bislang nur wenig untersucht.

Es wurde daher in der vorliegenden Arbeit zunächst eine umfassende Analyse der Chemokin- und Chemokinrezeptorexpression in 15 Kopf-Hals-Karzinomzelllinien und zwei Normalgewebszelllinien durchgeführt; wobei deren spontane Expression sowie die Expression 6 Stunden nach einer Bestrahlung mit 2 Gy bestimmt wurde. Zur Validierung der Ergebnisse wurden in einer zweiten unabhängigen Analyse bestimmte Chemokine und Chemokinrezeptoren in ausgewählten Zelllinien erneut analysiert. Zusätzlich wurde in der zweiten Analyse eine Expressionskinetik über 48 Stunden nach Bestrahlung vorgenommen. Die Genexpression der Chemokine und ihrer Rezeptoren wurden durch Real-Time-PCR nachgewiesen. Der Nachweis korrespondierender Proteine erfolgte mittels ELISA. Die Überlebensfähigkeit der untersuchten Zellen nach Bestrahlung wurde durch einen Koloniebildungstest erbracht. In allen untersuchten Zellinien wurden die Chemokine CCL5 und CCL 20 exprimiert, wobei keine der analysierten Zelllinien die Chemokine CCL4, CCL19 oder die Rezeptoren CCR2, CCR5, CCXR2 und CCXR3 exprimierte.

Weiterhin hervorzuheben ist die Expression der Chemokine CXCL1, CXCL2, CXCL3, CXCL10 und CXCL11 von den meisten der untersuchten Zelllinien. Die Expression 
der Chemokine CXCL9 und CXCL12 beschränkte sich dahingegen auf wenige Zelllinien. Die Chemokinrezeptoren wurden in den untersuchten Zelllinien insgesamt weniger verbreitet exprimiert als die untersuchten Chemokine.

Die Bestrahlung mit $2 \mathrm{~Gy}$ verursachte in allen untersuchten Zelllinien eine veränderte Expression der Chemokine und Chemokinrezeptoren. Hier wurden bei den Chemokinen sowohl strahleninduzierte Expressionsteigerungen als auch Expressionsminderungen festgestellt, wohingegen bei den untersuchten Rezeptoren die Expression nach Bestrahlung vorherrschend herunterreguliert wurde.

Die Validierungsexperimente stimmten gut mit der ersten Analyse überein, zeigten aber auch, dass Expressionsveränderungen über den gesamten Zeitraum von 48 Stunden nach Bestrahlung messbar sind. Sowohl zu den frühen Messzeiten von einer bzw. drei Stunden nach einer Bestrahlung als auch zu späten Messzeiten (12 48 Stunden) traten Expressionssteigerungen und Minderungen auf.

Die Proteinexpression der Chemokine CXCL1 und CXCL12 wurde ebenfalls untersucht und entspricht der RNA-Expression.

Zusammenfassend betrachtet führt die Bestrahlung von Kopf-Hals-Karzinom- und Normalgewebszellen mit 2 Gy zu einer strahleninduzierten Veränderung der Genexpression der untersuchten Chemokine- und deren Rezeptoren. Die Ergebnisse der vorliegenden Arbeit können daher genutzt werden, um ein mögliches Therapieansprechen von Kopf-Hals-Karzinomen weitergehend zu untersuchen und die Therapie so letztendlich zu optimieren. 


\section{$6 \quad$ Literaturverzeichnis}

Abiko Y, Nishimura M, Kusano K, Nakashima K, Okumura K, Arakawa T, Takuma T, Mizoguchi I, Kaku T (2003): Expression of MIP-3alpha/CCL20, a macrophage inflammatory protein in oral squamous cell carcinoma. Arch Oral Biol 48(2), 171-175

Acharyya S, Oskarsson T, Vanharanta S, Malladi S, Kim J, Morris PG, ManovaTodorova K, Leversha M, Hogg N, Seshan VE, et al. (2012): A CXCL1 paracrine network links cancer chemoresistance and metastasis. Cell 150, 165-178

Allen C, Duffy S, Teknos T, Islam M, Chen Z, Albert PS, Wolf G, Van Waes C (2007): Nuclear factor-kappaB-related serum factors as longitudinal biomarkers of response and survival in advanced oropharyngeal carcinoma. Clin Cancer Res $\underline{13}$, 3182-3190

Almofti A, Uchida D, Begum NM, Tomizuka Y, Iga H, Yoshida H, Sato M (2004): The clinicopathological significance of the expression of CXCR4 protein in oral squamous cell carcinoma. Int J Oncol 25, 65-71

Altieri A, Bosetti C, Talamini R, Gallus S, Franceschi S, Levi F, Dal Maso L, Negri E, La Vecchia C (2002): Cessation of smoking and drinking and the risk of laryngeal cancer. Br J Cancer 87, 1227-1229

Ang KK, Sturgis EM (2012): Human papillomavirus as a marker of the natural history and response to therapy of head and neck squamous cell carcinoma. Semin Radiat Oncol 22, 128-142

Arya M, Patel HR, Williamson M (2003): Chemokines: key players in cancer. Curr Med Res Opin 19, 557-564

Bachmeier BE, Mohrenz IV, Mirisola V, Schleicher E, Romeo F, Hohneke C I (2008): 
Curcumin downregulates the inflammatory cytokines CXCL1 and -2 in breast cancer cells via NFkappaB. Carcinogenesis 29(4) 779-789

Baggiolini M, Loetscher P (2000): Chemokines in inflammation and immunity. Immunol Today 21, 418-420

Balkwill F (2004): The significance of cancer cell expression of the chemokine receptor CXCR4. Semin Cancer Biol 14, 171-179

Basile J, Thiers B, Maize J, Sr., Lathers DM (2008): Chemokine receptor expression in non-melanoma skin cancer. J Cutan Pathol $\underline{35}, 623-629$

Belardelli F (1995): Role of interferons and other cytokines in the regulation of the immune response. APMIS $\underline{103}, 161-179$

Ben-Baruch A (2006): Inflammation-associated immune suppression in cancer: the roles played by cytokines, chemokines and additional mediators. Semin Cancer Biol $16,38-52$

Ben-Baruch A (2006): The multifaceted roles of chemokines in malignancy. Cancer Metastasis Rev 25, 357-371

Ben-Baruch A (2008): Organ selectivity in metastasis: regulation by chemokines and their receptors. Clin Exp Metastasis 25, 345-356

Bieche I, Chavey C, Andrieu C, Busson M, Vacher S, Le Corre L, Guinebretiere JM, Burlinchon S, Lidereau R, Lazennec G (2007): CXC chemokines located in the 4q21 region are up-regulated in breast cancer. Endocr Relat Cancer 14, 1039-1052

Blot WJ, McLaughlin JK, Winn DM, Austin DF, Greenberg RS, Preston-Martin S, Bernstein L, Schoenberg JB, Stemhagen A, Fraumeni JF, Jr. (1988): Smoking and drinking in relation to oral and pharyngeal cancer. Cancer Res $\underline{48}$, 3282-3287 
Boecker W, Denk H, Heitz PU (Hrsg.): Pathologie. 5.Auflage; Urban \& Fischer Verlag, München 2012

Boenninghaus HG, Lenarz T (Hrsg.): Hals-Nasen-Ohrenheilkunde. 12. Auflage; Springer-Verlag, Berlin 2005

Bonner J, Harari P, Giralt J, Azarnia N, Shin DM, Cohen RB, Jones CU, Sur R, Raben D, Jassem J, et al. (2006): Radiotherapy plus cetuximab for squamous-cell carcinoma of the head and neck. N Engl J Med 354, 567-578

Bourhis J (2005): New approaches to enhance chemotherapy in SCCHN. Ann Oncol 16 (6), 20-24

Brat D, Bellail A, Van Meir E (2005): The role of interleukin-8 and its receptors in gliomagenesis and tumoral angiogenesis. Neuro Oncol $\underline{7}, 122-133$

Brockstein B, Masters G (Hrsg.): Head and Neck Cancer, Springer Verlag, Berlin 2003

Buettner M, Meyer B, Schreck S, Niedobitek G (2007): Expression of RANTES and MCP-1 in epithelial cells is regulated via LMP1 and CD40. Int J Cancer 121, 27032710

Calcagno A, Chewning K, Wu C, Ambudkar V (2006): Plasma membrane calcium ATPase (PMCA4): a housekeeper for RT-PCR relative quantification of polytopic membrane proteins. BMC Mol Biol 7:29

Cattani P, Hohaus S, Bellacosa A, Genuardi M, Cavallo S, Rovella V, Almadori G, Cadoni G, Galli J, Maurizi M, et al. (1998): Association between cyclin D1 (CCND1) gene amplification and human papillomavirus infection in human laryngeal squamous cell carcinoma. Clin Cancer Res $\underline{4}$, 2585-2589 
Chakraborty K, Bose A, Goswami KK, Mukherjee KK, Goswami S, Ghosh D, Chakraborty T, Sarkar K, Pal S, Bhowmick A, et al. (2012): Dysregulated CC receptor/ligand in monocytes/macrophages from tongue squamous cell carcinoma patients is partially rectified by interferon alpha-2b. Hum Immunol 73, 38-47

Chakraborty K, Bose A, Pal S, Chattopadhyay U, Baral R (2008): Interferon-alpha2b restores the impaired chemotactic activity of peripheral blood mononuclear cells from head and neck squamous cell carcinoma patients by modulating CXC receptor ligand interaction. J Interferon Cytokine Res 28, 487-499

Chang KP, Hao SP, Chang JH, Wu CC, Tsang NM, Lee YS, Hsu CL, Ueng SH, Liu SC, Liu YL, et al. (2008): Macrophage inflammatory protein-3alpha is a novel serum marker for nasopharyngeal carcinoma detection and prediction of treatment outcomes. Clin Cancer Res 14, 6979-6987

Chang KP, Wu CC, Fang KH, Tsai CY, Chang YL, Liu SC, Kao HK (2013): Serum levels of chemokine (C-X-C motif) ligand 9 (CXCL9) are associated with tumor progression and treatment outcome in patients with oral cavity squamous cell carcinoma. Oral Oncol 49, 802-807

Chao KS, Wippold FJ, Ozyigit G, Tran BN, Dempsey JF (2002): Determination and delineation of nodal target volumes for head-and-neck cancer based on patterns of failure in patients receiving definitive and postoperative IMRT. Int J Radiat Oncol Biol Phys 53, 1174-1184

Charo IF, Ransohoff RM (2006): The many roles of chemokines and chemokine receptors in inflammation. N Engl J Med 354, 610-621

Chen B, Lu L, Tao L, Zhou L, Li S, Zhu L (2010): Expression of CCR6 and CCR7 in laryngeal squamous cell carcinoma. Lin Chung Er Bi Yan Hou Tou Jing Wai Ke Za Zhi 24, 975-979 
Chuang JY, Yang WH, Chen HT, Huang CY, Tan TW, Lin YT, Hsu CJ, Fong YC, Tang $\mathrm{CH}$ (2009): CCL5/CCR5 axis promotes the motility of human oral cancer cells. J Cell Physiol 220, 418-426

Copper M, Jovanovic A, Nauta J, Braakhuis B, de Vries N, van der Waal I, Snow GB (1995): Role of genetic factors in the etiology of squamous cell carcinoma of the head and neck. Arch Otolaryngol Head Neck Surg 121, 157-160

Crowe DL, Hacia JG, Hsieh CL, Sinha UK, Rice H (2002): Molecular pathology of head and neck cancer. Histol Histopathol 17, 909-914

Cummings B, Keane T, Pintilie M, Warde P, Waldron J, Payne D, Liu FF, Bissett R, McLean M, Gullane P, et al. (2007): Five year results of a randomized trial comparing hyperfractionated to conventional radiotherapy over four weeks in locally advanced head and neck cancer. Radiother Oncol 85, 7-16

Delilbasi CB, Okura M, lida S, Kogo M (2004): Investigation of CXCR4 in squamous cell carcinoma of the tongue. Oral Oncol $40,154-157$

Dellacasagrande J, Schreurs OJ, Hofgaard PO, Omholt H, Steinsvoll S, Schenck K, Bogen B, Dembic Z (2003): Liver metastasis of cancer facilitated by chemokine receptor CCR6. Scand J Immunol 57, 534-544

Demaria S, Formenti SC (2007): Sensors of ionizing radiation effects on the immunological microenvironment of cancer. Int J Radiat Biol 83, 819-825

Deutsch AJ, Aigelsreiter A, Steinbauer E, Fruhwirth M, Kerl H, Beham-Schmid C (2008): Distinct signatures of B-cell homeostatic and activation-dependent chemokine receptors in the development and progression of extragastric MALT lymphomas. J Pathol 215(4), 431-444 
Diamandis EP, Fritche HA, Lilja H: Tumor markers: physiology, pathobiology, technology, and clinical applications. 1.Auflage; AACC Press, Washington D.C. 2002

Ding X, Wang K, Wang H, Zhang G, Liu Y, Yang Q, Chen W, Hu S (2012): High expression of CCL20 is associated with poor prognosis in patients with hepatocellular carcinoma after curative resection. J Gastrointest Surg 16, 828-836

Ding Y, Shimada Y, Maeda M, Kawabe A, Kaganoi J, Komoto I, Hashimoto Y, Miyake M, Hashida H, Imamura M (2003): Association of CC chemokine receptor 7 with lymph node metastasis of esophageal squamous cell carcinoma. Clin Cancer Res $\underline{9}$, 3406-3412

Doll D, Keller L, Maak M, Boulesteix AL, Siewert JR, Holzmann B, Janssen KP (2010): Differential expression of the chemokines GRO-2, GRO-3, and interleukin-8 in colon cancer and their impact on metastatic disease and survival. Int $J$ Colorectal Dis $\underline{25}, 573-581$

Egunsola AT, Zawislak CL, Akuffo AA, Chalmers SA, Ewer JC, Vail CM, Lombardo JC, Perez DN, Kurt RA (2012): Growth, metastasis, and expression of CCL2 and CCL5 by murine mammary carcinomas are dependent upon Myd88. Cell Immunol 272, 220-229

Eisbruch A, Foote RL, O'Sullivan B, Beitler JJ, Vikram B (2002): Intensity-modulated radiation therapy for head and neck cancer: emphasis on the selection and delineation of the targets. Semin Radiat Oncol 12, 238-249

Ferreira FO, Ribeiro FL, Batista AC, Leles CR, de Cassia Goncalves Alencar R, Silva TA (2008): Association of CCL2 with lymph node metastasis and macrophage infiltration in oral cavity and lip squamous cell carcinoma. Tumour Biol $\underline{29}$, 114-121

Flaitz CM, Hicks MJ (1998): Molecular piracy: the viral link to carcinogenesis. Oral 
Oncol 34, 448-453

Foulkes WD, Brunet JS, Kowalski LP, Narod SA, Franco EL (1995): Family history of cancer is a risk factor for squamous cell carcinoma of the head and neck in Brazil: a case-control study. Int J Cancer $\underline{63}, 769-773$

Fujimori A, Okayasu R, Ishihara H, Yoshida S, Eguchi-Kasai K, Nojima K, Ebisawa S, Takahashi S (2005): Extremely low dose ionizing radiation up-regulates CXC chemokines in normal human fibroblasts. Cancer Res $\underline{65}, 10159-10163$

Furness S, Glenny A, Worthington H, Pavitt S, Oliver R, Clarkson J, Macluskey M, Chan K, Conway D (2011): Interventions for the treatment of oral cavity and oropharyngeal cancer: chemotherapy. Cochrane Database Syst Rev 13(4), CD006386

Fusi A, Liu Z, Kümmerlen V, Nonnemacher A, Jeske J, Keilholz U (2012): Expression of chemokine receptors on circulating tumor cells in patients with solid tumors. Journal of Translational Medicine. 10 1186-1479

Ghadjar P, Rubie C, Aebersold DM, Keilholz U (2009): The chemokine CCL20 and its receptor CCR6 in human malignancy with focus on colorectal cancer. Int J Cancer $\underline{125}, 741-745$

Gillison M, Koch W, Capone R, Spafford M, Westra W, Wu L, Zahurak M, Daniel R, Viglione M, Symer D (2000): Evidence for a causal association between human papillomavirus and a subset of head and neck cancers. J Natl Cancer Inst 92, 709720

Gomperts B, Strieter R (2006): Chemokine-directed metastasis. Contrib Microbiol 13, $170-190$

Gonzalez HE, Leiva A, Tobar H, Bohmwald K, Tapia G, Torres J, Mosso L, Bueno S, Gonzalez P, Kalergis AM, et al. (2009): Altered chemokine receptor expression in 
papillary thyroid cancer. Thyroid 19, 957-965

Guo Y, Zhu XD, Qu S, Li L, Su F, Li Y, Huang ST, Li DR (2012): Identification of genes involved in radioresistance of nasopharyngeal carcinoma by integrating gene ontology and protein-protein interaction networks. Int J Oncol $\underline{40,85-92}$

Hashibe M, Brennan P, Chuang SC, Boccia S, Castellsague X, Chen C, Curado MP, Dal Maso L, Daudt AW, Fabianova E, et al. (2009): Interaction between tobacco and alcohol use and the risk of head and neck cancer: pooled analysis in the International Head and Neck Cancer Epidemiology. Consortium Cancer Epidemiol Biomarkers Prev 18, 541-550

Heath H, Qin S, Rao P, Wu L, LaRosa G, Kassam N, Ponath PD, Mackay CR (1997): Chemokine receptor usage by human eosinophils. The importance of CCR3 demonstrated using an antagonistic monoclonal antibody. J Clin Invest $\underline{99}, 178-184$

Hensbergen PJ, Wijnands PG, Schreurs MW, Scheper RJ, Willemze R, Tensen CP (2005): The CXCR3 targeting chemokine CXCL11 has potent antitumor activity in vivo involving attraction of CD8+ T lymphocytes but not inhibition of angiogenesis.

J Immunother $\underline{28}, 343-351$

Hesselgesser J, Horuk R (1999): Chemokine and chemokine receptor expression in the central nervous system. J Neurovirol $\underline{5}, 13-26$

Hiddemann W, Bartram CR (Hrsg.): Die Onkologie. 2. aktualisierte Auflage; Springer-Verlag, Berlin 2009

Jemal A, Siegel R, Xu J, Ward E (2010): Cancer statistics, 2010. CA Cancer J Clin $60,277-300$

Johrer K, Zelle-Rieser C, Perathoner A, Moser P, Hager M, Ramoner R, Gander H, Holtl L, Bartsch G, Greil R, et al. (2005): Up-regulation of functional chemokine 
receptor CCR3 in human renal cell carcinoma. Clin Cancer Res 11, 2459-2465

Kato A, Chustz RT, Ogasawara T, Kulka M, Saito H, Schleimer RP et al (2009): Dexamethasone and FK506 inhibit expression of distinct subsets of chemokines in human mast cells. J Immunol 182(11), 7233-7243

Kauffmann GW, Moser E, Sauer R (Hrsg.): Radiologie. 3, völlig überarbeitete Auflage; Urban \& Fischer Verlag, München 2006

Kawada K, Sonoshita M, Sakashita H, Takabayashi A, Yamaoka Y, Manabe T, Inaba K, Minato N, Oshima M, Taketo MM (2004): Pivotal role of CXCR3 in melanoma cell metastasis to lymph nodes. Cancer Res 64 , 4010-4017

Kleeff J, Kusama T, Rossi DL, Ishiwata T, Maruyama H, Friess $H$, Buchler MW, Zlotnik A, Korc M (1999): Detection and localization of Mip-3alpha/LARC/Exodus, a macrophage proinflammatory chemokine, and its CCR6 receptor in human pancreatic cancer. Int J Cancer 81, 650-657

Krebs in Deutschland 2009/2010. 9. Ausgabe. Robert Koch-Institut (Hrsg.) und die Gesellschaft der epidemiologischen Krebsregister in Deutschland e.V. (Hrsg.), Berlin 2013

Kryczek I, Wei S, Keller E, Liu R, Zou W (2007): Stroma-derived factor (SDF1/CXCL12) and human tumor pathogenesis. Am J Physiol Cell Physiol 292, 987-995

Kumar B, Cordell KG, Lee JS, Prince ME, Tran HH, Wolf GT, Urba SG, Worden FP, Chepeha DB, Teknos TN, et al. (2007): Response to therapy and outcomes in oropharyngeal cancer are associated with biomarkers including human papillomavirus, epidermal growth factor receptor, gender, and smoking. Int $J$ Radiat Oncol Biol Phys 69, 109-111

Lee YJ, Kim DH, Lee SH, Nam HS, Roh MR, Cho MK (2010): Chemokine Receptor 
CCR3 Expression in Malignant Cutaneous Tumors. Ann Dermatol 22, 412-417

Leitlinienprogramm Onkologie (2012): Diagnostik und Therapie des Mundhöhlenkarzinoms. Deutsche Krebsgesellschaft 2012; Langversion 2.0; AWMF Registriernummer: 007-1000L

Leon X, del Prado Venegas M, Orus C, Lopez M, Garcia J, Quer M (2009): Influence of the persistence of tobacco and alcohol use in the appearance of second neoplasm in patients with a head and neck cancer: A case-control study. Cancer Causes \& Control 20, 645-652

Li A, Varney ML, Singh RK (2001): Expression of interleukin 8 and its receptors in human colon carcinoma cells with different metastatic potentials. Clin Cancer Res $\underline{7}$, 3298-3304

Liu S, Wang X, Xu X (2006): Expression of GRO-1 and its relationship with VEGF in squamous cell carcinoma of larynx. Lin Chuang Er Bi Yan Hou Ke Za Zhi 20, 541544

Lo B, Yu M, Zloty D, Cowan B, Shapiro J, McElwee KJ (2010): CXCR3/Ligands Are Significantly Involved in the Tumorigenesis of Basal Cell Carcinomas. The American Journal of Pathology. 176(5),2435-2446

Loberg RD, Ying C, Craig M, Day LL, Sargent E, Neeley C, Wojno K, Snyder LA, Yan L, Pienta KJ (2007): Targeting CCL2 with systemic delivery of neutralizing antibodies induces prostate cancer tumor regression in vivo. Cancer Res $\underline{67}$, 9417-9424

Lockhart PB, Norris CM, Jr., Pulliam C (1998): Dental factors in the genesis of squamous cell carcinoma of the oral cavity. Oral Oncol 34, 133-139

Loetscher P, Moser B, Baggiolini M (2000): Chemokines and their receptors in lymphocyte traffic and HIV infection. Adv Immunol $\underline{74}, 127-180$ 
Lordick F, Krauss J, Jager D (2008): Tumor markers and biomarkers in squamous cell cancer of the head and neck. HNO $\underline{56}, 881-885$

Luster AD (1998): Chemokines--chemotactic cytokines that mediate inflammation. N Engl J Med 338, 436-445

Luther SA, Bidgol A, Hargreaves DC, Schmidt A, Xu Y, Paniyadi J, Matloubian M, Cyster JG (2002): Differing activities of homeostatic chemokines CCL19, CCL21, and CXCL12 in lymphocyte and dendritic cell recruitment and lymphoid neogenesis. J Immunol 169, 424-433

Marcus B, Arenberg D, Lee J, Kleer C, Chepeha DB, Schmalbach CE, Islam M, Paul S, Pan Q, Hanash S, et al. (2004): Prognostic factors in oral cavity and oropharyngeal squamous cell carcinoma. Cancer 101, 2779-2787

Michiels K, Schutyser E, Conings R, Lenaerts JP, Put W, Nuyts S, Delaere P, Jacobs R, Struyf S, Proost P, et al. (2009): Carcinoma cell-derived chemokines and their presence in oral fluid. Eur J Oral Sci 117, 362-368

Milano F, Jorritsma T, Rygiel AM, Bergman JJ, Sondermeijer C, Ten Brinke A, vanHam SM, Krishnadath KK (2008): Expression pattern of immune suppressive cytokines and growth factors in oesophageal adenocarcinoma reveal a tumour immune escape-promoting microenvironment. Scand J Immunol 68, 616-623

Miyazaki H, Patel V, Wang H, Edmunds RK, Gutkind JS, Yeudall WA (2006): Downregulation of CXCL5 inhibits squamous carcinogenesis. Cancer Res 66 , 4279-4284 Montag M, Dyckhoff G, Lohr J, Helmke BM, Herrmann E, Plinkert PK, Herold-Mende C (2009): Angiogenic growth factors in tissue homogenates of HNSCC: expression pattern, prognostic relevance, and interrelationships. Cancer Science 100, 1210 1218 
Mosmann TR, Cherwinski H, Bond MW, Giedlin MA, Coffman RL (2005): Two types of murine helper $\mathrm{T}$ cell clone. I. Definition according to profiles of lymphokine activities and secreted proteins. J Immunol 175, 5-14

Muller A, Sonkoly E, Eulert C, Gerber PA, Kubitza R, Schirlau K, Franken-Kunkel P, Poremba C, Snyderman C, Klotz LO, et al. (2006): Chemokine receptors in head and neck cancer: association with metastatic spread and regulation during chemotherapy. Int J Cancer 118, 2147-2157

Murphy PM (1994): The molecular biology of leukocyte chemoattractant receptors. Annu Rev Immunol 12, 593-633

Murphy PM, Baggiolini M, Charo IF, Hebert CA, Horuk R, Matsushima K, Miller LH, Oppenheim JJ, Power CA (2000): International union of pharmacology. XXII. Nomenclature for chemokine receptors. Pharmacol Rev 52, 145-176

Nath A, Chattopadhya S, Chattopadhyay U, Sharma NK (2006): Macrophage inflammatory protein (MIP)1alpha and MIP1beta differentially regulate release of inflammatory cytokines and generation of tumoricidal monocytes in malignancy. Cancer Immunol Immunother 55, 1534-1541

National Cancer Institute (2010): Common Terminology Criteria for Adverse Events (CTCAE) (v4.03)

http://evs.nci.nih.gov/ftp1/CTCAE/CTCAE_4.03_2010-06-

14_QuickReference_5x7.pdf (Zugriff am 09.08.2016)

Okamoto Y, Folco EJ, Minami M, Wara A, Feinberg M, Sukhova G (2008): Adiponectin inhibits the production of CXC receptor 3 chemokine ligands in macrophages and reduces T-lymphocyte recruitment in atherogenesis. Circ Res 102(2), 218-225 
Oliveira-Neto HH, Silva ET, Leles CR, Mendonca EF, Alencar Rde C, Silva TA, Batista AC (2008): Involvement of CXCL12 and CXCR4 in lymph node metastases and development of oral squamous cell carcinomas. Tumour Biol 29, 262-271

Ou DL, Chen CL, Lin SB, Hsu CH, Lin LI (2006): Chemokine receptor expression profiles in nasopharyngeal carcinoma and their association with metastasis and radiotherapy. J Pathol 210, 363-373

Parkin DM, Bray F, Ferlay J, Pisani P (2005): Global cancer statistics, 2002 CA Cancer J Clin 55, 74-108

Payne A, Cornelius L (2002): The role of chemokines in melanoma tumor growth and metastasis. J Invest Dermatol 118, 915-922

Pellegrino A, Antonaci F, Russo F, Merchionne F, Ribatti D, Vacca A, Dammacco F (2004): CXCR3-binding chemokines in multiple myeloma. Cancer Lett 207, 221-227

Pignon JP, le Maitre A, Maillard E, Bourhis J, Group M-NC (2009): Meta-analysis of chemotherapy in head and neck cancer (MACH-NC): an update on 93 randomised trials and 17,346 patients. Radiother Oncol 92, 4-14

Quon H, O'Malley BW, Jr., Weinstein GS (2011): Postoperative adjuvant therapy after transoral robotic resection for oropharyngeal carcinomas: rationale and current treatment approach. ORL J Otorhinolaryngol Relat Spec $\underline{73}, 121-130$

Raman D, Baugher PJ, Thu YM, Richmond A (2007): Role of chemokines in tumor growth. Cancer Lett 256, 137-165

Rehman AO, Wang CY (2008): SDF-1alpha promotes invasion of head and neck squamous cell carcinoma by activating NF-kappaB. J Biol Chem 283, 19888-19894

Rosati G, Riccardi F, Tucci A (2000): Use of tumor markers in the management of head and neck cancer. Int J Biol Markers $\underline{15}, 179-183$ 
Sankaranarayanan R, Masuyer E, Swaminathan R, Ferlay J, Whelan S (1998): Head and neck cancer: a global perspective on epidemiology and prognosis. Anticancer $\operatorname{Res} \underline{18}, 4779-4786$

Schmidtner J, Distel LV, Ott OJ, Nkenke E, Sprung CN, Fietkau R, Lubgan D (2009): Hyperthermia and irradiation of head and neck squamous cancer cells causes migratory profile changes of tumour infiltrating lymphocytes. Int $J$ Hyperthermia 25 , 347-354

See AL, Chong PK, Lu SY, Lim YP (2014): CXCL3 is a potential target for breast cancer metastasis. Curr Cancer Drug Targets 14, 294-309

Shang ZJ, Liu K, Chen XM (2008): Expression of chemokine receptor-7 in oral squamous cell carcinoma and its relation to cervical lymph node metastasis. Zhonghua Kou Qiang Yi Xue Za Zhi $\underline{43}$, 592-596

Shibuya K, Mathers CD, Boschi-Pinto C, Lopez AD, Murray CJ (2002): Global and regional estimates of cancer mortality and incidence by site: II. Results for the global burden of disease 2000. BMC Cancer 2, 37

Shintani S, Ishikawa T, Nonaka T, Li C, Nakashiro K, Wong DT, Hamakawa H (2004): Growth-regulated oncogene-1 expression is associated with angiogenesis and lymph node metastasis in human oral cancer. Oncology $\underline{66}, 316-322$

Siegel R, Ward E, Brawley O, Jemal A (2011): Cancer statistics, 2011: the impact of eliminating socioeconomic and racial disparities on premature cancer deaths. $C A$ Cancer J Clin 61, 212-236

Silva TA, Ribeiro FL, Oliveira-Neto HH, Watanabe S, Alencar Rde C, Fukada SY, 
Cunha FQ, Leles CR, Mendonca EF, Batista AC (2007): Dual role of CCL3/CCR1 in oral squamous cell carcinoma: implications in tumor metastasis and local host defense. Oncol Rep 18, 1107-1113

Sindermann $H$, Jordan $K$, Seegenschmidt $M H$, Sänger S: Empfehlungen zur Klassifizierung und Graduierung unerwünschter Ereignisse und Therapienebenwirkungen. In: Schmoll H-J, Höffken K, Possinger K (Hrsg.), Kompendium Internistische Onkologie. 4., völlig überarb. und erw. Auflage; SpringerVerlag, Berlin 2006, 6493-6578

http://www.springerlink.com/content/j32848240g6v7037/

Silverman S, Jr., Gorsky M, Lozada F (1984): Oral leukoplakia and malignant transformation. A follow-up study of 257 patients. Cancer $\underline{53}, 563-568$

Simon C, Plinkert PK (2008): Combined modality approaches in the treatment of head and neck cancer patients. HNO $\underline{56}, 575-584$

Singh S, Nannuru KC, Sadanandam A, Varney ML, Singh RK (2009): CXCR1 and CXCR2 enhances human melanoma tumourigenesis, growth and invasion. $\mathrm{Br} J$ Cancer 100, 1638-1646

Smirnova T, Adomako A, Locker J, Van Rooijen N, Prystowsky MB, Segall JE (2011): In vivo invasion of head and neck squamous cell carcinoma cells does not require macrophages. Am J Pathol 178, 2857-2865

Soria G, Ben-Baruch A: The CCL5/CCR5 Axis in Cancer. In: Fulton AM (Hrsg.): Chemokine Receptors in Cancer. 1.Auflage, Human Press, Totowa 2009 109-130 Stelow EB, Mills SE: Biopsy Interpretation of the Upper Aerodigestive Tract and Ear. 1 Auflage; Lippincott Williams \& Wilkins, Philadelphia 2007

St John MA, Abemayor E, Wong DT (2006): Recent new approaches to the treatment of head and neck cancer. Anticancer Drugs 17, 365-375 
Strieter RM, Polverini PJ, Kunkel SL, Arenberg DA, Burdick MD, Kasper J, Dzuiba J, Van Damme J, Walz A, Marriott D, et al. (1995): The functional role of the ELR motif in CXC chemokine-mediated angiogenesis. J Biol Chem 270, 27348-27357

Strutz J, Mann W: Praxis der HNO-Heilkunde, Kopf- und Halschirurgie.

2. völlig überarb. und erw. Auflage; Georg Thieme Verlag, Suttgart 2009

Sturgis EM, Wei Q, Spitz MR (2004): Descriptive epidemiology and risk factors for head and neck cancer. Semin Oncol 31, 726-733

Talamini R, Bosetti C, La Vecchia C, Dal Maso L, Levi F, Bidoli E, Negri E, Pasche C, Vaccarella S, Barzan L, et al. (2002): Combined effect of tobacco and alcohol on laryngeal cancer risk: a case-control study. Cancer Causes \& Control 13, 957-964

Tan EH, Adelstein DJ, Droughton ML, Van Kirk MA, Lavertu P (1997): Squamous cell head and neck cancer in nonsmokers. Am J Clin Oncol 20, 146-150

Tezal M, Sullivan MA, Hyland A, Marshall JR, Stoler D, Reid ME, Loree TR, Rigual NR, Merzianu M, Hauck L, et al. (2009): Chronic periodontitis and the incidence of head and neck squamous cell carcinoma. Cancer Epidemiol Biomarkers Prev 18, 2406-2412

Tsuzuki H, Takahashi N, Kojima A, Narita N, Sunaga H, Takabayashi T, Fujieda S (2006): Oral and oropharyngeal squamous cell carcinomas expressing CCR7 have poor prognoses. Auris Nasus Larynx 33, 37-42

Uchida D, Begum NM, Almofti A, Nakashiro K, Kawamata H, Tateishi Y, Hamakawa H, Yoshida H, Sato M (2003): Possible role of stromal-cell-derived factor-1/CXCR4 signaling on lymph node metastasis of oral squamous cell carcinoma. Exp Cell Res 290, 289-302 
Vandercappellen J, Van Damme J, Struyf S (2008): The role of CXC chemokines and their receptors in cancer. Cancer Lett 267, 226-244

Varney ML, Li A, Dave BJ, Bucana CD, Johansson SL, Singh RK (2003): Expression of CXCR1 and CXCR2 receptors in malignant melanoma with different metastatic potential and their role in interleukin-8 (CXCL-8)-mediated modulation of metastatic phenotype. Clin Exp Metastasis 20, 723-731

Varney ML, Singh S, Li A, Mayer-Ezell R, Bond R, Singh RK (2011): Small molecule antagonists for CXCR2 and CXCR1 inhibit human colon cancer liver metastases. Cancer Lett 300, 180-188

Verbeke H, Geboes K, Van Damme J, Struyf S (2012): The role of CXC chemokines in the transition of chronic inflammation to esophageal and gastric cancer. Biochim Biophys Acta 1825, 117-129

Verbeke H, Struyf S, Laureys G, Van Damme J (2011): The expression and role of CXC chemokines in colorectal cancer. Cytokine Growth Factor Rev 22, 345-358

Wahl S, Allen J, Wong H, Dougherty S, Ellingsworth L (1990): Antagonistic and agonistic effects of transforming growth factor-beta and IL-1 in rheumatoid synovium. J Immunol 145, 2514-2519

Wang B, Hendricks DT, Wamunyokoli F, Parker MI (2006): A growth-related oncogene/CXC chemokine receptor 2 autocrine loop contributes to cellular proliferation in esophageal cancer. Cancer Res $\underline{66}, 3071-3077$

Wang CL, Sun BS, Tang Y, Zhuang HQ, Cao WZ (2009): CCR1 knockdown suppresses human non-small cell lung cancer cell invasion. J Cancer Res Clin Oncol $135,695-701$

Wang F, Arun P, Friedman J, Chen Z, Van Waes C (2009): Current and potential 
inflammation targeted therapies in head and neck cancer. Curr Opin Pharmacol $\underline{9}$, 389-395

Wang J, Seethala RR, Zhang Q, Gooding W, van Waes C, Hasegawa H, Ferris RL (2008): Autocrine and paracrine chemokine receptor 7 activation in head and neck cancer: implications for therapy. J Natl Cancer Inst 100, 502-512

Wang J, Xi L, Gooding W, Godfrey TE, Ferris RL (2005): Chemokine receptors 6 and 7 identify a metastatic expression pattern in squamous cell carcinoma of the head and neck. Adv Otorhinolaryngol 62, 121-133

Wang J, Xi L, Hunt JL, Gooding W, Whiteside TL, Chen Z, Godfrey TE, Ferris RL (2004): Expression pattern of chemokine receptor 6 (CCR6) and CCR7 in squamous cell carcinoma of the head and neck identifies a novel metastatic phenotype. Cancer Res 64, 1861-1866

Wang J, Zhang X, Thomas SM, Grandis JR, Wells A, Chen ZG, Ferris RL (2005): Chemokine receptor 7 activates phosphoinositide-3 kinase-mediated invasive and prosurvival pathways in head and neck cancer cells independent of EGFR. Oncogene 24, 5897-5904

Wang Z, Feng X, Liu X, Jiang L, Zeng X, Ji N, Li J, Li L, Chen Q (2009): Involvement of potential pathways in malignant transformation from oral leukoplakia to oral squamous cell carcinoma revealed by proteomic analysis. BMC Genomics $\underline{10}, 383$

Wannenmacher M, Debus J, Wenz F (Hrsg.): Strahlentherapie.

1. Auflage; Springer-Verlag, Berlin 2006

Wiernik G, Millard PR, Haybittle JL (1991): The predictive value of histological classification into degrees of differentiation of squamous cell carcinoma of the larynx and hypopharynx compared with the survival of patients. Histopathology 19, 411-417 
Wittekind C, Meyer HJ: TNM: Klassifikation maligner Tumoren. 7. Auflage; WileyVCH Verlag, Weinheim 2010

Wittekind C, Weber A, Weidenbach H: Pathologie und Prognosefaktoren von Plattenepithelkarzinomen des Kopf-Hals-Bereiches. In: Höffken K, Schmidtberger H, Schlag M (Hrsg.): Der Onkologe 7(5); Springer-Verlag, Berlin 2011, 498-504

Wolff HA, Daldrup B, Jung K, Overbeck T, Hennies S, Matthias C, Hess CF, Roedel RM, Christiansen H (2011): High-grade acute organ toxicity as positive prognostic factor in adjuvant radiation and chemotherapy for locally advanced head and neck cancer. Radiology 258, 864-871

Wolff HA, Overbeck T, Roedel R, Hermann RM, Herrmann MK, Kertesz T, Vorwerk $H$, Hille A, Matthias C, Hess CF, et al. (2009): Toxicity of daily low dose cisplatin in radiochemotherapy for locally advanced head and neck cancer. J Cancer Res Clin Oncol 135, 961-967

Wu X, Fan J, Wang X, Zhou J, Qiu S, Yu Y, Liu Y, Tang Z (2007): Downregulation of CCR1 inhibits human hepatocellular carcinoma cell invasion. Biochem Biophys Res Commun 355, 866-871

Wu Y, Li YY, Matsushima K, Baba T, Mukaida N (2008): CCL3-CCR5 axis regulates intratumoral accumulation of leukocytes and fibroblasts and promotes angiogenesis in murine lung metastasis process. J Immunol 181, 6384-6393

Yamauchi K, Akbar SM, Horiike N, Michitaka K, Onji M (2003): Increased serum levels of macrophage inflammatory protein-3alpha in hepatocellular carcinoma: relationship with clinical factors and prognostic importance during therapy. Int $\mathrm{J} \mathrm{Mol}$ Med 11, 601-605

Yeudall WA, Miyazaki H (2007): Chemokines and squamous cancer of the head and 
neck: targets for therapeutic intervention? Expert Rev Anticancer Ther $\underline{7}, 351-360$

Yoon Y, Liang Z, Zhang X, Choe M, Zhu A, Cho HT, Shin DM, Goodman MM, Chen ZG, Shim H (2007): CXC chemokine receptor-4 antagonist blocks both growth of primary tumor and metastasis of head and neck cancer in xenograft mouse models. Cancer Res $\underline{67}, 7518-7524$

Zhao ZJ, Liu FY, Sun CF (2009): Effect of chemokine receptor 7 small interfering RNA on proliferation and invasion of squamous cell carcinoma of head and neck. Zhonghua Kou Qiang Yi Xue Za Zhi 44, 5-10

Zhou W, Jiang Z, Song X, Liu Y, Wen P, Guo Y (2008): Promoter hypermethylationmediated down-regulation of CXCL12 in human astrocytoma. J Neurosci Res 86(13), 3002-3010

Zlotnik A (2006): Chemokines and cancer. Int J Cancer 119, 2026-2029

Zlotnik A, Yoshie O (2000): Chemokines: a new classification system and their role in immunity. Immunity $\underline{12}, 121-127$ 


\section{Danksagung}

Mein ganz besonderer Dank gilt Herrn PD Dr. med. Hendrik Wolff sowie Frau Dipl. Biol. M. Rave-Fränk, die mir jederzeit hilfreich zur Seite gestanden und mich stets ausgiebig unterstützt haben. Die gesamte Arbeit wurde von beiden intensiv, professionell und sehr warmherzig begleitet. Die kompetente Hilfe kam mir in zahlreichen Angelegenheiten sehr zugute und hat daher maßgeblich zum Gelingen dieser Arbeit beigetragen.

Weiterhin möchte ich Herrn Dr. Markus Schirmer danken, der ebenso am erfolgreichen Abschluss dieser Arbeit beteiligt war.

Für die Unterstützung und engagierte Hilfe im Labor möchte ich mich zudem besonders bei Frau Alexandra Bitter, Frau Juliane Kasten-Krapp und Frau Sandra Hoffmeister bedanken. 